\title{
SYNTHESIS AND STUDY OF SELECT HETEROCYCIES
}

\author{
A. G. Anastassiou \\ Department of Chemistry, \\ Syracuse University, Syracuse, New York 13210, USA
}

\begin{abstract}
The central theme of this review is the synthesis and subsequent study of a variety of $\pi$ heterocycles with particular emphasis placed on the recognition of key steric and electronic factors controlling the development of heteroaromaticity as well as its less conventional variants, heterohomoaromaticity and heterobicycloaromaticity. The first three sections are devoted to the hetero[9]annulenes, their benzologues and the hetero[13]annulenes respectively and incorporate information attesting to the validity of Hückel's $4 n+2$ rule in spite of frequent need for rather major, potentially damaging, skeletal readjustments. In each case, there is also unmistakable indication of an inverse relationship between heteroatom electronegativity and the development of 'aromatic' character. Section D contains information establishing the existence of bicycloconjugation in the 9-heterobicyclo[4.2.1]nona-2,4,7-triene system. Lastly, section $\mathrm{E}$ deals with the 2-heterobicyclo[3.2.1] octa-3,6-diene skeleton, incorporating data which are indicative of the system's ability to realize a homoconjugated frame.
\end{abstract}

\section{INTRODUCTION}

The use of the lone pair as a double bond substitute has long intrigued chemists and certainly holds special fascination for those actively engaged in the study of 'aromaticity'. Undoubtedly, the origins of chemical awareness into the similarity between lone pair and double bond date back to the early work with the cyclopentadienyl anion ${ }^{1}$ and certain $\pi$-excessive heterocyclic analogues, e.g. pyrrole (Bayer, 1870), furan (Bayer, 1877) and thiophene (Mayer, 1882), and has since been formalized theoretically by E. Hückel in his historic treatise on the theory of aromaticity, published some 40 years $\mathrm{ago}^{2}$. And while the literature now abounds with such compounds as are frequently cited in support of Hückel's $4 n+2$ rule of 'aromaticity' none appears to illustrate its strength more convincingly than the electrically charged $\pi$ monocycles shown in 1-8, each consisting of an acyclic array of conjugated double bonds joined at the termini by a single $s p^{2}$ hybrid. What is, doubtlessly, the most striking characteristic of these systems is the strict control imposed on their overall stability and shape by the occupancy of the $p$ orbital associated with the bridging unit. It has thus been amply and in many instances dramatically demonstrated over the years that whereas the $4 n+2$ members of this 
family, 1-4, are endowed with stable, fully delocalized, planar frames (e.g. $D_{9 h}$ for 4 ), the $4 n$ counterparts, 5-8, are invariably plagued by pronounced instability, each member existing fleetingly at best and strongly resisting charge delocalization.

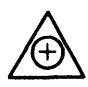

1

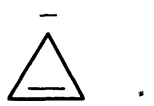

5

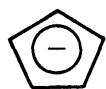

2

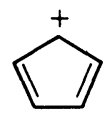

6

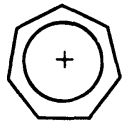

3

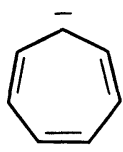

7

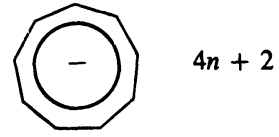

4

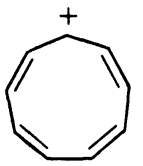

$4 n$

8

Extension of the lone pair concept to substances whose odd $p$ ao is located on a heteroatom instead of carbon, offers valuable insight into the electronic properties of $\pi$-excessive heterocycles. The long known stability and to some extent aromatic characteristics of the general heterocyclic frame shown in 9 is thus ascribed to its $6 \pi$-electron potential, i.e. to its being iso- $\pi$-electronic with 2 and, to a less obvious degree, with benzene, while the well documented instability of its $\pi$-homologue, i.e. the heterepin frame (10) is best reasoned in terms of its $8 \pi$ potential and its formal resemblance to the tropyl anion (7). The next member of the family, the nine-membered heteronin (11), is the heterocyclic analogue of the cyclononatetraenyl anion (4) which is now accepted as the largest possible $\mathrm{C}_{n} \mathrm{H}_{n}$ molecule with access to a flat, fully delocalized all-cis frame, i.e. one where $\pi$ stabilization clearly overrides the adverse effect of angle strain $\left(180^{\circ}\right)$ attending this geometry. Evidently then, the heteronin frame with its inherent ability for controlled variation of heteroatom electronegativity and, consequently, of lone pair availability, is ideally suited for the purpose of probing into the delicate balance of opposing structural factors, i.e. $\pi$ stabilization with its tendency to flatten the system and skeletal strain with its strong demand for a puckered frame. In other words the heteronin family occupies a position of prominence among $\pi$-excessive heteromonocycles in that it is endowed with such unique size as is necessary for the study of what is possibly the most fundamental question in the theory of heteroaromaticity, namely to what extent does heteroatom electronegativity influence the development of aromatic properties?

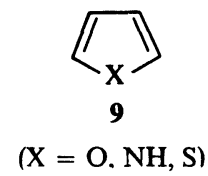

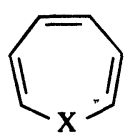

10

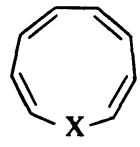

11 
Seeking answers to this and other questions we have, over the past few years, devoted a major portion of our research activities to the synthesis and study of the heteronin system and of choice benzologues, vinylogues and valence tautomers thereof. Now, since much of our work with the heteronins has already been reviewed elsewhere ${ }^{3}$ we give here only a brief account of the subject chiefly emphasizing findings not previously discussed. For the most part, then, the present account deals with several extensions of our heteronin experiences into other related molecules which have recently attracted our attention. In specific terms, section B deals with the benzoheteronin system, section $C$ describes our recent experience with 13-membered $\pi$-excessive molecules and sections $\mathrm{D}$ and $\mathrm{E}$ address themselves, respectively, to the questions of bicycloconjugation and homoconjugation as applied to heterocyclic systems. Finally, section $F$ incorporates recently acquired information directly relating to the areas of research described under the previous headings. Obviously, our work in the area is far from complete. Nevertheless, we find the information collected thus far to be sufficiently straightforward to permit rational interpretation. We might also note at this point that while the account is primarily devoted to a description of our own discoveries in the area it does incorporate in its main text any directly pertinent original information contributed by other groups as well. Finally, in order to properly credit the individuals directly associated with the various areas of research, each heading and/or subheading is accompanied by a list of contrubutors from within our own research group.

\section{A. THE HETERONINS}

\section{(1) Synthesis}

\section{Work by: R. P. Cellura, S. W. Eachus, J. H. Gebrian and V. Orfanos}

In our quest for a convenient general entry into the heteronin frame we reached the early decision that classical synthetic methods would be unnecessarily cumbersome if not altogether inadequate. As a result, we resolved to explore the use of symmetry-controlled valence isomerization as a means of realizing our synthetic goal expeditiously and, most important, in the absence of potentially harmful reagents. To this end, we concentrated our attention on the readily available 9-heterobicyclo[6.1.0]nona-2,4,6-triene skeleton $\mathbf{1 2}^{4}$ about which we had earlier theorized ${ }^{5}$, on the basis of orbital symmetry ${ }^{6}$, the possibility of conrotatory opening to the mono-trans heteronin skeleton 13 under thermal activation and of disrotatory retroelectrocyclization to the all-cis frame 11 under the influence of light.

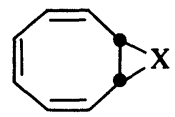

12

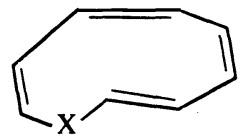

13

(a) $\mathrm{X}=\mathrm{O}$

(b) $\mathrm{X}=\mathrm{NCOOC}_{2} \mathrm{H}_{5}$

(c) $X=N C N$ 


\section{A. G. ANASTASSIOU}

Now, since we were, for obvious reasons, primarily concerned with the preparation of the all-cis variant we pursued the photochemical route ${ }^{7}$ and soon realized the photosynthesis of two heat-sensitive all-cis heteronins, $N$-carbethoxyazonine (11b) ${ }^{8}$ and oxonin (11a) ${ }^{9}$ from bicyclic progenitors $12 \mathrm{~b}$ and 12a respectively. Urethane 11b was then converted to the parent amine (16) as well as to a host of $N$-substituted derivatives (11 d-11l) on successive low-temperature $\left(-78^{\circ}\right.$ to $\left.-20^{\circ}\right)$ exposure to potassium $t$-butoxide and an appropriate electrophile ${ }^{11}$. Moreover, the intermediacy of the azoninyl anion 15 in the synthetic sequence was securely established by its isolation in association with a variety of gegenions $\left(\mathrm{Li}^{+}, \mathrm{Na}^{+}, \mathrm{K}^{+}, \mathrm{Rb}^{+}, \mathrm{Cs}^{+}\right)^{12}$. For purposes of classification of the various available heteronins it was of course also necessary to prepare the previously unknown classical polyenic model

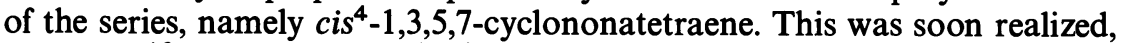
both here ${ }^{13}$ and elsewhere ${ }^{14-16}$, by the low-temperature protonation of its aromatic conjugate base 4 .

\section{Scheme 1}

(a)

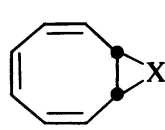

12

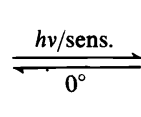

(a) $\mathrm{X}=\mathrm{O}$

(b) $\mathrm{X}=\mathrm{NCOOC}_{2} \mathrm{H}_{5}$

(d) $\mathrm{X}=\mathrm{CH}_{2}$

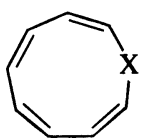

11

(b)
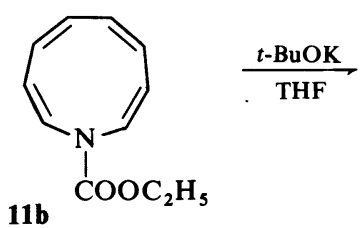
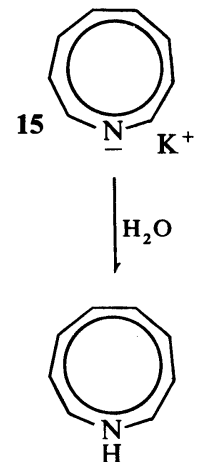

16

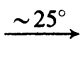<smiles>[X]c1ccccc1-c1ccccc1</smiles>

14

electrophile

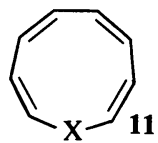

(e) $\mathrm{NCOCH}_{3}$

(f) $\mathrm{HSO}_{2} \phi$

(g) $\mathrm{NCON}\left(\mathrm{CH}_{3}\right)_{2}$

(h) $\mathrm{NCONH} \phi$

(i) $\mathrm{NCOCH}\left(\mathrm{CH}_{3}\right) \phi$

(j) $\mathrm{NCOC}\left(\mathrm{CH}_{3}\right)_{2} \phi$

(k) $\mathrm{NCH}_{3}$

(l) $\mathrm{NC}_{2} \mathrm{H}_{5}$

(m) $\mathrm{NCH}_{2} \phi$

\section{(2) The Question of Aromaticity}

\section{Work by: R. P. Cellura, S. W. Eachus, H. Yamamoto and J. H. Gebrian}

Once the rather wide selection of heteronins, described in the previous section, became available in our laboratories attention was naturally given to the classification of the various members along the wide spectrum of properties bordered by the aromatic anion 4 on one end and its polyenic 
conjugate acid 11d on the other. Our efforts along these lines centred on three key criteria: (i) thermal stability, (ii) n.m.r. characteristics and (iii) u.v. spectral properties, which we shall now briefly discuss.

In terms of physical properties the heteronins may be grouped in two basic categories, each differing from the other on several counts. First, we note that there are striking differences in thermal sensitivity. It is immediately seen for example from the thermal stability data collected in Table 1 that the two parent

Table 1. Thermal activation constants ${ }^{\mathrm{a}}$

\begin{tabular}{|c|c|c|c|c|c|}
\hline \multicolumn{6}{|c|}{ Substance } \\
\hline No. & $\mathrm{X}$ & $\begin{array}{c}\Delta H^{\neq} \\
(\mathrm{kcal} / \mathrm{mol})^{\mathrm{b}}\end{array}$ & $\begin{array}{l}\Delta S^{\neq} \\
(\mathrm{eu})\end{array}$ & $\begin{array}{c}\Delta F^{\neq}\left(30^{\circ}\right) \\
(\mathrm{kcal} / \mathrm{mol})\end{array}$ & $t_{\frac{1}{2}}\left(50^{\circ}\right)$ \\
\hline $11 \mathrm{a}$ & $\mathrm{O}$ & 18.2 & -13 & 22.2 & $3 \mathrm{~min}$ \\
\hline 11c & $\mathrm{CH}_{2}$ & $19.8^{\mathrm{c}}$ & -10.4 & 23.0 & $10 \mathrm{~min}$ \\
\hline $11 b$ & $\mathrm{NCOOC}_{2} \mathrm{H}_{5}$ & 21.2 & -7 & 23.3 & $14 \mathrm{~min}$ \\
\hline 11f & $\mathrm{NSO}_{2} \mathrm{Ph}^{2}$ & 22.3 & -3 & 23.0 & $8 \mathrm{~min}$ \\
\hline 11e & $\mathrm{NCOCH}_{3}$ & 23.4 & 0 & 23.5 & $13 \mathrm{~min}$ \\
\hline $11 \mathrm{~g}$ & $\mathrm{NCON}\left(\mathrm{CH}_{3}\right)_{2}$ & 24.8 & +3 & 24.1 & $32 \mathrm{~min}$ \\
\hline $11 \mathrm{~m}$ & $\mathrm{NCH}_{2} \mathrm{Ph}$ & - & - & - & $\sim 70 \mathrm{~min}$ \\
\hline 11k & $\mathrm{NCH}_{3}$ & - & - & - & $\sim 4 \mathrm{~h}$ \\
\hline 111 & $\mathrm{NC}_{2} \mathrm{H}_{5}$ & - & - & $\cdots$ & $\sim 4 \mathrm{~h}$ \\
\hline 16 & $\mathrm{NH}^{2}$ & - & - & - & $>100 \mathrm{~h}$ \\
\hline 15 & NK & - & - & - & stable \\
\hline
\end{tabular}

\footnotetext{
a The first six entries were evaluated by monitoring the conversion of 11 to 14 by n.m.r. spectroscopy in $\mathrm{CDCl}_{3}$ at three or more different temperatures while the remaining five values were determined by following the rate of decomposition of the azonine by n.m.r. in acetone- $\mathrm{d}_{6}$ at $c a .50^{\circ}$

b A maximum error of ten per cent is associated with these values.
}

substances, oxonin $\left(11 \mathrm{a} ; t_{\frac{1}{2}} \sim 3 \mathrm{~min}\right.$, at $\left.50^{\circ}\right)$ and azonine, in conjugate acid $\left(16 ; t_{\frac{1}{2}}>12000 \mathrm{~min}\right.$. at $\left.50^{\circ}\right)$ or conjugate base $\left(15\right.$; stable at $\left.100^{\circ}\right)$ form, show significant variation in thermal stability, with oxonin closely resembling the polyenic model, 11d $\left(t_{1} \sim 10 \mathrm{~min}\right.$, at $\left.50^{\circ}\right)$ both in the degree and nature (disrotation to 14) of its thermal response. Oxonin may thus be safely classed as a polyenic heterocycle while $1 \mathrm{H}$-azonine (16) and its conjugate base (15) are seen to possess a significantly more stable $\pi$ system, i.e. one endowed with the type of thermal stability one normally attributes to the presence of aromatic character. Similar, albeit less pronounced, differences are also seen to exist between the two sets of $N$-substituted azonines, with the members bearing electron-withdrawing $N$-appendages (11b, 11e-11g), i.e. groups characterized by positive $\sigma_{\mathrm{p}}^{-}$terms, resembling oxonin in general thermal behaviour (rapid disrotation to the cis-fused bicycle 14) and those carrying electrondonating groups $(\mathbf{1 1 k}-11 \mathrm{~m})$ responding in manner reminiscent of parent azonine.

N.m.r. spectroscopy fully confirms the notion that oxonin (Figure la) and $N$-substituted azonines 11b (Figure 1 b), 11e, 11f and 11g are no more than mere polyenes and, most important, offers unambiguous demonstration that $1 \mathrm{H}$-azonine (Figure 1 c) and its anion (Figure $1 d$ ) are endowed with significant ring diamagnetism and are thus securely classed as aromatic. Interestingly, 


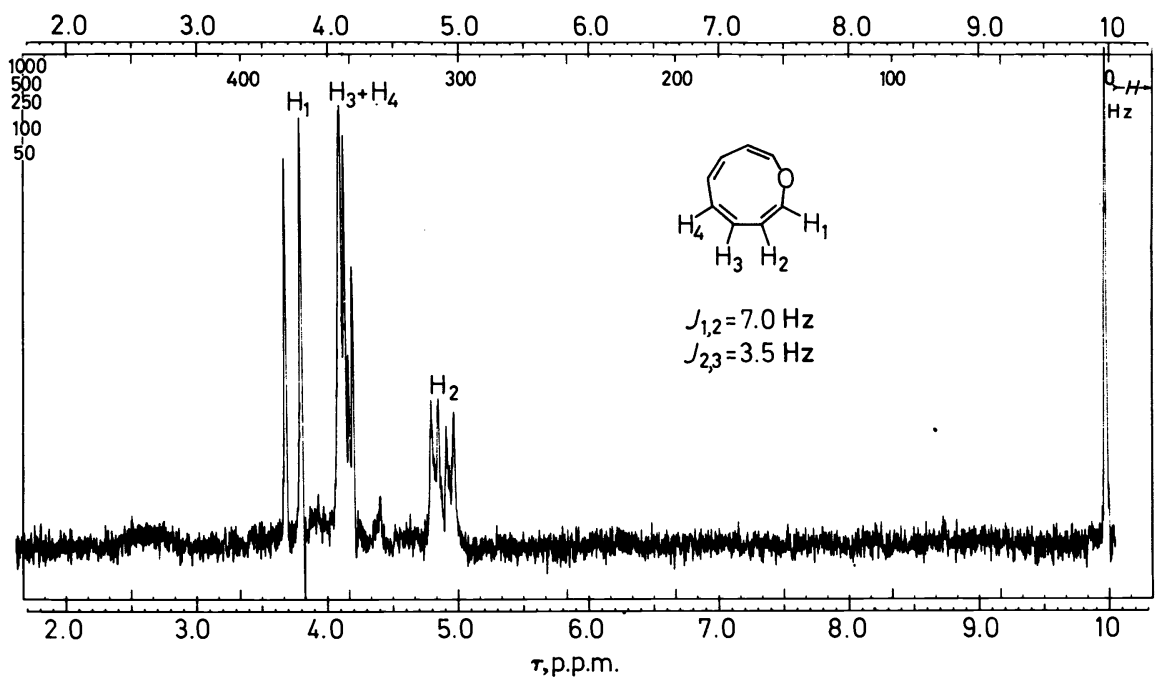

Figure 1 . The n.m.r. spectra $(60 \mathrm{MHz})$ of (a) oxonin, $11 \mathrm{a}$ (in $\mathrm{CDCl}_{3}$ ).

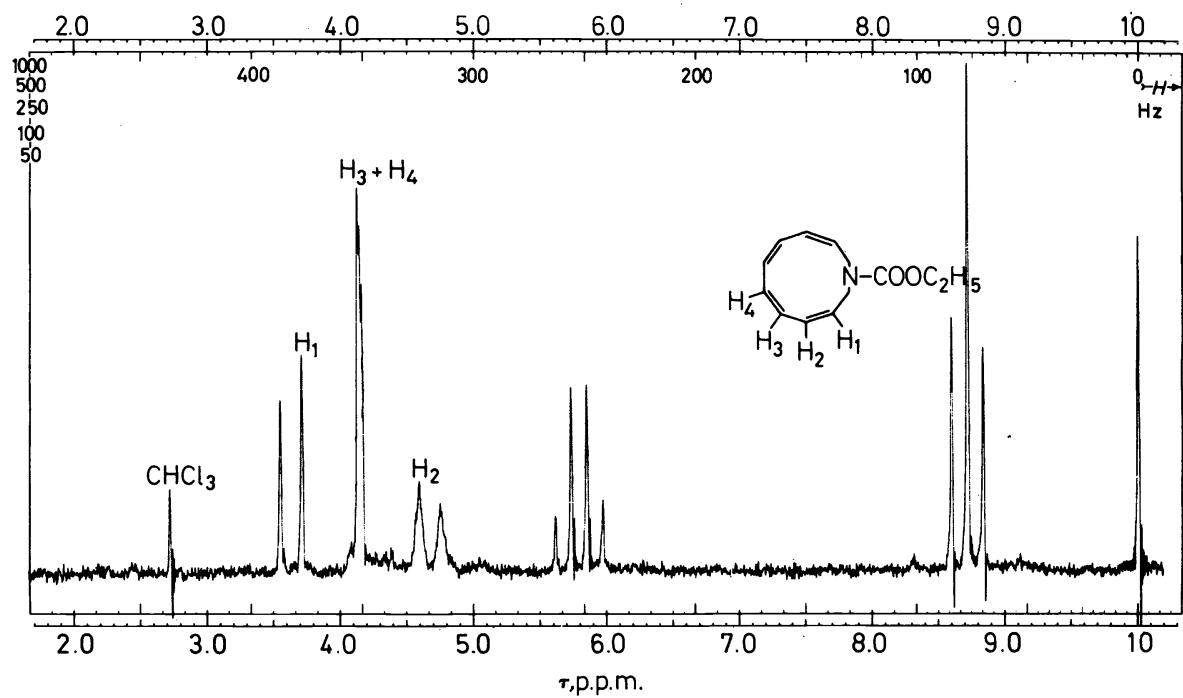

(b). $N$-ethoxycarbonyl azonine, $11 b$ (in $\mathrm{CDCl}_{3}$ ).

the $N$-alkyl counterparts $11 \mathrm{k}$ (Figure $1 e$ ), $11 \mathrm{l}$ and $11 \mathrm{~m}$ show n.m.r. characteristics (the $\mathrm{H}_{\alpha}$ resonance appearing, in each case, at higher field than the $\mathbf{H}_{\gamma}+\mathbf{H}_{\delta}$ band) indicative of mild ring diamagnetism within a frame which is slightly buckled due to the steric interference between $N$-alkyl and adjacent ring hydrogens $\left(\mathrm{H}_{\alpha}\right)^{17}$. The differences between the two types of heteronin indicated by the n.m.r. spectra receive added confirmation from more direct 
SYNTHESIS AND STUDY OF SELECT HETEROCYCLES

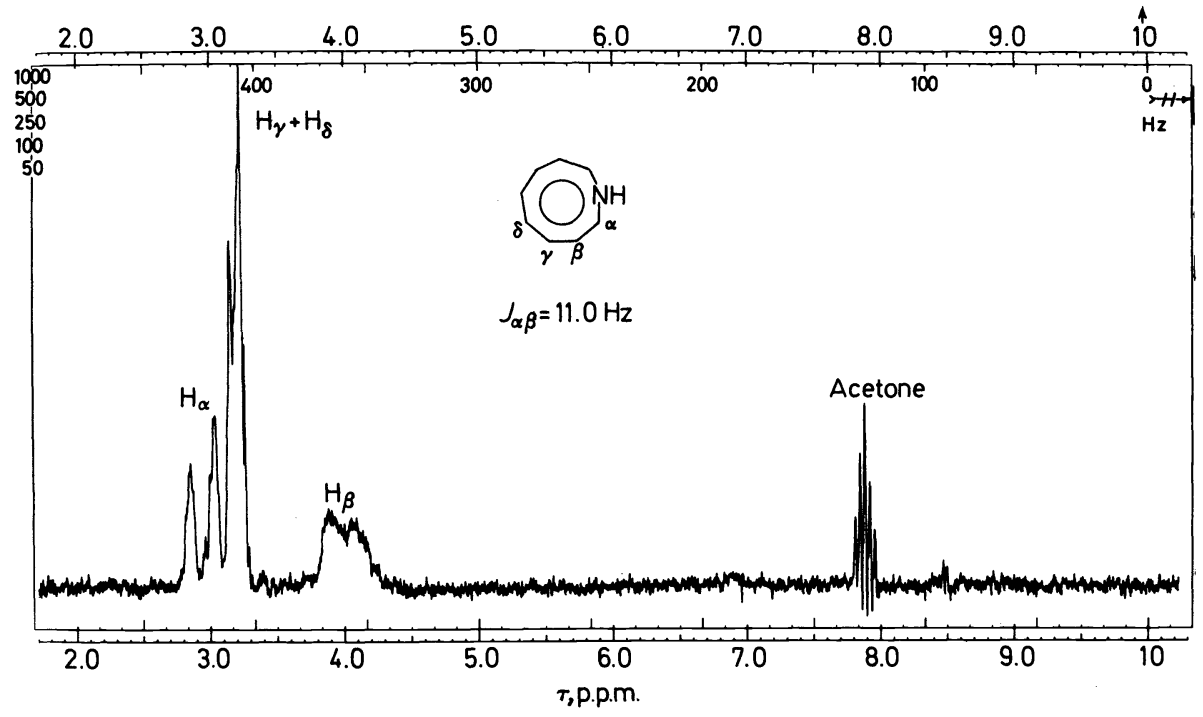

(c). $1 \mathrm{H}$-azonine, 16 (in acetone- $\mathrm{d}_{6}$ ).

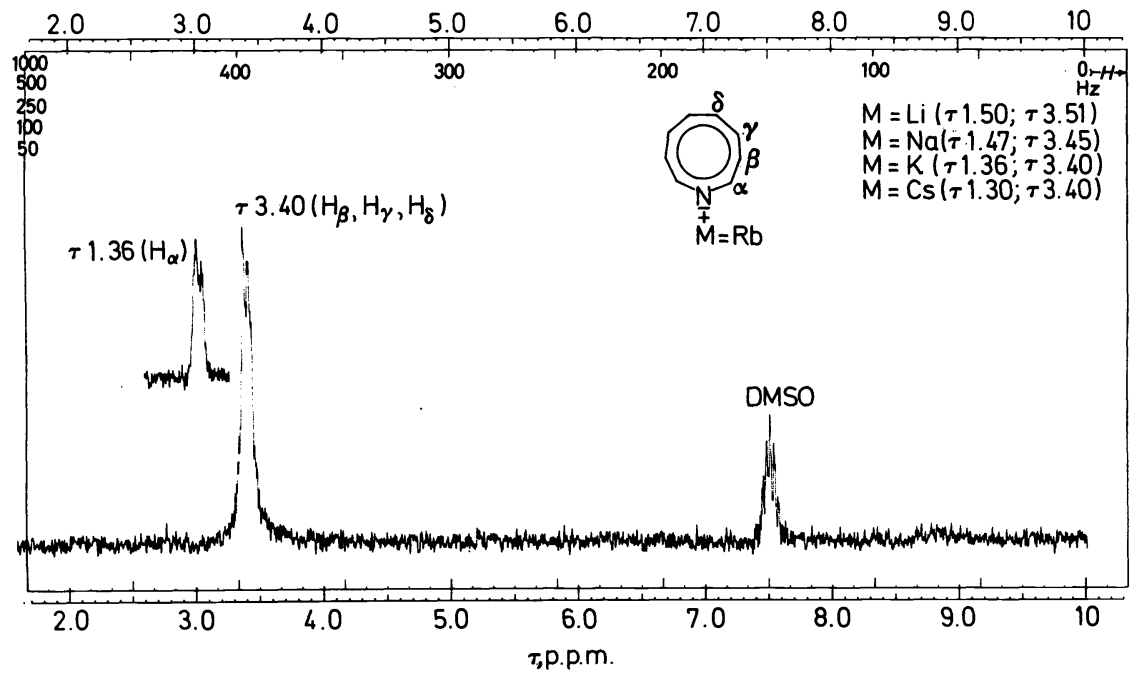

(d). Alkali metal azonides, 15 (in DMSO-d 6 ).

measurement of ring current as given by the n.m.r. solvent shift(S) parameters ${ }^{18}$. $1 \mathrm{H}$-azonine (16) was thus found ${ }^{19}$ to possess an $S$ value which is both large and positive $(+1.35)$, i.e. one indicative of extensive ring diamagnetism, the $N$-methyl derivative (11k) one which is small and positive $(+0.34)$, i.e. one reflective of but mild diamagnetism. and the polyenic counterparts, oxonin (11a) and CNT (11d) to be associated with negligibly small negative $S$ values 


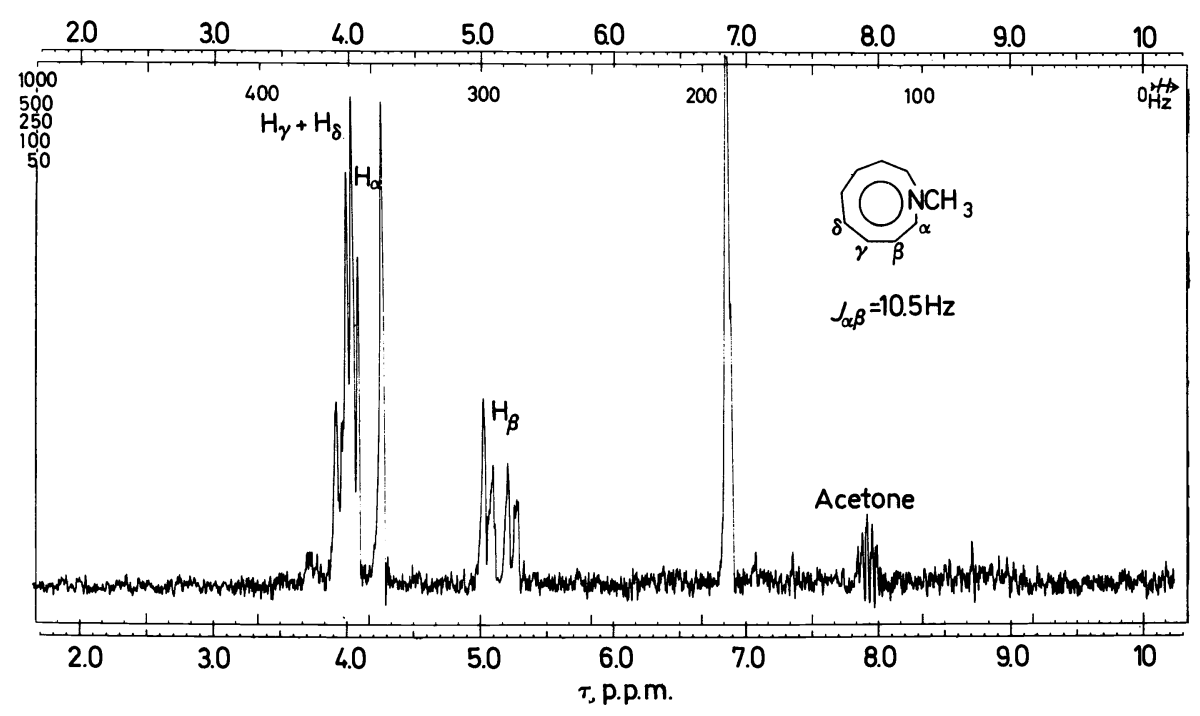

(e). $N$-methyl azonine, 11k (in acetone- $\mathrm{d}_{6}$ ).

$(-0.05$ to -0.07$)$ as expected of $\pi$ frames which are virtually devoid of ring current, i.e. atropic.

N.m.r. spectroscopy has also revealed meaningful and otherwise invisible differences between $1 \mathrm{H}$-azonine (16) and its conjugate base, the azoninyl anion $(15)^{20}$. Specifically, one finds a reduction in temperature to activate the following changes in the n.m.r. spectrum: (i) detectable increase in $J_{12}$ (as seen in Figure 2) and (ii) displacement of the entire absorption manifold substantially to lower field (as seen in Figure 3). Obviously, these changes are mutually consistent pointing to a frame which becomes more nearly planar (increase in coupling constant) and which experiences enhanced diatropism (downfield shift of resonances) at the lower temperatures. Operationally, these observations are best reasoned by the existence of a thermally induced conformational equilibrium, $K$, between the planar $(\mathrm{P})$ molecule and one or more less stable non-planar (N) variant(s). Now, in terms of the n.m.r. observables, this equilibrium may be approximated by:

$$
K=\left\{\sigma_{\mathrm{i}}(\mathrm{P})-\sigma_{\mathrm{i}}(\text { obs. })\right\} /\left\{\sigma_{\mathrm{i}}(\text { obs. })-\sigma_{\mathrm{i}}(\mathrm{N})\right\}
$$

where $\sigma_{\mathrm{i}}(\mathrm{P})$ and $\sigma_{\mathrm{i}}(\mathrm{N})$ are, respectively, the chemical shifts (in $\mathrm{Hz}$ ) of the hypothetical extreme planar and puckered frames and $\sigma_{\mathrm{i}}(\mathrm{obs}$.) denotes the observed chemical shift at any temperature. Significantly, evaluation of the relationship shown in equation 1 by approximating the constants $\sigma_{i}(P)$ and $\sigma_{i}(\mathrm{~N})$ with the ambient-temperature chemical shifts of the $\beta$ proton of the azoninyl anion (planar model) and $N$-carbethoxyazonine (puckered model) respectively, afforded good linear correlation between $\ln K$ and $1 / T$ (Van't Hoff plot shown in Figure 4) with $\Delta H_{0}(\mathrm{~N} \rightarrow \mathrm{P})=-1.9 \mathrm{kcal} / \mathrm{mole}$ and $\Delta S_{0}(\mathrm{~N} \rightarrow \mathrm{P})=-8.5 \mathrm{eu}$ at $+35^{\circ}$. Besides yielding a semi-quantitative 


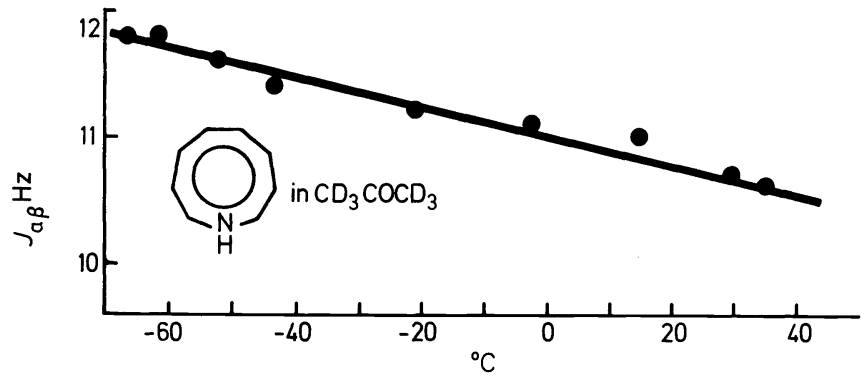

Figure 2. Plot of n.m.r. coupling constant (in $\mathrm{Hz}$ ) versus temperature (in ${ }^{\circ} \mathrm{C}$ ) for $1 \mathrm{H}$-azonine.

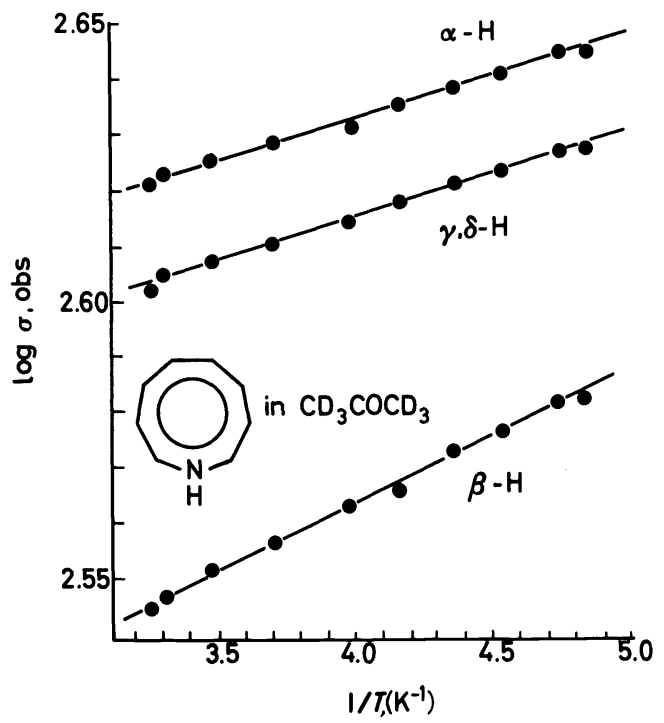

Figure 3. Plot of n.m.r. chemical shift (in $\mathrm{Hz}$ from tetramethylsilane) versus temperature (in $\mathrm{K}$ ) for $1 \mathrm{H}$-azonine.

estimate of the resistance offered by planar, delocalized, $1 \mathrm{H}$-azonine to skeltal distortion, the linearity of the plot clearly justifies the basic operational assumption that the value of $\sigma_{\beta}$ extracted from the n.m.r. spectrum of the azoninyl anion (15), taken at room temperature, closely approximates that of the planar azonine frame. To sum up then, variable temperature n.m.r. work appears to indicate that both $1 \mathrm{H}$-azonine (16) and its conjugate base (15) show distinct affinity for a planar frame with the latter more decidedly so than the former.

U.v. spectroscopy serves to further accentuate the existence of geometrical differences between the two parents, $1 \mathrm{H}$-azonine and oxonin, and, in addition, offers indication that the heteronin frame undergoes gradual molecular flattening in the course of its change from polyenic to aromatic. It is seen, for instance, on brief inspection of the u.v. data collected in Table 2, that the low energy 


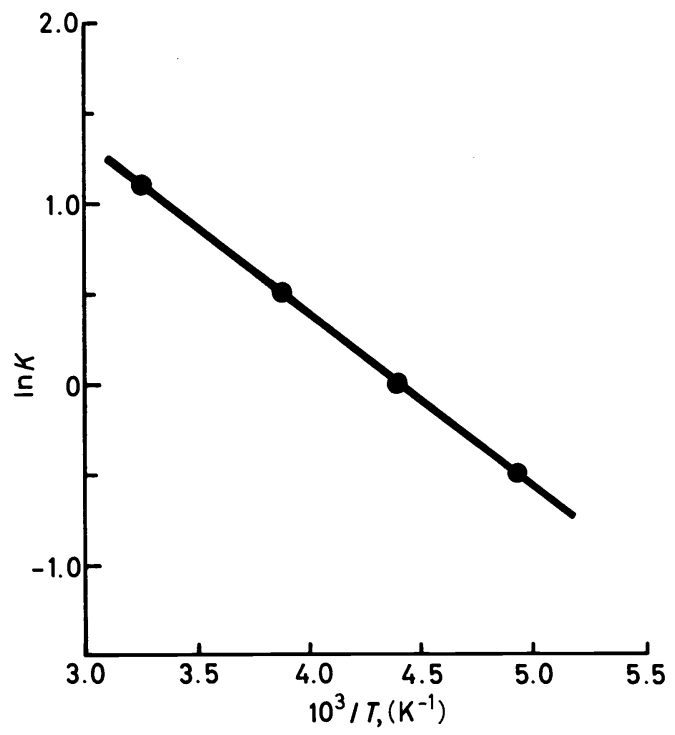

Figure 4. Plot of equilibrium constant (from equation 1) versus inverse temperature (in K).

Table 2. U.v. absorption spectra

\begin{tabular}{|c|c|c|c|c|}
\hline $\begin{array}{l}\text { S } \\
\text { No. }\end{array}$ & $\mathbf{X}$ & Solvent & $\begin{array}{c}\text { Weak band } \\
\mathrm{nm}(\varepsilon)\end{array}$ & $\begin{array}{c}\text { Strong band } \\
\mathrm{nm}(\varepsilon)\end{array}$ \\
\hline $\begin{array}{l}\text { 11a } \\
11 \mathrm{c} \\
11 \mathrm{~b} \\
11 \mathrm{f} \\
11 \mathrm{e} \\
11 \mathrm{~g} \\
11 \mathrm{k} \\
111 \\
16\end{array}$ & $\begin{array}{l}\mathrm{O} \\
\mathrm{CH}_{2} \\
\mathrm{NCOOC}_{2} \mathrm{H}_{5} \\
\mathrm{NSO}_{2} \mathrm{Ph} \\
\mathrm{NCOCH}_{3} \\
\mathrm{NCON}_{\left(\mathrm{CH}_{3}\right)_{2}} \\
\mathrm{NCH}_{3} \\
\mathrm{NC}_{2} \mathrm{H}_{5} \\
\mathrm{NH}\end{array}$ & $\begin{array}{l}\mathrm{C}_{6} \mathrm{H}_{14} \\
\mathrm{C}_{6} \mathrm{H}_{14} \\
\mathrm{C}_{6} \mathrm{H}_{14} \\
\mathrm{C}_{6} \mathrm{H}_{14} \\
\mathrm{C}_{6} \mathrm{H}_{14} \mathrm{H}_{14} \\
\mathrm{C}_{6} \mathrm{H}_{14} \\
\mathrm{C}_{6} \mathrm{H}_{14} \\
\mathrm{C}_{6} \mathrm{H}_{14} \\
\mathrm{C}_{6} \mathrm{H}_{14} \\
\mathrm{Et}_{2} \mathrm{O}^{2}\end{array}$ & $\begin{array}{l}253 \operatorname{sh}(4300) \\
248 \operatorname{sh}(2500) \\
265 \operatorname{sh}(2200) \\
270 \operatorname{sh}(6000) \\
270 \operatorname{sh}(4400) \\
288(2900) \\
303(3100) \\
306(3500) \\
335(2700) \\
344 \operatorname{sh}(1500) \\
328(2200) \\
298(2930) \\
330(4500) \\
339 \operatorname{sh}(3900)\end{array}$ & $\begin{array}{l}218 \\
205 \\
220(9000) \\
219 \\
223(9000) \\
225(11200) \\
223(12000) \\
223(10000) \\
252(20500) \\
233(24500)\end{array}$ \\
\hline
\end{tabular}

band present at 253 and $248 \mathrm{~nm}$ respectively, in the spectra of oxonin and CNT gradually changes to one at $288 \mathrm{~nm}$ on reaching the carbamoyl derivative $11 \mathrm{~g}$ then appears at $303 \mathrm{~nm}$ in the $N$-alkyl counterpart 11k and finally emerges at considerably lower energies $(335-340 \mathrm{~nm})$ in $1 \mathrm{H}$-azonine and the azoninyl anion. Significantly, SCF-CI calculations ${ }^{21}$ on a hypothetical planar fully delocalized heteronin frame place the lowest-energy electronic transition of oxonin at $346 \mathrm{~nm}$ (in sharp disagreement with the observed value of $253 \mathrm{~nm}$ ) and that of $1 \mathrm{H}$-azonine at $323 \mathrm{~nm}$ (in remarkable agreement with the experimental value of $335 \mathrm{~nm}$ ). The obvious conclusion then to be derived from a 
comparison of theory and experiment is that (i) oxonin exists in heavily distorted form, (ii) $1 \mathrm{H}$-azonine is delocalized and planar or very nearly so, and (iii) the heteronin frame undergoes gradual, u.v.-detectable, skeletal uncoiling on passing from polyenic to aromatic. As expected, the prediction of gradual molecular flattening directly parallels the observation of increased thermal stability, the direction of change being in both cases oxonin or CNT < $11 \mathrm{~g}<11 \mathrm{k}<1 \mathrm{H}$-azonine or 15. In addition, the notion that the thermally unstable heteronins, i.e. oxonin and those azonines bearing electronwithdrawing $N$-substituents, possess buckled frames receives unmistakable support from an $x$-ray study on a representative member, namely the carbamoyl derivative $1 \mathbf{~ g}^{22}$, recently executed in collaboration with Professor I. C. Paul at the University of Illinois (Urbana). It is evident from the molecular dimensions and torsional data collected in Figure 5 that the molecule consists of a heavily distorted helical frame incorporating a fully localized array of $c i s$ double bonds, ranging in length from 1.30 to $1.33 \AA$, and linked by a mildly pyramidal ring nitrogen $(0.181 \AA$ from the plane defined by the three substituents). In other words, the observed molecular shape of $\mathbf{1 1 g}$ bears close resemblance to that deduced from a 'Dreiding' molecular model. On the other hand, there are two important structural features of 11g which are not immediately apparent on inspection of models. Specifically, it is seen that (i) the butadiene function directly linked to nitrogen, i.e. the $\mathrm{C}_{6} \mathrm{C}_{7} \mathrm{C}_{8} \mathrm{C}_{9}$ sequence, is significantly less buckled $\left(\mathrm{C}_{7}-\mathrm{C}_{8}\right.$ torsion angle: $\left.47^{\circ}\right)$ than the more remote $\mathrm{C}_{4} \mathrm{C}_{5} \mathrm{C}_{6} \mathrm{C}_{7}$ array $\left(\mathrm{C}_{5}-\mathrm{C}_{6}\right.$ torsion angle: $\left.67^{\circ}\right)$, and (ii) the link between $\mathrm{N}_{1}$ and $\mathrm{C}_{9} \mathrm{C}_{8} \mathrm{C}_{7} \mathrm{C}_{6}$, i.e. $\mathrm{N}_{1}-\mathrm{C}_{9}$, is unusually short $(1.39 \AA)$ for a single bond. The obvious operational interpretation of these structural characteristics is, of course, that the lone pair on $\mathbf{N}_{1}$ is extensively, albeit regionally, delocalized over the neighbouring butadiene segment. Significantly, reactivity data fully support this interpretation insofar as the $\mathrm{C}_{6} \mathrm{C}_{7} \mathrm{C}_{8} \mathrm{C}_{9}$ array emerges a far more effective $\pi$ donor in thermal cycloaddition than its more remote $\mathrm{C}_{4} \mathrm{C}_{5} \mathrm{C}_{6} \mathrm{C}_{7}$ neighbour (see subsection 3).

Last, but certainly not least, the notion of an aromatic $1 \mathrm{H}$-azonine derives added credence from proton exchange experiments ${ }^{12}$ establishing the molecule as more acidic than both pyrrole (by $c a .1 .8 \mathrm{pkA}$ units) and methanol (by ca. 0.8 pkA units).

To sum up, then, we note that heteroatom electronegativity exerts controlling influence on the development of aromaticity in the heteronin molecule, with strongly electronegative atoms such as oxygen and nitrogen bearing electron-withdrawing substituents resisting participation of the lone pair and leading to the development of heavily distorted localized frames closely resembling that of the model polyene of the series, CNT (11d). By contrast,

less electronegative heteroatom functions such as $>\mathrm{NH}$ and $>\mathrm{Nb}$ readily

share their electron pair with attendant development of planar, extensively delocalized skeletons, i.e. structures bearing strong resemblance to the aromatic model of the family, the cyclononatetraenyl anion (4). The question with regard to the classification of the sulphur analogue, i.e. thionin $(11 ; X=S)$ remains, at this stage, still open insofar as the molecule has yet to be synthesized in parent form. Our initial attempts to prepare this coveted heteronin 


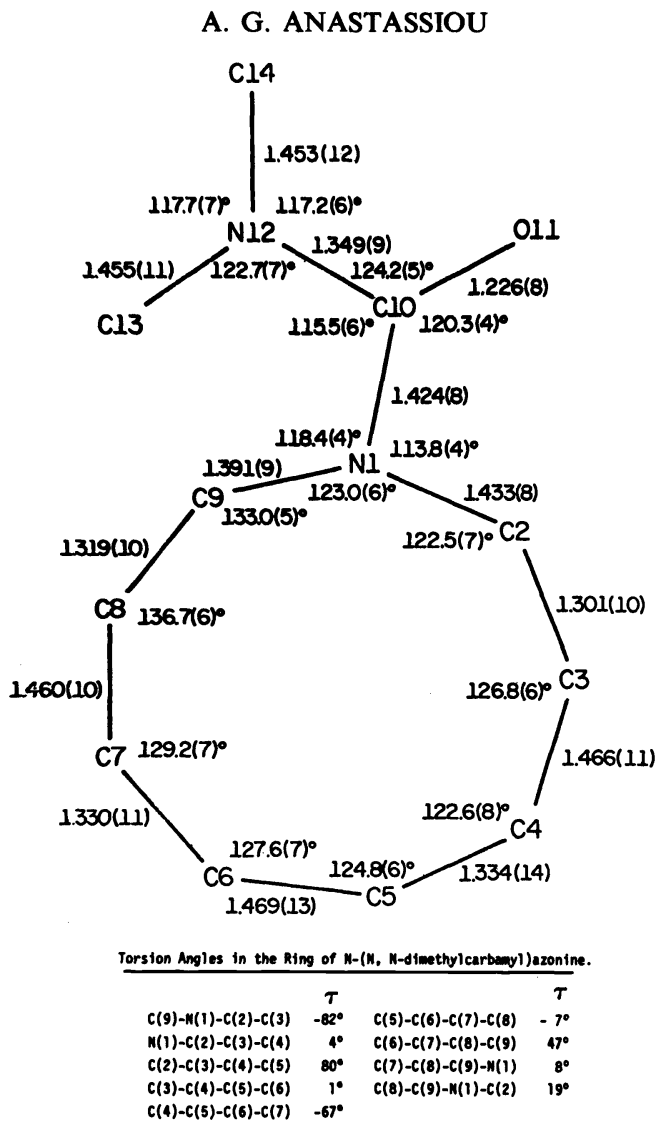

Figure 5. X-ray molecular dimensions and torsion angles for $N$-(N,N-dimethyl)carbamoyl azonine, 11g.

Scheme 2

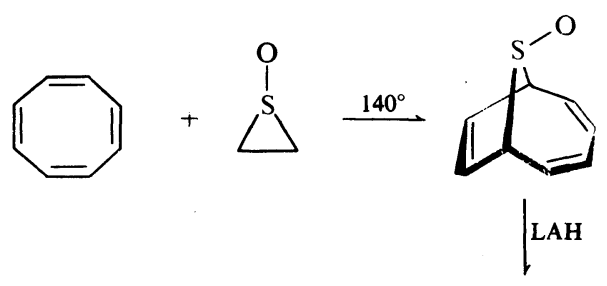

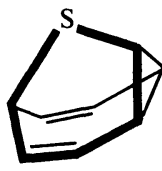

18 $\frac{h v / \text { sens. }}{0^{\circ}}$

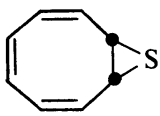

17

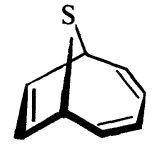


were frustrated by the unavailability of the desired photoprogenitor, namely the episulphide of cyclooctatetraene, 17. Synthetic frustration persisted, however, even after the successful photoinduced construction of $\mathbf{1 7}$ in our laboratories by the sequence shown in Scheme $2^{\mathbf{2 3}}$, insofar as exposure of this substance (17) to the type of irradiation previously employed in the successful preparation of heteronins 11a and. 11b led not to thionin but rather to the hitherto unknown thiabarbaralane $\mathbf{1 8}^{\mathbf{2 4 ,} 25}$. At this stage, then, one has no direct information upon which to base the classification of thionin and any position adopted on the matter must, of necessity, be purely conjectural. Bearing this in mind, but finding close precedent in the unmistakably heteroaromatic behaviour of the 5-membered analogue, thiophene, we offer the suggestion that thionin is likely to be endowed with aromatic character.

\section{(3) Chemical Studies}

Work by: R. P. Cellura, S. W. Eachus, (Mrs) E. Yakali and J. M. Spence

Our chemical studies on the all-cis heteronins and CNT have thus far been limited to a variety of pericyclic transformations such as thermal and photoinduced electrocyclization ${ }^{13,26,27}$ and thermal cycloaddition ${ }^{28-31}$. Since, however, this work has been reviewed in detail elsewhere ${ }^{3}$ suffice it to say here that all processes materialize along paths prescribed by orbital symmetry. The general structure obtained in each case is shown in Scheme 3.

Scheme 3<smiles>[X]c1ccccc1-c1ccccc1</smiles>

$14(a, b, d-h)$
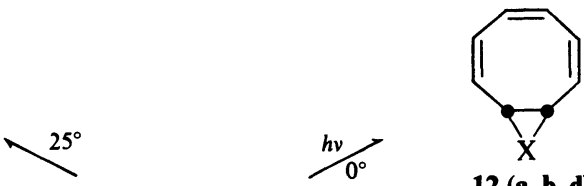

$12(a, b, d)$

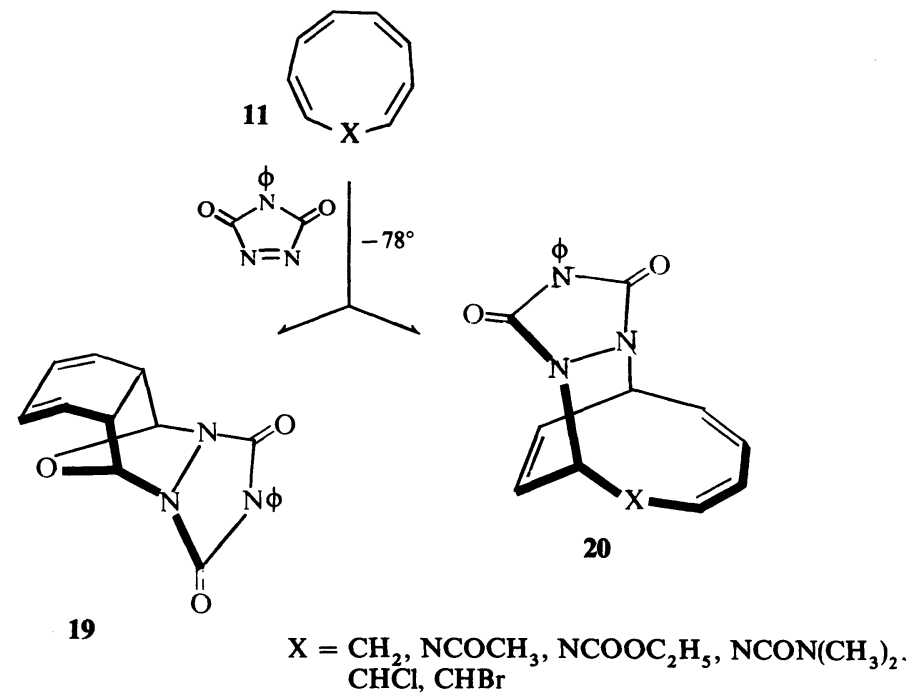


(4) Transient Mono-trans Heteronins

Work by: R. C. Griffith and R. L. Elliott

Because of its relatively small size the heteronin frame may not be rationally expected to accommodate more than one trans double bond and even then it is doubtful whether either of the two possible mono-trans variants, cis $^{3}$, trans (13) or cis, trans, cis $^{2}(\mathbf{2 3})^{*}$, will be able to attain planarity as readily as the cis counterpart 11. In fact, the greater affinity of the all-cis skeleton for attaining the desired planar conformation was convincingly demonstrated a few years ago $^{32}$ in connection with the model 'aromatic' member of the family, namely the cyclononatetraenyl anion. In brief, it was shown ${ }^{32}$ that while strongly diatropic by n.m.r. ('inner' proton resonates at $\tau$ 13.5) initially generated mono-trans anion 22 rapidly undergoes geometrical isomerization to its allcis relative 4 when warmed to ambient temperature. Moreover, since both anions emerge as aromatic under the n.m.r. criterion, one may reasonably attribute the greater stability of the $c i{ }^{4}$ variant primarily to more favourable skeletal disposition for attaining planarity. At the risk of appearing to digress from the main theme, we might briefly note that the high stereoselectivity of the alkali metal-induced conversion of 21 to 22 (the product mixture reportedly contains only about four per cent of 4) ${ }^{32}$ offers unmistakable demonstration that crosslink scission in $12(X=\bar{C} H)$ is strongly controlled by orbital symmetry in the manner predicted earlier ${ }^{5}$ (vide supra). Returning now to the question of relative stability among configurational isomers, we note that while most heteronins are expected to parallel the cyclononatetraenyl anion in this connection, the situation might be expected to reverse in molecules incorporating monoatomic hetero functions such as $\mathrm{X}=\overline{\mathrm{N}}, \mathrm{O}, \mathrm{S}$, for here the mono-trans variant should have ready access to what certainly constitutes the most suitable conformation for attaining planarity, i.e. that shown in $\mathbf{2 3}$, without experiencing the adverse effect of internal non-bonded repulsion; in fact interaction between the lone 'inner' proton and X in 23 may well be energetically beneficial since the two opposing groups here must attract electrostatically. In practice, one of course knows that the $c i s^{4}$ to cis, trans, $c i s^{2}$ process does not obtain in the case of the azoninyl anion, i.e. $15 \rightarrow 23 \mathrm{a}$,

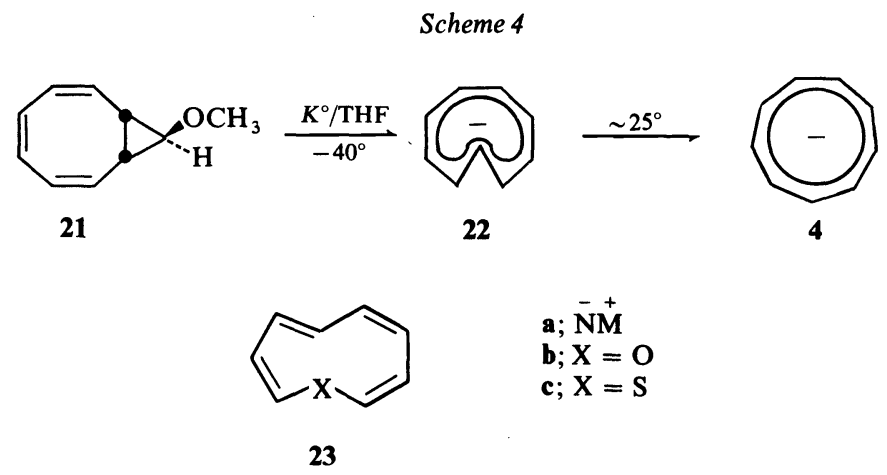

\footnotetext{
* For the convention adopted in the description of the sequence of double bonds, see ref. 45.
} 
at least not in the solid state where 15 is stable to prolonged heating at $100^{\circ}$. On the other hand, the question of whether the all-cis frame is more or less stable than 23 in the case of the oxygen and sulphur counterparts $23(\mathbf{b}, \mathbf{c})$ is still open and certainly deserving of attention.

For obvious structural and preparative reasons then (vida supra) our work with the heteronins has thus far concentrated almost exclusively on the more abundant all-cis variants. Nonetheless, mono-trans heteronins have been known to exist transiently, their presence being either inferred from the interconversion of valence tautomers, under the assumption of strict symmetry control, or more firmly established by actual cycloadditive trapping. Now, since the second of these processes, i.e. trapping, constitutes the very core of our synthetic entry into the frames described in sections $B$ and $C$ we shall devote a major portion of this section to a discussion of work pertaining to the conception and practice of this procedure.

Historically, the earliest report of a valence isomerization intermediated by a trans heteronin dates back to the first published photosynthetic search ${ }^{33}$ for oxonin from epoxide 12a, which led to the isolation of bicyclic isomers, $14 a^{27,34}, \mathbf{2 4}^{10}$ and $25^{33}$. Of these, 14a was, as indicated previously, conclusively shown ${ }^{27,34}$ to arise from thermal electrocyclization of $\mathrm{cis}^{4}$-oxonin, while the trans-fused counterpart 24 was conjectured to form from mono-trans oxonin assigned ${ }^{10}$ the $c i s^{3}$, trans configuration shown in $\mathbf{2 6}$. Now, while there is little doubt that $\mathbf{2 4}$ materializes from thermal disrotation of a mono-trans oxonin, which also reportedly yields oxacyclodecane on low-temperature catalytic hydrogenation ${ }^{10}$, the specific assignment of a cis $^{3}$, trans frame is clearly no more than arbitrary speculation insofar as the alternate arrangement, i.e. 23b (or its $c^{2}{ }^{2}$, trans, cis rotamer to be exact) is equally capable of undergoing symmetry-allowed thermal disrotation to $\mathbf{2 4}$ and, of course, catalytic hydrogenation to oxacyclodecane. Obviously then, the specific formulation shown in $\mathbf{2 4}$ must be regarded as highly speculative and opinion relating to its confirmation or rejection is best withheld until such time as the species becomes amenable to direct observation.

\section{Scheme 5}

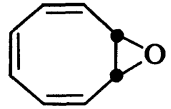

$12 \mathbf{a}$

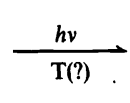<smiles>C1=CC2C=COC2C=C1</smiles>

14a

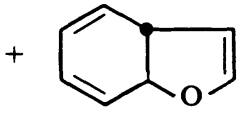

24

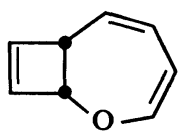

25

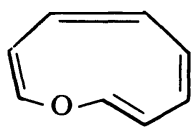

$13 \mathbf{a}$

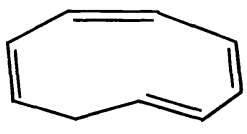

26

Similar results were also obtained with the related hydrocarbons ${ }^{16}$, the carbocyclic analogue of 12a, i.e. 12d, presumably yielding as much as $25 \mathrm{per}$ cent $^{25 \mathrm{~b}}$ mono-trans CNT (in combination with other products including the 
all-cis counterpart 11d) on direct $2537 \AA$ irradiation at $-60^{\circ}$. However, and this despite a brief statement to the effect that the mono-trans CNT (unlike the oxonin counterpart) was actually isolated in high (ca.95 per cent) purity ${ }^{25 b}$, the molecule does not appear to have been directly observed, and structural characterization rests again on chemical response, the molecule reportedly yielding trans-fused 8,9-dihydroindene on thermolysis $\left(\mathrm{ca} .-15^{\circ}\right)$ and cyclononane on low temperature $\left(\mathrm{ca} .-70^{\circ}\right)$ catalytic hydrogenation. As a result, the specific assignment of a $c i s^{3}$, trans frame to this carbomonocycle, e.g. $27^{16,25 b}$, must again be viewed as strictly speculative.

Our own encounter with mono-trans heteronins is closely linked to the recognition, several years $\mathbf{a g o}^{5}$, that the well documented ${ }^{35}$ thermal conversion of bicycle 12d predominantly to cis-8,9-dihydroindene (14d) is disallowed by orbital symmetry and our subsequent resolve to probe into the mechanism by searching for possible transient intermediates by means of cycloadditive trapping. Initially, this was accomplished with the use of 2,5-dimethyl-3,4diphenylcyclopenta-2,4-dienone (27) and resulted in the isolation, in high yield (75 per cent), of diastereomeric cycloadducts 28 and $29^{36}$. The stereochemistry and position of the juncture in these cycloadducts clearly point to their origin as products of suprafacial cycloaddition between the $4 \pi$ system of 27 and the trans bond of cis $^{2}$, trans, cis CNT, 31. It is perhaps worth stressing before proceeding further that, unlike electrocyclization, cycloadditive trapping normally preserves the basic skeleton of the transient intermediate, and thus constitutes a powerful tool in structural characterizations. In the present instance, the procedure is seen to unmistakably establish both the presence and exact location of a trans function in the molecule.

While still on the subject of cycloadditive trapping of thermally generated mono-trans CNT 31, it is of interest to note that a 1:1 adduct prepared some ten years $\mathrm{ago}^{37}$, on exposure of $12 \mathrm{~d}$ to TCNE at ambient temperature, was recently shown to possess the gross structure ${ }^{38,39}$ and stereochemistry ${ }^{40}$ depicted in 32a and that more recent work with the anti 9-methyl analogue shown in 12d resulted in the formation of the specific methyl analogue shown in 32b. Similarly the use of chlorosulphonyl isocyanate (CSI) in the reaction instead of TCNE led (after reductive removal of the $\mathrm{SO}_{2} \mathrm{CI}$ appendage) to cycloadducts 33a and $33 b^{41}$. Unfortunately, the question of origin here remains largelý unsettled, for while early mechanistic work ${ }^{40,41}$ was interpreted as being clearly indicative of direct dipolar addition of TCNE or CSI to the intact [6.1.0] frame of 12d (or its anti 9-methyl relative), more recent kinetic scrutiny ${ }^{2,43}$ revealed, instead, strong likelihood for the active participation of mono-trans CNT 31 in the reaction.

Our successful interception of $\mathbf{3 1}$ with the use of dienone 27 raised the possibility of trapping a mono-trans azonine along analogous lines, i.e. by thermally activating urethane 12b instead of hydrocarbon 12d. Unfortunately, the initial phase of our work here proved to be a rather frustrating experience, for we were faced with the tedious and largely unrewarding task of correcting existing inaccuracies in the scant published literature ${ }^{4 b, 25 a}$ on the subject. In brief, our studies here revealed ${ }^{44,45}$ that (i) the reportedly ${ }^{4 b}$ clean thermal conversion of $\mathbf{1 2 b}$ to 34 , effected on brief heating at $80^{\circ}$, is a far less specific process, generating as much as 23 per cent trans-fused dihydroindole, 35, and (ii) the recent claim, again published by Masamune et $a .^{25 a}$, 
SYNTHESIS AND STUDY OF SELECT HETEROCYCLES

Scheme 6

$\longrightarrow \frac{80^{\circ}}{\cdots}$

12d

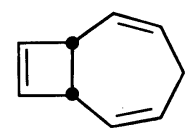

30

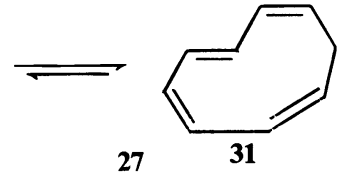

27

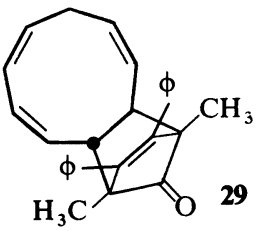

33

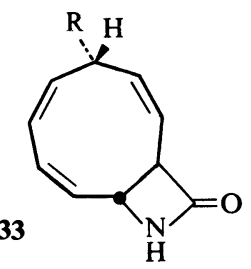

a; $\mathbf{R}=\mathbf{H}$

b; $\mathbf{R}=\mathrm{CH}_{3}$

Scheme 7

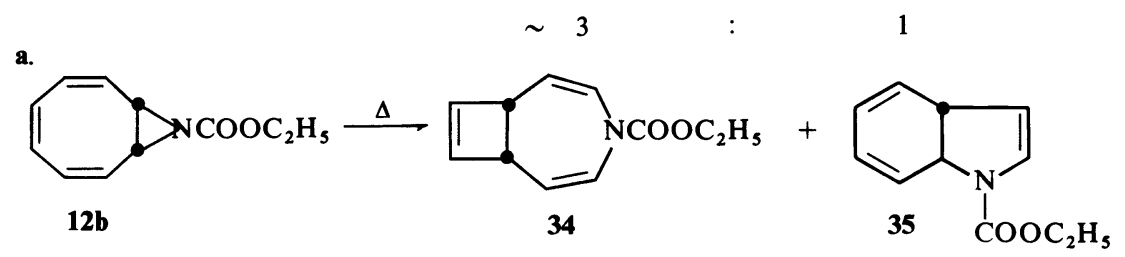<smiles>CCOC(=O)n1ccc2ccccc21</smiles>

b.<smiles>CC(=O)N1C=CC2C=CC2C=C1</smiles>

36<smiles>O=C(Cl)N1C=CC=CC2C=CC21</smiles>

37

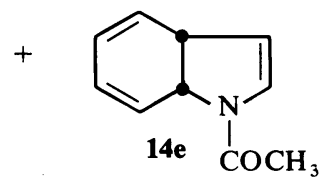

14e $\stackrel{\mathrm{COCH}}{3}$ 

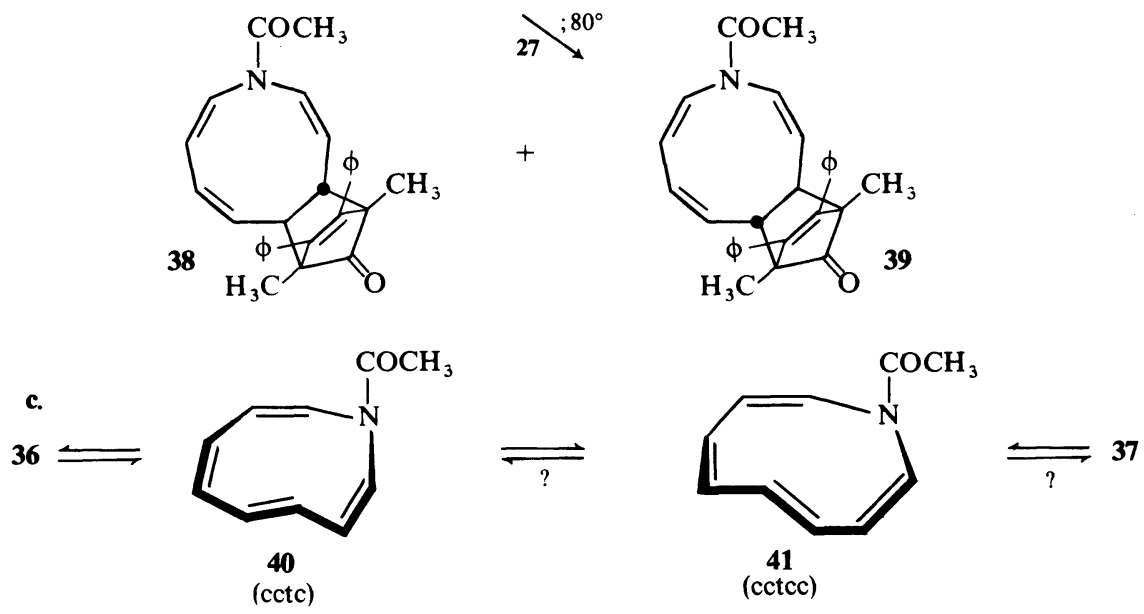

that 34 thermally rearranges to cis-fused dihydroindole $14 \mathrm{~b}$ at higher temperatures, is seriously inaccurate, the substance (34) thermolysing in our hands chiefly (ca. 70 per cent) to the trans counterpart 35 (Scheme $7 a)^{46}$. Once the thermolytic behaviour of urethane $12 \mathrm{~b}$ and 34 and their methoxycarbony $1^{44}$ and acetyl ${ }^{45}$ (Scheme $7 b$ ) counterparts became firmly established we resumed our search for monocycles in thermal transit and discovered acetamide $36^{\mathbf{4 7}}$ to be particularly suitable for this purpose. In specific terms, we found the unperturbed thermal response of this substance, i.e. conversion into a nearly equimolar proportion of $14 \mathrm{e}$ and 37 , to be effectively inhibited by the presence of 27, and the diastereomeric pair of cycloadducts shown in $\mathbf{3 8}$ and $\mathbf{3 9}$ to form instead. Obviously, the dienone acts here as an effective $\pi 4 s$ interceptor (the combined cycloadducts, $38+39$, account for $c a .93$ per cent of the crude thermolysate) of an $\mathrm{N}$-acetylazonine incorporating a remote trans double bond, i.e. one not directly linked to nitrogen. On the other hand it is not obvious from structures $\mathbf{3 8}$ and 39 as to which rotamer of this mono-trans azonine, i.e. cis $^{2}$, trans, cis (40) or cis, trans, cis $^{2}(\mathbf{4 1})$, is primarily involved in cycloaddition here. There is strong likelihood of course that both are, since the observed conversion of $\mathbf{3 6}$ to $\mathbf{3 7}$ by monocyclic intermediates requires the prior isomerization of $\mathbf{4 0}$ (only symmetry-allowed monocyclic product of 36) to 41 (only symmetry-allowed monocyclic progenitor of 36 ).

\section{(5) Some remarks and clarifications}

We now conclude the section on the heteronins by briefly clarifying our stand with regard to certain interpretations we offered recently and which were subsequently objected to by Masamune in a review ${ }^{25 b}$ of his peripheral and largely confirmatory work in the area. The criticism is not directly pertinent to the central theme of this review, i.e. the question of 'aromatic' character, but is sufficiently vexing as to elicit our response. On the other hand, since we do not wish to burden the reader with extensive commentary on subjects of marginal interest we shall in each case limit our response to a few brief statements. 
First, we should like to dispose of Masamune's assault on our brief warning comment with regard to one's uncertainty as to the exact source of the substituent-induced molecular asymmetry developed in certain polyenic heteronins at low temperatures, namely that: 'Perhaps the most useful outcome of these studies is the realization that lack of appropriate models precludes a safe choice between the two mechanisms considered'3b, i.e. nitrogen inversion versus substituent rotation. This, our critic counters with the overly confident statement: '... the mass of data is uniquely consistent with restricted rotation as the cause of the temperature dependent spectra'25b. Now, besides invoking n.m.r. spectral data pertaining chiefly to acyclic species, in support of the mechanism of restricted rotation, Masamune places strong emphasis on the fact that such species are known by $x$-ray to incorporate a planar $(<0.01 \AA$ out-of-plane) nitrogen function. This, we submit is at variance with recent $\mathrm{x}$-ray information on $11 \mathrm{~g}$ ( $\mathrm{a}$ typical polyenic azonine) which revealed the ring nitrogen as decidedly non-planar, extending by as much as $0.18 \AA$ out of the plane defined by its three substituents. Naturally then, we deem this finding to be strongly supportive of our reservations concerning Masamune's model compounds; it compels us to adhere all the more strongly to our original statement of caution quoted above.

Secondly, we call attention to criticism levelled at our interpretation of the n.m.r. resonance due to the magnetically identical $\alpha$ protons of the various alkali metal azonides, which appears at approximately the same strikingly low field $(\tau 1.30-1.50)$ in all the members $(\mathrm{M}=\mathrm{Li}, \mathrm{Na}, \mathrm{K}, \mathrm{Rb}, \mathrm{Cs})$ when the spectrum was recorded in the strongly dipolar solvent DMSO, but emerges at widely different regions of the spectrum in the less ionizing medium, acetone, ranging from $\tau 2.40$ for $\mathrm{M}=\mathrm{Li}$ to $\tau 1.74$ for $\mathrm{M}=\mathrm{Na}$ to $\tau 1.36$ for $\mathrm{M}=\mathrm{K}$, to $\tau 1.30 \mathrm{M}=\mathrm{Rb}$. Our interpretation here ${ }^{12}$ is that the spectra in DMSO are those of solvent-separated species while those in acetone are reflective of ion pairs. Moreover, we offered the suggestion that the progressive shift of the $\alpha$ proton resonance to lower fields with increasing size of the gegenion is very likely due to the increased deshielding influence exerted by the larger cations. In other words we proposed that the chemical shift of the $\alpha$ proton here reflects the size of the neighbouring alkali metal cation. In criticism of the latter interpretation Masmune expresses confusion ${ }^{25 b}$ at the fact that potassium azonide displays the $\alpha$ proton resonance at approximately the same low field in both media, DMSO and acetone, while in the corresponding lithio salt the same resonance appears at higher fields $(\tau 2.40)$ in acetone than in DMSO $(\tau 1.50)$. Admittedly, the situation is not as explicit as one would like it to be, but it hardly calls for the degree of confusion expressed by Masamune. There is, for example, obvious misconception in the criticism that the positive charge of the metal somehow vanishes on passing to solvent-separated species. In actual fact, of course, the metallic charge is merely replaced by the positively polarized end, e.g. the sulphur of DMSO, of one or more of the dipoles effecting the separation; after all, the nitrogen atom should, for obvious electronic reasons, remain the centre of highest electron density irrespective of medium polarity -or, for that matter, degree of lone-pair delocalization. In the present instance it is possible that the bulky sulphur atoms of one or more DMSO units influence the $\alpha$ protons in the manner of a large diffuse pseudo gegenion, i.e. not unlike $\mathrm{K}^{+}, \mathrm{Rb}^{+}$or $\mathrm{Cs}^{+}$. Alternatively, it is not inconceivable that the n.m.r. 
chemical shifts of the $\alpha$ protons associated with the solvent-separated species are mostly affected by the increase in ring diamagnetism expected of the more weakly complexed, and thus more strongly diatropic, azoninyl anion with consequent downfield displacement to a position in the spectrum which happens to coincide with that occupied by their counterparts in the ion-paired species associated with the large gegenions, i.e. $\mathrm{K}^{+}, \mathrm{Rb}^{+}, \mathrm{Cs}^{+}$. There is, of course, a third possible explanation of the observed shifts, and one that first comes to one's mind, namely that what we are witnessing with the larger cations $\left(\mathrm{K}^{+}, \mathrm{Rb}^{+}, \mathrm{Cs}^{+}\right)$are solvent-separated species in both media, DMSO and acetone, while the smaller, harder, alkali metals $\left(\mathrm{Li}^{+}, \mathrm{Na}^{+}\right)$form solventseparated species in DMSO but largely ion-pairs in acetone. The one major drawback of this interpretation is of course that it sets the chemical shift of the $\alpha$ protons in the relatively free azoninyl anion at a strikingly low field, i.e. $c a . \tau 1.4$. Moreover, it does not account for the fact that the chemical shift of the $\beta+\gamma+\delta$ proton combination n.m.r. band remains essentially invariant on changing either the gegenion or the medium; the band only shifts from $\tau 3.30$ to $\tau 3.40$ on passing from lithium azonide in acetone (ideal situation for ion-pairing) to caesium azonide in DMSO (ideal conditions for the generation of solvent-separated species). For obvious reasons, this latter observation appears to add strength to the original notion that the observed $\alpha$-proton shifts are primarily the result of localized perturbation (the gegenion effect) rather than of any intrinsic change in the degree of $\pi$ delocalization; in fact, one need only glance at the difference in $\mathrm{H}_{\alpha}$ chemical shift between lithium and sodium azonides in the two media $(\tau 2.40$ in acetone and 1.50 in DMSO for $\mathrm{M}=\mathrm{Li}$ and $\tau 1.74$ in acetone and 1.47 in DMSO for $\mathrm{M}=\mathrm{Na}$ ) to be convinced that the proposed gegenion effect is no figment of one's imagination.

Finally, Masamune chooses to criticize our proposal of a dividing line between 'aromatic' and polyenic specimens of the heteronin family on the basis of thermal stability of the various known members. and proceeds to offer instruction (complete with surprisingly simplistic examples, e.g. he informs the reader that COT is thermally stable!!) that thermal stability is no criterion for aromaticity. What our critic failed of course to indicate in formulating his objection here is that the same demarcation line emerges from data relating to the presence or absence of ring diamagnetism (n.m.r. shifts and $S$ values) and the possession or lack of planar geometry (u.v. shifts in conjunction with SCF calculation). For obvious reasons then we strongly adhere to our original position that thermal stability constitutes a reliable readily discernible criterion of 'aromaticity' among the heteronins.

\section{B. THE BENZOHETERONINS}

\section{Work by: (Miss) E. Reichmanis, R. C. Griffith and R. L. Elliott}

Benzannelation offers a simple, convenient, means of making direct comparison between a nonbenzenoid aromatic and benzene in terms of $\pi$ delocalization. The imposed test is a demanding one however, since the molecule is, in effect, forced to share a common link with what has, over the years, justly earned the title of 'ultimate aromatic'. In addition, of course, to the $\pi$-readjustment the molecule will have to undergo in order to absorb 
the crosslink into its frame and still retain a delocalized system, one must also take account of a potentially damaging steric effect, namely the peri $\mathrm{H}-\mathrm{H}$ interaction generated as a result of ring fusion. In fact, this steric perturbation of the nonbenzenoid portion of the molecule may well raise serious structural problems in an all-cis-frame the size of a heteronin (cf. the $\mathrm{N}$-alkylazonines) where even under the most favourable conditions, e.g. $1 \mathrm{H}$-azonine and metal azonides, the affinity to delocalize is believed to only slightly exceed the molecule's tendency to distort.

Bearing all these points in mind and seeking added insight into the extent of $\pi$ stabilization in the 'aromatic' acid-base pair 16 and 15, we decided to examine the behaviour of these two $\pi$ entities under the perturbing influence of benzannelation. Synthetically, one is again faced with the rather serious problem of modifying a basically unstable skeleton or, more specifically, of realizing benzannelation of the heteronin frame without triggering the type of thermal and oxidative response normally attending perturbation of this sensitive system. Now, a brief survey of prior art on the subject revealed that the complication of dealing directly with a heteronin in the transformation sequence had been effectively circumvented in previous work with the singlestep synthesis of the symmetrical dibenzopolyenes shown in $42(a-d)^{48-50}$ (in fact $\mathbf{4 2 a}$ and $\mathbf{4 2 b}$ are the first recorded compounds possessing a fully unsaturated heteronin frame $)^{48}$ from precursors entirely unrelated to the heteronin skeleton; this is shown in Scheme 8a. Closer examination reveals,

Scheme 8

a.

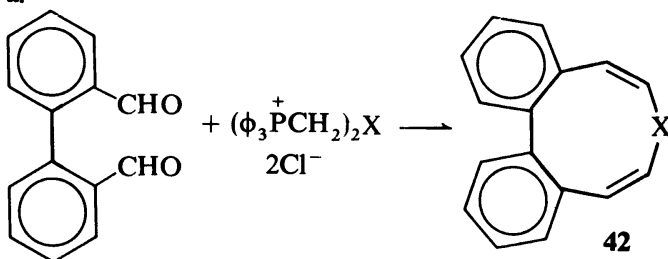

(a) $\mathrm{X}=\mathrm{O}$

(b) $\mathrm{X}=\mathrm{S}$

(c) $\mathrm{X}=\mathrm{CH}_{2}$

(d) $\mathrm{X}=\mathrm{CO}^{2}$

b.

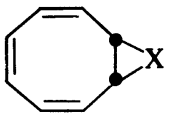

12<smiles>O=c1cccco1</smiles>

43

(a) $\mathrm{X}=\mathrm{CH}_{2}$

(b) $\mathrm{X}=\mathrm{NCOCH}_{3}$

\section{$\stackrel{\sim 70^{\circ}}{\longrightarrow}$ [mixture of cycloadducts]}

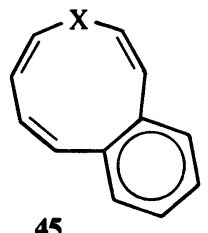

o-chloranil
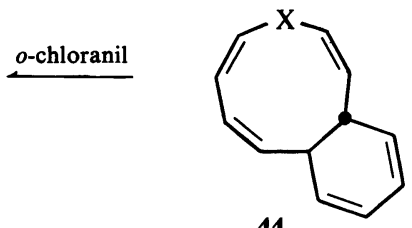

44 


\section{A. G. ANASTASSIOU}

however, that while uniquely suitable as a means of constructing dibenzoheteronins, the condensation process is, in its present form, inappropriate for the purpose of preparing monobenzo variants. Moreover, judging from the low yields reported for the transformations depicted in Scheme $8 a(<15$ per cent yield of $\mathbf{4 2 a}$ and $\mathbf{4 2 b}$ ) we chose not to attempt possible modification of this sequence in our effort to prepare a monobenzoheteronin. Instead, we focused attention on the possible synthetic utilization of our recent mechanistic discovery that cycloadditive trapping of thermally generated cis, cis, trans, cis- CNT (31) or $N$-acetylazonine leads, in high yield (75-93 per cent), to the formation of bridged [7.4.0] skeletons (see Schemes 6 and $7 b$ ). These, are obviously well designed for two-step conversion (bridge extrusion followed by aromatization) to the desired benzannelated frame. While attractively brief and reasonably straightforward the procedure outlined in Scheme 6 is, nonetheless, self-defeating in its inability to furnish the sought skeleton in parent form. In an attempt to eliminate this undesirable feature, i.e. to prepare the unsubstituted benz[9] annulene skeleton, while still adhering to the proposed scheme, we changed the diene trap from dienone 27 to $\alpha$-pyrone (43). Gratifyingly. this modified process led efficiently to the desired cycloadducts which were, in turn, converted to the novel trans-fused [7.4.0] pentaenes, 44, on careful vacuum pyrolysis. Finally, straightforwrd, high yield ( $>80$ per cent), dehydrogenation of $\mathbf{4 4}$ with $o$-chloranil completed the synthetic sequence by furnishing the desired benz[9] annulenes shown in $\mathbf{4 5}^{51}$ and $45 b^{52}$.

It is interesting to note that because it lacks the uninterrupted $6 \pi$ segment necessary for thermal disrotation. the general benzannulene frame shown in 45 resists thermal change. Consequently, the criterion of relative thermal sensitivity is not applicable here and comparison between the various members of this family must rest solely on spectral information. In terms of required model compounds, hydrocarbon 45a is obviously the ultimate benzopolyene of the family while its $14 \pi$-electron conjugate base, the benzocyclononatetraenyl anion (46), is the member most likely to be endowed with 'aromatic' properties. Naturally then, effort in this project was next directed at synthesizing the said carbanion and this was conveniently accomplished on exposure of $45 \mathrm{a}$ to potassium amide in liquid ammonia. N.m.r. comparison between carbanion and hydrocarbon progenitor reveals several meaningful differences. It is seen, for example, from Figure 6(a,b) that on passing from $45 \mathrm{a}$ to 46 , (i) the two $1 \mathrm{H}$ doublets in the spectrum $\left(\mathrm{H}_{2}\right.$ at $\tau 3.28$ and $\mathrm{H}_{5}$ at $\left.\tau 3.68\right)$ reduce to a single $2 \mathrm{H}$ doublet $\left(\mathrm{H}_{1}\right.$ at $\tau 2.18$ ), (ii) the benzenoid absorption changes from a $4 \mathrm{H}$ singlet at $\tau 2.81$ to two $2 \mathrm{H}$ doublet of doublets centred at $\tau 1.78$, and 3.04 and (iii) all protons bound to the $\mathrm{C}_{9}$ moiety of the molecule experience significant downfield shift. The first of these changes clearly reflects the development of twofold symmetry in $\mathbf{4 6}$ (not present in 45a) and thus the genesis of a delocalized frame, while the second (significant separation of benzenoid resonances) securely establishes that charge delocalization is not limited to the $\mathrm{C}_{9}$ portion of the molecule but extends into the benzene moiety as well. Finally, the downfield shift of resonances effected on passing from 45a to 46, and this in spite of the shielding effect of the added negative charge, may safely be interpreted to mean that $\pi$-electron delocalization in $\mathbf{4 6}$ is attended by strong ring diamagnetism. The benzocyclononatetraenyl anion may thus be securely classified as an 'aromatic' molecule and one best viewed as a $14 \pi$ 
unit rather than a benzannelated $10 \pi$ system $^{53}$. In other words, our findings on the subject clearly establish that the cyclononatetraenyl anion (4) is closely comparable to benzene in its affinity toward $\pi$-delocalization; a striking demonstration of the validity of Hückel's $4 n+2$ rule when one considers the high, potentially damaging, $\sigma$ strain associated with a planar 9-membered ring.

Despite its obvious aromatic character, however, the benzocyclononatetraenyl anion (46) undergoes slow but irreversible thermal change $\left(\Delta G_{56^{\circ}}=\right.$ $26 \mathrm{kcal} / \mathrm{mol}$ ) when allowed to stand at ambient temperature ${ }^{54}$. The nature of this transformation becomes immediately understood on inspection of the n.m.r. spectrum of the newly formed substance whose one most striking characteristic is a strongly coupled $(16 \mathrm{~Hz}) 1 \mathrm{H}$ doublet centred at $\tau 12.35$ ! (while slightly more complex, the remainder of the spectrum resembles that of 46). The splitting pattern and location of the upfield signal clearly establish the presence of a proton which is (i) associated with a single neighbouring hydrogen (clean doublet). (ii) bound to a trans bond $(J=16 \mathrm{~Hz}$ ) and (iii) located inside a strongly diatropic ring (high chemical shift). Translating this regional information to overall structure we conclude that the thermal product of $\mathbf{4 6}$ is in fact the mono-trans counterpart shown in $\mathbf{4 7 ^ { 5 4 }}$. Chemical evidence that both 46 and 47 are benzocyclononatetraenyl anions was obtained from the ready protonation of these species to yield benzo-CNT. Anion 46 was thus found to yield mostly 45a on slow quench and chiefly 48 on rapid quench while 47 produced only 48 (exclusive protonation of trans bond) irrespective of the rate of quenching.

At first glance, the thermally induced cis $\rightarrow$ trans isomerization required to convert $\mathbf{4 6}$ to $\mathbf{4 7}$ might strike one as surprising especially since the parent system, i.e. the cyclononatetraenyl anion, is known to undergo the reverse process (trans $\rightarrow$ cis) when warmed ${ }^{32}$; see Scheme 4. Closer scrutiny of the situation, however, rewards one with a rational interpretation. Specifically, we note that, unlike its parent, the monobenzo derivative $\mathbf{4 6}$ is plagued by a pair of peri $\mathrm{H}-\mathrm{H}$ interactions about the juncture which, judging from the size of the nonbenzonoid moiety, ought to be quite severe ${ }^{17}$ and thus potentially damaging to the affinity shown by the 9-membered frame for a planar, delocalized arrangement. Now, the molecule may relieve the steric congestion introduced by the peri interaction in one of two ways: (i) it may distort, thus partially removing both sets of $\mathrm{H}-\mathrm{H}$ repulsions and (ii) it may undergo cis $\rightarrow$ trans isomerization of a double bond carrying one of the peri hydrogens, thus completely removing one set of $\mathrm{H}-\mathrm{H}$ repulsions while partly preserving the other. Not unexpectedly, the molecule shows preference for the second alternative, i.e. cis $\rightarrow$ trans isomerization, since only in this manner is it capable of preserving its planarity and, consequently, its aromaticity.

While still on the subject of benzannelated $10 \pi$ hydrocarbon anions we might briefly note that the anion derived from dibenzo-CNT 42c was recently generated on treatment of the latter with butyllithium and was described to first materialize in puckered non-aromatic form and then undergo thermallyinduced flattening to an all-cis 'aromatic' frame ${ }^{55}$. In the light of our present views concerning the severity of peri non-bonded $\mathrm{H}-\mathrm{H}$ repulsions in the monobenzo analogue we find it difficult to understand why the 1,3-dibenzocyclononatetraenyl anion, with its added destabilization due to peri interaction 


\section{A. G. ANASTASSIOU}

between 'inner' ortho benzene protons, should be thermally stable and 'aromatic' in an all-cis planar arrangement. In brief, the question that immediately confronts one here is why does the molecule not isomerize to the mono-trans counterpart as does the monobenzo analogue. The answer to this question is obviously not clear at this stage.
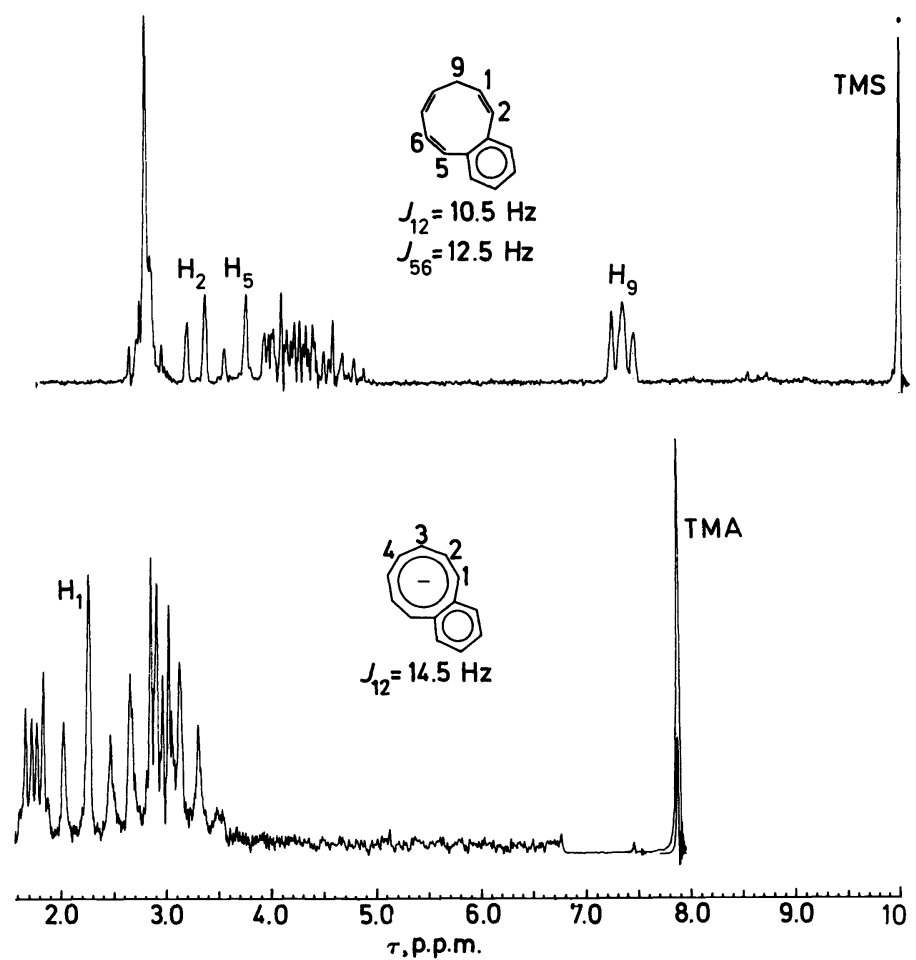

Figure 6. The n.m.r. spectra $(60 \mathrm{MHz})$ of (above) cis ${ }^{4}$-3,4-benzocyclonona-1,3,5,7-tetraene, 45a (in $\mathrm{CDCl}_{3}$ ); (below) potassium $c i s^{4}$-benzocyclononatetraenide, 46 (in $\mathrm{NH}_{3}$ ).

Once the key properties of model hydrocarbons $45 a, 46$ and 47 became known, our efforts were once more centred on the heteronin skeleton. To begin with. acetamide $45 \mathrm{~b}$ was converted to carbamate 49a and urea $49 \mathrm{~b}$ on successive exposure to methyllithium and the proper electrophile ${ }^{52}$. As expected, all three $\mathrm{N}$-substituted benzazonines, 45b, 49a and 49b, were found to display such spectral characteristics as are expected of benzopolyenic frames. It is noted for example that their n.m.r. spectra give no indication of ring diamagnetism in the 9-membered ring while the similarity of their lowenergy u.v. bands $(267-288 \mathrm{~nm})$ to that of parent hydrocarbon $45 a(240 \mathrm{~nm})^{51}$ suggests that in each case the heteronin portion of the molecule is heavily distorted.

Next, we attended to the more challenging case of parent 4,5-benzazonine (50) whose heteronin moiety, i.e. 16, shows clear signs of aromaticity in the absence of benzannelation. The molecule (50) was conveniently prepared on 
Scheme 9

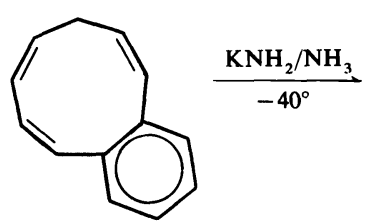

$45 \mathbf{a}$

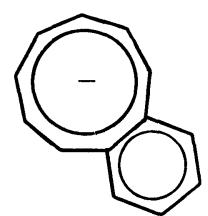

46

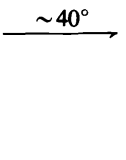

$\mid \mathrm{H}_{2} \mathrm{O}$

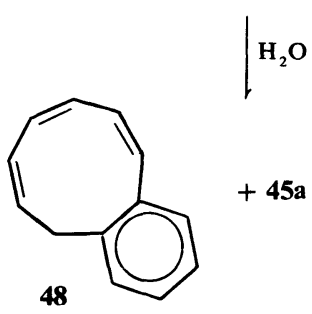

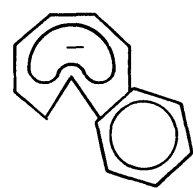

47

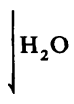

48

low temperature $\left(-78^{\circ}\right)$ protonation of lithium 4,5-benzazonide (generated in situ from $45 b)^{56}$; it is characterized by the n.m.r. spectrum shown in Figure 7, displays its low-energy u.v. band at $290 \mathrm{~nm}$ and yields carbamate $49 \mathrm{~b}$ on consecutive treatment with methyllithium and methyl chloroformate at $-78^{\circ}$. Brief inspection of the n.m.r. spectrum of $\mathbf{5 0}$, shown in Figure 7, reveals the position of resonances associated with the azonine moiety of the molecule to be that of an unexceptional polyene. It is noted, for example, that the n.m.r. signals due to the $\alpha\left(\tau 3.92\right.$ and 4.37 for $\mathrm{H}_{2}$ and $\left.\mathrm{H}_{9}\right)$ and $\beta(\tau 4.72$ and 5.71 for $\mathrm{H}_{3}$ and $\mathrm{H}_{8}$ ) protons are significantly displaced to higher field relative to their counterparts in the spectrum of $1 \mathrm{H}$-azonine ( $\tau 2.93$ for $\mathrm{H}_{\alpha}$ and 4.00 for $\mathrm{H}_{\beta}$ ). Moreover, unlike $1 \mathrm{H}$-azonine whose n.m.r. spectrum is displaced to lower fields relative to those of its $\mathrm{N}$-substituted variants, compare for instance Figures $1(\mathrm{a}-\mathrm{d})$. comparison of 50 with its $\mathrm{N}$-substituted derivatives 45b, 49a and $49 \mathrm{~b}$ in terms of $\mathrm{H}_{8}$, i.e. the $\beta$ proton least likely to be influenced by the benzene group, actually reveals an upfield shift in the case of the parent and one which satisfies the linear correlation between $\delta\left(\mathrm{H}_{\beta}\right)$ and $\sigma_{p}^{-}$recently

shown ${ }^{57}$ to be characteristic of the isolated $\stackrel{\beta}{-\mathrm{C}}=\stackrel{\alpha}{\mathrm{C}}-\mathrm{NR}$ function. The

9-membered segment of $\mathbf{5 0}$ emerges as a distorted polyene also on the basis of its u.v. spectrum whose lowest-energy band $(290 \mathrm{~nm})$ exhibits the type of mild bathochromic shift by comparison with its counterpart in the $\mathrm{N}$-substituted derivatives (267-288 $\mathrm{nm}$ ) best accountable on the basis of decreased heteroatom electronegativity in the absence of major skeletal readjustment. The spectral information thus uniformly points to the presence of an unexceptional benzopolyenic frame in 50, leading to the obvious conclusion that benzenoid fusion on to $1 \mathrm{H}$-azonine introduces sufficient perturbation to 'tip' the scales of the sensitive energy balance and thus reverse the controlling influence from $\pi$ stability in the parent molecule to relief of $\sigma$ strain in the monobenzo derivative. The specific factor believed to be responsible for this rather 
striking change clearly emerges from related work with the benzazoninyl anion to be discussed next.

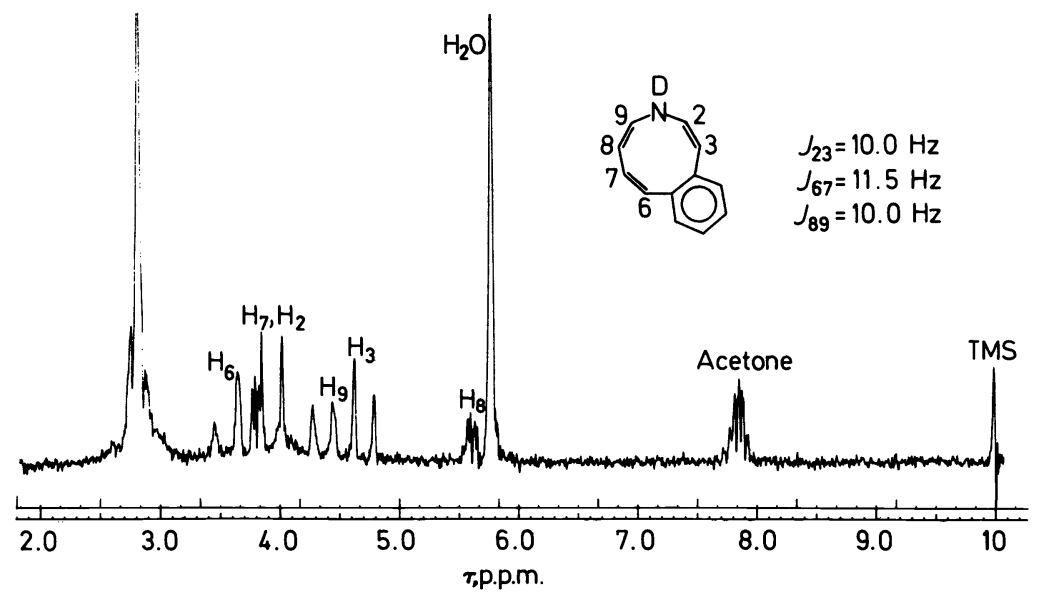

Figure 7. The n.m.r. spectrum ( $60 \mathrm{MHz}$ ) of $1 \mathrm{D}-4,5$-benzazonine, 50 (in acetone- ${ }_{6}$ ).

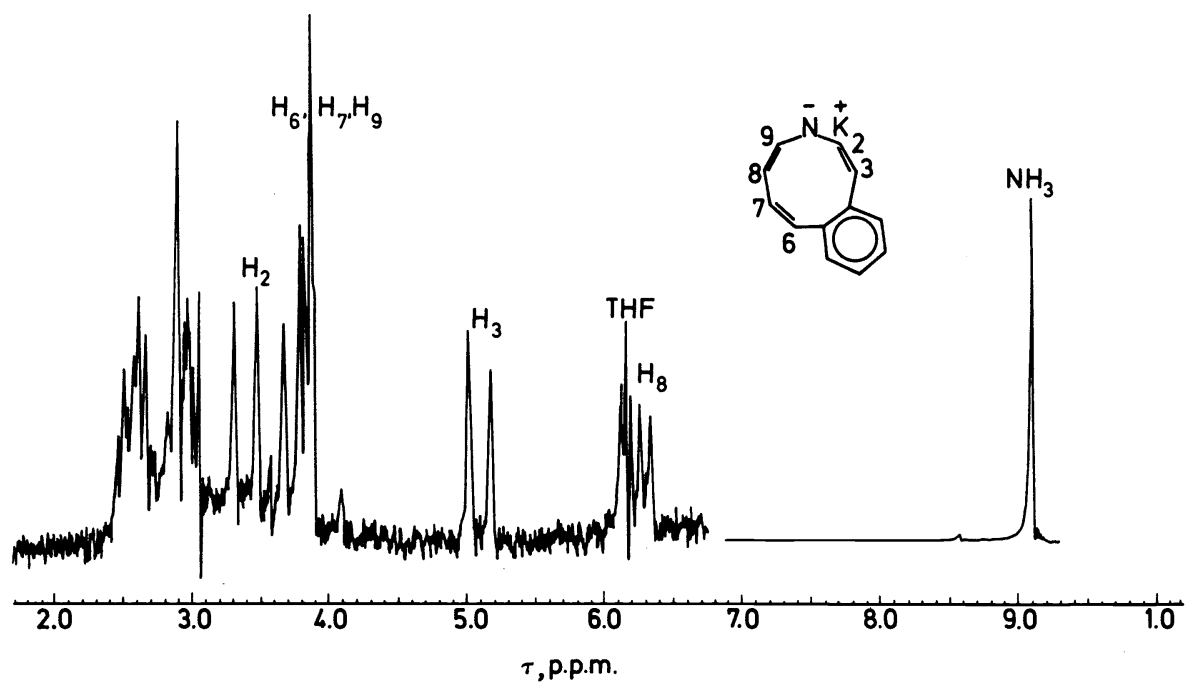

Figure 8. The n.m.r. spectrum (60 MHz) of potassium 4,5-benzazonide, 51 (in $\mathrm{NH}_{3}$ ).

With the realization that $\mathbf{5 0}$ consists of a polyenic azonine moiety we naturally undertook the task of preparing the corresponding conjugate base, the 4,5-benzazoninyl anion, in the hope that the attendant reduction in heteroatom electronegativity might provide the necessary impetus for the develop- 
SYNTHESIS AND STUDY OF SELECT HETEROCYCLES

Scheme 10
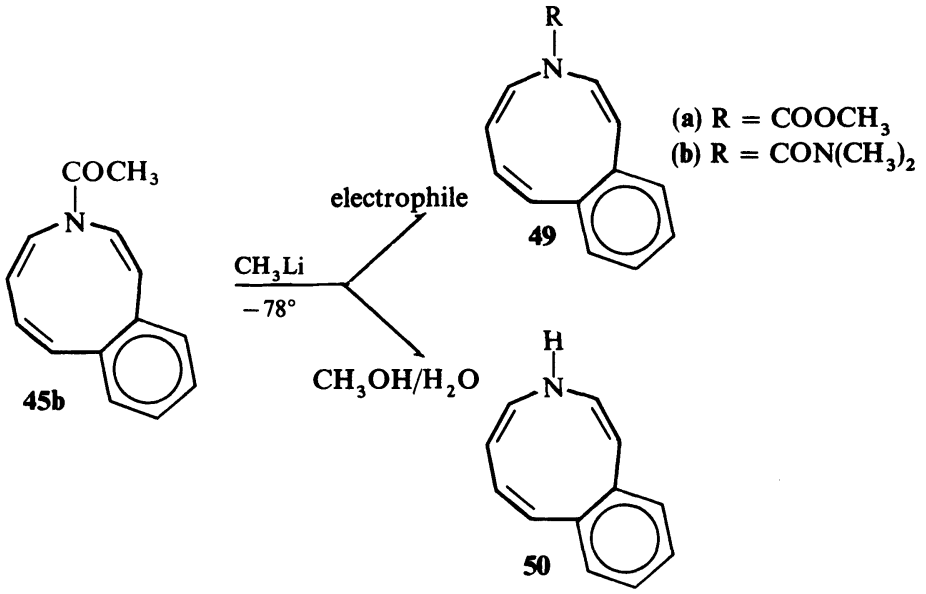

50
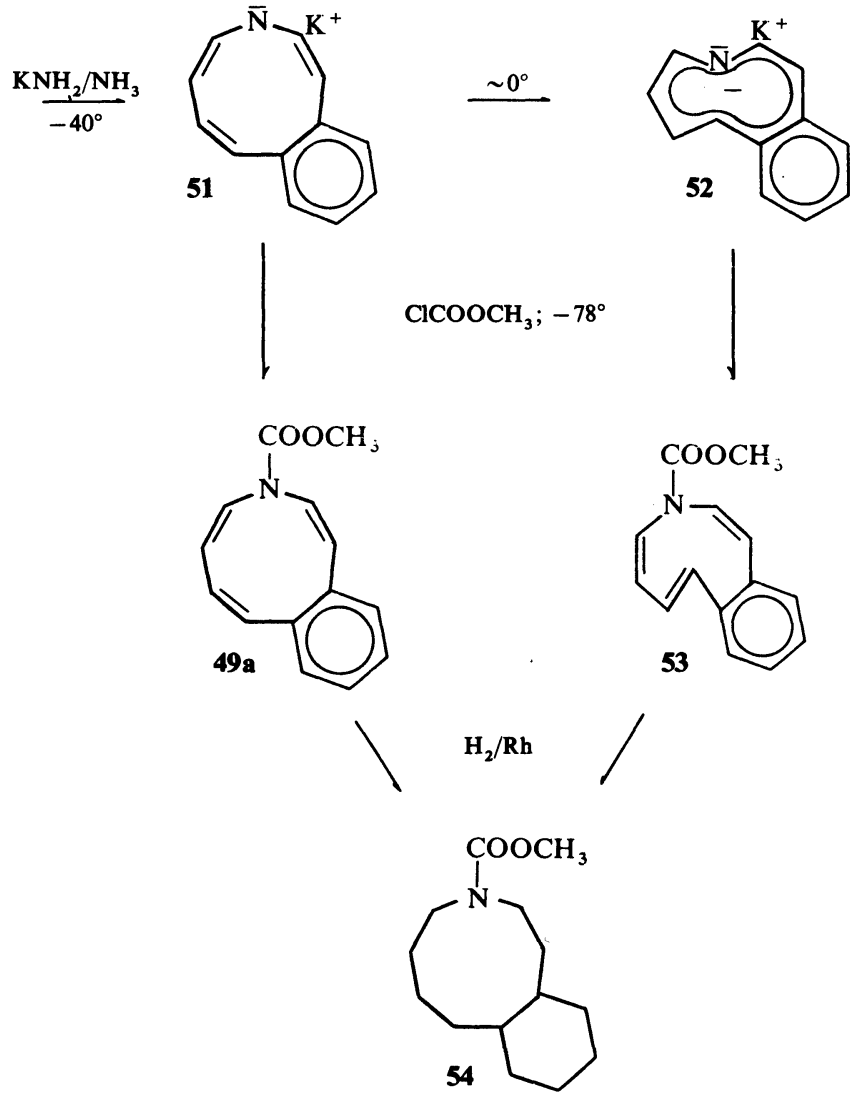

717 
ment of a delocalized heteronin skeleton in spite of the adverse effect of benzannelation. Treatment of $\mathbf{5 0}$ with potassium amide in liquid ammonia at $c a$. $-50^{\circ}$ afforded the desired anion, 51, which exhibits the n.m.r. spectrum depicted in Figure 8. Again, and this time to our obvious surprise, the molecule fails to sustain ring diamagnetism in its 9-membered segment. This is best evidenced by the upfield shift of $\beta$ protons $\mathrm{H}_{3}$ (by $23 \mathrm{~Hz}$ ) and $\mathrm{H}_{8}$ (by $32 \mathrm{~Hz}$ ) on going from $\mathbf{5 0}$ to 51 which simply reflects the increased availability of the lone pair for limited delocalization but is clearly inconsistent with the development of the diamagnetic ring current expected of this system. Interestingly, however, the molecule becomes unmistakably diatropic, its n.m.r. resonance undergoing significant downfield shifts on warming to $0^{\circ} 58$. This interesting change, which is irreversible and which requires only mild thermal activation $\left(\Delta G_{0^{\circ}}=20 \mathrm{kcal} / \mathrm{mol}\right)$ was traced to cis $\rightarrow$ trans isomerization, the diatropic species having been securely characterized as 52 . In particular, the acquisition of 'aromaticity' on passing from $\mathbf{5 1}$ to $\mathbf{5 2}$ is manifested by the dramatic shift of the $\mathrm{H}_{8}$ resonance from $\tau 6.2$ in 51 to $\tau 4.3$ in 52. Chemically, the structures of $\mathbf{5 1}$ and $\mathbf{5 2}$ were established by the transformations depicted in the concluding portion of Scheme 10.

Before closing this section it may be of interest to compare the cis $\rightarrow$ trans isomerizations $\mathbf{4 6} \rightarrow \mathbf{4 7}$ and $\mathbf{5 1} \rightarrow \mathbf{5 2}$ in terms of activation energy. It is immediately seen that the two differ substantially in this connection with the aza analogues undergoing this transformation at a considerably faster pace $\left(\Delta \Delta G^{\neq}=6 \mathrm{kcal} / \mathrm{mol}\right)$. It is tempting to attribute this rather substantial energy difference to the ability of the mono-trans 4,5 -benzazoninyl anion to readily adopt the virtually strainless configuration shown in $\mathbf{5 2}$ and the inability of the corresponding carbobicycle (47) to do so without generating seriously destabilizing 'inner' proton opposition. In fact, based on a simple electrostatic model it may be argued that interaction between 'inner' proton and negatively charged nitrogen in $\mathbf{5 2}$ should be stabilizing.

To sum up then, we find that the chief perturbing effect attending the benzannelation of a planar all-cis 9 -membered $\pi$ frame is the development of a pair of peri $\mathrm{H}-\mathrm{H}$ interactions about the crosslink. These are sufficiently severe to distort $1 \mathrm{H}-4,5$-benzazonine (50) and its corresponding anion, 51, and thus to prevent realization of their aromatic potential, but are not capable of suppressing delocalization in the more aromatic carbobicyclic analogue $\mathbf{4 6}$. Nonetheless, both anions, 46 and 51. show strong tendency to eliminate one peri interaction by undergoing ready cis $\rightarrow$ trans isomerization to 47 and 52 respectively; the $46 \rightarrow 47$ change occurring with retention of aromaticity and the $51 \rightarrow 52$ transformation actually leading to the acquisition of this property. Interestingly, current experimental awareness of the severity of neighbouring $\mathrm{H}-\mathrm{H}$ repulsions attending planarity in a 9-membered ring was preceded by a purely theoretical recognition of the problem in a ten-year-old paper by Simmons and Williams ${ }^{17}$.

Finally we should like to close this section with a brief note of warning against utilizing information derived from benzannelated models in matters relating to the parent system; comparison of 'aromatic' $1 \mathrm{H}$-azonine to its polyenic benzologue $\mathbf{5 0}$ offers vivid demonstration of the inadequacy of such extrapolations. 


\section{THE HETERO[13]ANNULENES}

Work by: R. L. Elliott

As the immediate ' $4 n+2$ ' $-\pi$ homologue of the heteronin, the hetero[13]annulene represents the next higher $\pi$-excessive heterocycle to be endowed with aromatic potential. Nonetheless, because of obvious size differences, the two relatives are expected to show preference for fundamentally different geometries if they are to assume planar frames and thus benefit from the stabilizing influence of $\pi$ delocalization. There is, for instance, little doubt that the combined adversity of high angle strain and severe $\mathbf{H}-\mathbf{H}$ repulsions will effectively prevent the 13-membered ring from attaining planarity in the allcis form. On the other hand, introduction of one or more trans bonds into the system should lower both the angle strain and the $\mathrm{H}-\mathrm{H}$ repulsions associated with the hypothetical planar arrangement and thus reduce the molecule's resistance to flattening (in effect the introduction of trans functions into the molecular frame is tantamount to dividing the system into smaller, less strained segments). Moreover, 'Dreiding' molecular models reveal the planar frame to possess a sufficiently large cavity as to readily accommodate the presence of a limited number of 'inner' protons without developing excessive repulsive interaction. All indication then is that the ability of a hetero[13]annulene to attain the required planar geometry will crucially depend on the number and relative position of trans bonds, the presence of one and preferably more of these functions being necessary for realizing this objective. In other words, the skeletal situation here is the exact reverse of that encountered with the corresponding hetero[9] annulenes (section A) where planarity was shown to favour the all-cis form.

Ideally we should have liked to model our coverage of the 13-membered $\pi$-excessives after that of the heteronin section. This is not strictly possible however, for unlike the heteronin case where our work provided all the central answers, other contributions being either peripheral or repetitive in nature, the hetero[13] annulene problem has received major clarification from the work of Gerhard Schröder and his group at Karlsruhe. In order then to offer effective description of our work in the area we shall have to make frequent mention of Schröder's findings as well. Luckily, there has been no overlap of results in the two investigations. In fact the two works are strongly complementary, the combined information collected at Syracuse and Karlsruhe serving to yield essentially complete understanding of the requirements of aromatic behaviour in the aza $[13\rceil$ annulene system.

The first aza[13]annulene was prepared in Karlsruhe ${ }^{59}$. It was obtained on direct low-temperature $(-70)$ irradiation of tetracyclic urethane $\mathbf{5 5}$ and was shown to possess the tetra-trans configuration shown in 56. While endowed with reasonable thermal stability, the molecule proved to be disappointingly polyenic by n.m.r. ${ }^{59}$. The atropic nature of 56 came of course as no surprise since the molecule incorporates such characteristics as might be expected to seriously limit its affinity for developing a planar delocalized frame. Specifically, it is seen that (i) the four inner protons will undoubtedly generate severe pairwise repulsions (each two hydrogens forming a nearly overlapping pair in the 'Dreiding' model) in the flat arrangement and (ii) the presence of the strongly electron-withdrawing ethoxycarbonyl appendage will surely 


\section{A. G. ANASTASSIOU}

reduce if not entirely suppress the crucial availability of the nitrogen lone pair for participation in the $\pi$ system. What was obviously needed then in order to test the aromatic potential of the aza[13] annulene system was the parent compound with the added condition that it possess fewer than four trans bonds. And since we had ourselves recently prepared a potential photogenitor of the 13-membered $\pi$-excessive azacycle, i.e. $44 b^{52}$, we initiated a synthetic project with the ultimate intention of securing the parent amine, hopefully in a configuration different from that indicated in $\mathbf{5 6 .}$

Scheme 11

a.

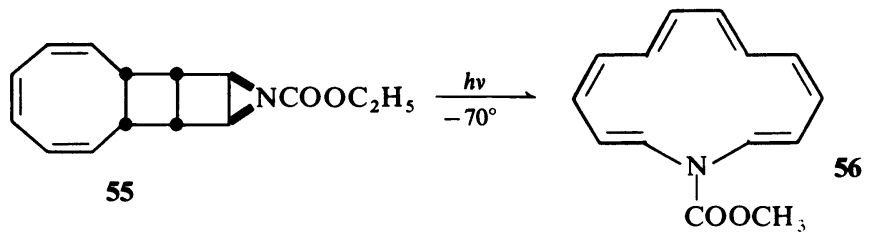

b.
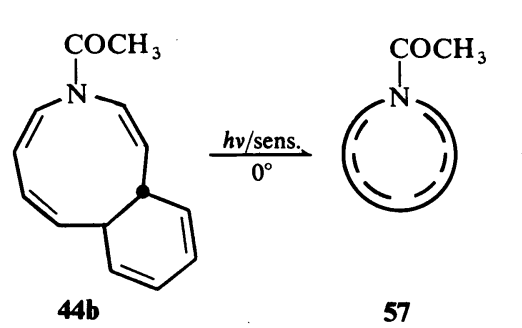<smiles>O=C(O)N1C=CC2C=CC=CC=CC2C=C1</smiles>

58

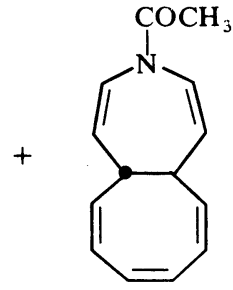

59

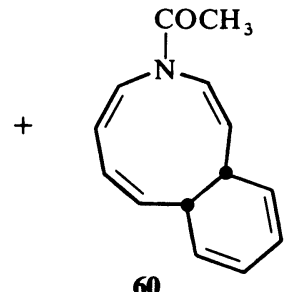

60

Gratifyingly, sensitized irradiation of $44 \mathrm{~b}$ at $0^{\circ}$ did indeed produce an aza[13] annulene, 57, in ca. 25 per cent yield together with three bicyclic isomers tentatively identified as 58, 59 and $\mathbf{6 0}$. The monocyclic structure of 57 (a sharp-melting bright yellow solid) ${ }^{60}$ was established by securing the customary spectral information and also by catalytic hydrogenation to $N$ acetyl azacyclotridecane. Again, as in the case of 56, the molecule (57) was found to be largely atropic by n.m.r., its spectrum, shown in Figure $9 b$, consisting of an absorption manifold best attributed to the presence of unexceptional 'olefinic' hydrogens. Chemically, 57 was found to readily undergo $\mathrm{N}$-substituent exchange on successive treatment with methyllithium and an appropriate electrophile at $-78^{\circ}$. In this fashion, we succeeded in preparing two additional $\mathrm{N}$-substituted aza[13]annulenes namely, the carbamate 61a 
and the urea $61 \mathrm{~b}$, both of which were isolated as yellow, sharp-melting solids. The molecules are seen again to be largely devoid of ring diamagnetism (see Figure $9 a, c$ ) although the upfield separation of a clean, strongly coupled $(14 \mathrm{~Hz})$, doublet in the spectrum of the carbamoyl derivative (Figure 9c) does appear to implicate the presence of an 'inner' ring proton located adjacent to nitrogen and shifted to higher field (normally, such $\alpha$ protons give rise to low-field resonances, see e.g. Figure $1 b, c$ ) because of some mild diamagnetic influence. In other words, what emerges from the n.m.r. spectrum of $61 \mathbf{b}$, whose substituent is, in fact, the least electronically demanding of the three discussed thus far, is the intriguing realization that what we are actually witnessing here may well be the gradual creation, so to speak, of ring diamagnetism; we shall return to this point later, after discussing the behaviour of the truly diatropic members of the series.
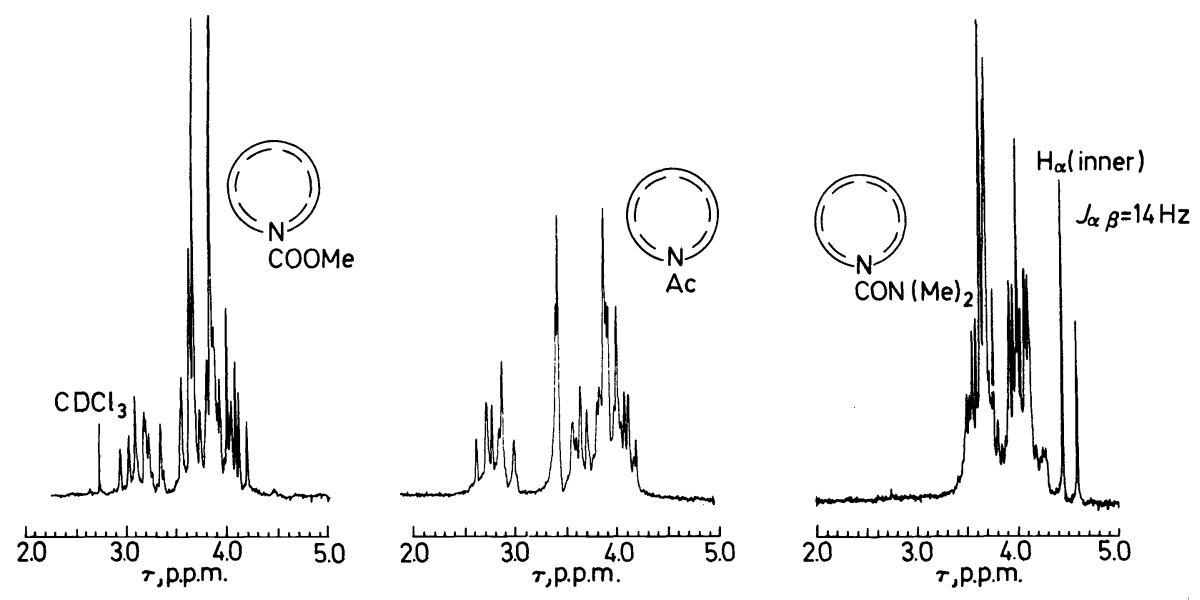

Figure 9. The n.m.r. spectra (100 MHz) of (left) $N$-methoxycarbonyl aza[13]annulene, 61a (in $\mathrm{CDCl}_{3}$ ); (centre) $N$-acetyl aza[13] annulene, 57 (in $\mathrm{CDCl}_{3}$ ); (right) $N$-( $N, N$-dimethyl)carbamoyl aza[13]annulene, $61 \mathrm{~b}$ (in $\mathrm{CDCl}_{3}$ ).

With the justifiable hope of discovering unambiguous evidence for ring diamagnetism in this family of compounds, we next turned our attention to the key figure of this investigation namely the parent aza[13]annulene. The preparation of this substance proved to be surprisingly simple, the replacement of the acetyl group in $\mathbf{5 7}$ by hydrogen merely requiring stepwise, lowtemperature $\left(-78^{\circ}\right)$, exposure of the acetamide to methyllithium and moist methanol. The $1 \mathrm{H}$-aza[13]annulene thus prepared was isolated as a yellow air-sensitive solid displaying the n.m.r. spectrum shown in Figure 10. Obviously the molecule is diatropic showing unmistakable signs of ring-current effects. In particular, we should like to draw attention to the striking highfield shifts of three well-separated $1 \mathrm{H}$ multiples from the largely overlapping resonance manifolds of 57 and 61a. In the first place, the large coupling constants $(14-16 \mathrm{~Hz})$ associated with these resonances are clearly indicative of 
a.

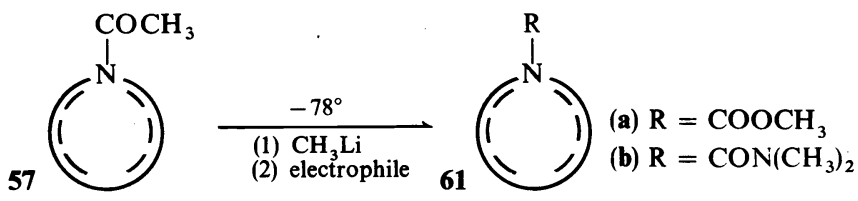

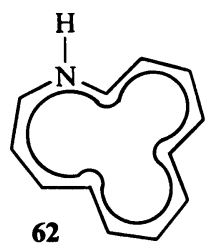

$$
\begin{aligned}
& \text { (2) } \mathrm{CH}_{3} \mathrm{I} \\
& -78^{\circ}
\end{aligned}
$$

(2) electrophile

b.<smiles>COC(=O)N1CCC=CCCCC1</smiles>

64

(two isomers)

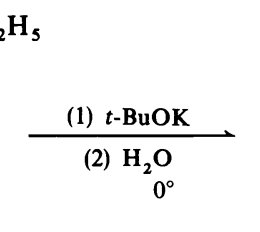

(1)

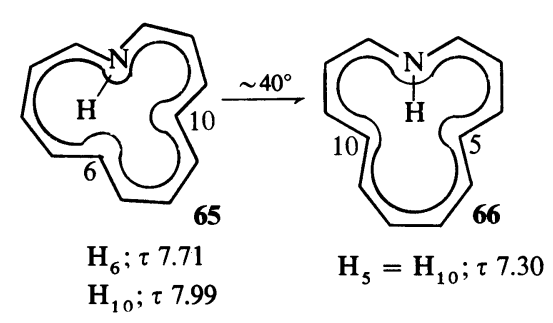

trans vicinal interactions. Secondly, judging from the high-field position ( $\tau$ 5.99-7.22) of these bands we conclude that they must represent protons located in a strongly shielding environment. Combining these two pieces of information we reach the obvious conclusion that the molecule incorporates tisree trans double bonds whose 'inner' hydrogens are influenced by a substantial diamagnetic ring current. Moreover, utilization of double irradiation procedures led to the regional proton assignments shown in Figure 11 and the strict condition that no two trans functions of the molecule be adjacent to one another.It follows that our $1 \mathrm{H}$-aza[13] annulene is structured as shown in 62. Interestingly, the alternating array of cis and trans bonds present in this molecule leads to formal division of the 13-membered frame into one sevenand two six-membered rings, which clearly benefits the molecule by reducing both skeletal strain and peripheral $\mathbf{H}-\mathbf{H}$ bond repulsions to manageable proportions. Moreover it appears that 'inner' proton repulsions are not sufficiently severe to prevent 62 from adopting the planar or nearly-planar geometry required for the development of $\pi$-electron delocalization; Dreiding' molecular models do indeed show planar 62 to be skeletally accessible and the distance between each two 'inner' protons to amount to $c a$. $1 \AA$. 
With a diatropic aza[13]annulene safely in hand we next addressed ourselves to the question of whether the molecule will retain its diatropic character when encumbered with an electron-releasing N-substituent such as the methyl group. We were, of course, particularly interested in the question of $N$-methyl substitution because of our earlier findings and interpretation in connection with $N$-methylazonine (section A) namely that the molecule is largely atropic because of serious steric congestion between the methyl group and its two adjacent $\alpha$ hydrogens. Obviously, no such congestion should be present in the cis, trans, cis, trans, cis, trans (ctctct) skeleton shown in 62 so that the $N$-methyl counterpart would be expected to have ready access to a flat frame and thus to be capable of sustaining ring diamagnetism. We have prepared the $N$-methyl aza[13] annulene shown in 63 on consecutive lowtemperature $\left(-78^{\circ}\right)$ exposure of 62 to methyllithium and methyl iodide and have indeed found it to be diatropic by n.m.r. ${ }^{61}$. In brief, the molecule displays an n.m.r. spectrum very similar to that of its parent, 62. Of particular significance is again the appearance of three distinct high field $1 \mathrm{H}$ resonances appearing at $\tau 6.18(\mathrm{dd} ; J=15.5,8.5 \mathrm{~Hz}), 6.41(\mathrm{dd} ; J=11.0,16.0 \mathrm{~Hz})$ and $7.25(\mathrm{~d}$; $J=14.0 \mathrm{~Hz}$, 'inner' $\left.\mathrm{H}_{\alpha}\right)$ in acetone- $\mathrm{d}_{6}$ at $c a .0^{\circ}$ and attributed to three strongly shielded 'inner' protons. In fact, judging from the slightly larger upfield shift experienced by the 'inner' protons of 63 compared to those of 62 and to the extent that these shifts constitute a sensitive probe of the magnitude of the molecule's diatropism, we are forced into the obvious conclusion that 63 is, if anything, more extensively diatropic than its parent, 62. Also noteworthy in this connection is the position of the methyl resonance in the spectrum of 63 which appears to reflect the reduction in heteroatom electron density expected for a well delocalized $\pi$ system. In specific terms we note that the methyl singlet of 63 appears at a detectably lower field $(\tau 7.45)$ than its counterpart $(\tau 7.85)$ in the spectrum of the essentially atropic 9 -membered analogue $N$-methylazonine (11k).

In parallel, strictly independent, work, Schröder and his associates succeeded in preparing the parent aza[13] annulene frame by successively exposing the isomeric pair of urethanes denoted by 64 to potassium $t$-butoxide and aqueous quench at $0^{\circ}$. This sequence led to the isolation of strongly diatropic 65 (see $\tau$ values alongside formula) ${ }^{62}$ which was, in turn, shown to undergo bond relocation to a similarly 'aromatic' isomer, 66, on heating to ca. $50^{\circ} .{ }^{63}$ Interestingly, Schröder's amines are geometrically isomeric with our specimen differing from it in two important aspects, (i) each contains only two trans $\mathrm{C}-\mathrm{C}$ bonds and (ii) both have internally directed NH links. A particularly significant outcome of the second structural characteristic, i.e. the central location of the $\mathbf{N}-\mathbf{H}$ bond is that the n.m.r. resonance associated with this strongly shielded function appears at $\tau 7.20$ in the spectrum of 65 as contrasted to $\tau 0.6$ for the deshielded 'outer' $\mathrm{N}-\mathrm{H}$ proton of our amine, 62 . Now, closer comparison between 62 and the 65, 66 pair reveals a subtle but meaningful similarity. Briefly, it is seen that despite the absence of a third $C=C$ double bond in 65 and 66 both molecules incorporate a total of three 'inner' hydrogens, one of which is invariably bound to nitrogen. In other words, the system shows unmistakable preference for a frame incorporating a total of three trans functions. This then appears to be the best configurational arrangement, a balance between favourable skeletal factors and unfavourable 'inner'- 


\section{A. G. ANASTASSIOU}

hydrogen interactions, for adoption by the aza[13] annulene system of the planar or nearly planar geometry so crucial to the realization of its $14 \pi$ potential.

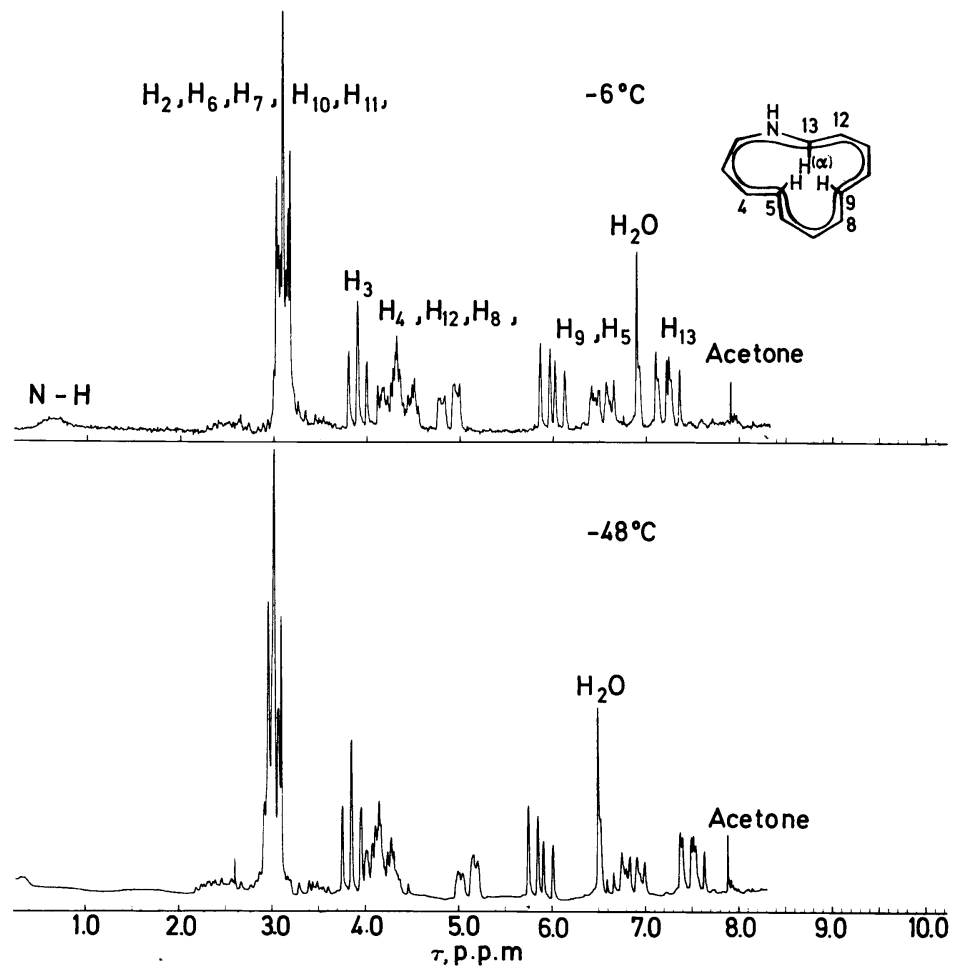

Figure 10. The n.m.r. spectrum (100 MHz) of cis, trans, cis, trans. cis, trans-1H-aza[13]annulene, 62 (in acetone- $\mathrm{d}_{6}$ ) recorded at: $-6^{\circ} \mathrm{C}$ and $-48^{\circ} \mathrm{C}$.

By eliminating the second step in the preparation of amine 65 the Karlsruhe group succeeded in generating and directly observing, by n.m.r., the intriguing aza[13] annulenyl anion shown in 68. This molecule is truly a textbook example of the term 'aromatic' as it relates to the presence of ring diamagnetism. It displays n.m.r. signals ranging from $\tau 0.45$ and 0.58 for the 'outer' $\alpha$ protons to $\tau 12.27$ and 13.05 for the two 'inner' hydrogens ${ }^{62}$ !! Not unexpectedly, the molecule emerges as considerably more diatropic than its conjugate acid 65. Our own attempts to prepare the aza[13]annulenyl anion of 62 have been only marginally successful, for while the expected species (67) did materialize on treatment of the amine (62) with potassium mirror in THF- $\mathrm{d}_{8}$ $-78^{\circ}$, it rapidly rearranged to 68 on warming to $c a .-40^{\circ}$. Owing then to the low temperature $\left(\mathrm{ca} .-60^{\circ}\right)$ necessary for direct observation of this thermally labile anion (67), its n.m.r. spectrum has yet to be recorded in entirely satisfactory form although it does clearly display the expected wide separation 


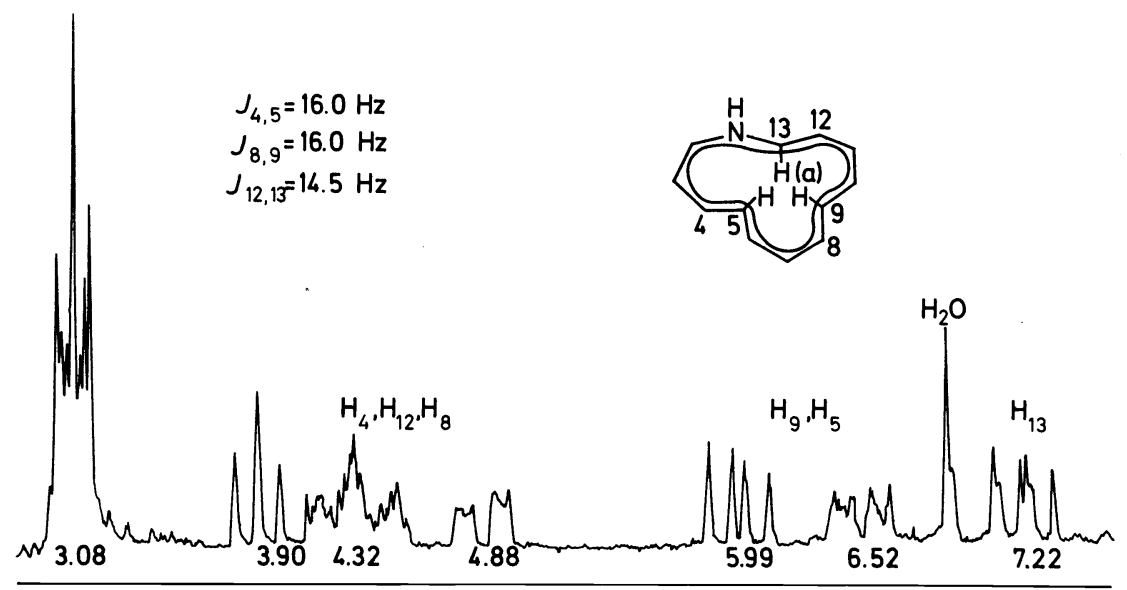

Figure 11. The n.m.r. spectrum (100 MHz) of cis, trans, cis, trans, cis, trans-1H-aza[13]annulene, 62 (in acetone- $d_{6}$ ) recorded at $-6^{\circ}$ and a sweep width of $500 \mathrm{~Hz}$.

Scheme 13

62

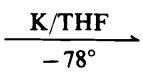

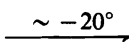

57

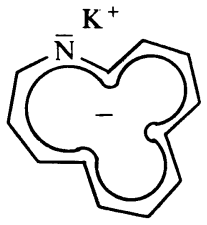

67
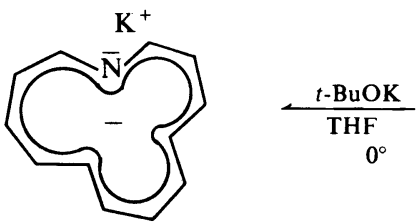

68<smiles>CC(=O)N1C=CC2C=CC3C=CC=CC3C21</smiles>

between the doublets representing the two $\alpha$ protons, one ('outer') showing at $\tau 1.9$ with $J=7 \mathrm{~Hz}$ and the other ('inner') appearing at $\tau 12.5$ with $J=14 \mathrm{~Hz}$.

At first glance, the ready conversion of 67 and 68 might strike one as puzzling, especially since the corresponding amines 62 and 65 or 66 are known not to interconvert (unidirectionally or otherwise) upon heating to $c a$. $50^{\circ} 60,62$. More careful scrutiny, however, supplies one with a perfectly good explanation of the situation. Specifically, it is seen what while the hypothetical interconversion between 62,65 and 66 is predicted to occur with overall preservation of the number of interfering 'inner' hydrogens, an 'inner' $\mathrm{C}-\mathrm{H}$ changing to an 'inner' $\mathrm{N}-\mathrm{H}$ on passing from 62 to 65 or 66 , the observed transformation of anion 67 to anion 68 occurs with actual removal of a sterically offending proton, i.e. here an 'inner' $\mathrm{C}-\mathrm{H}$ group is replaced by a bare, steri- 
cally innocuous, nitrogen function. In other words, we offer the suggestion here that geometrical isomerization among the diatropic aza[13] annulenes occurs strictly as a result of reduced 'inner'-proton repulsions and, consequently, that Schröder's anion, 68, may well represent the true thermodynamic 'sink' of the family.

We shall now describe some preliminary information relating to the response (or lack thereof) of the n.m.r. spectra of our aza[13]annulenes to temperature variations. In brief, we find the two types of aza[13]annulene to basically differ in this respect, the spectra of atropic members 57 and $61 \mathrm{~b}$ remaining largely unchanged in chemical shift on cooling to $\mathrm{ca} .-60^{\circ}$ and those of the diatropic counterparts 62 and 63 undergoing detectable shift in the same temperature range $\left(+40^{\circ}\right.$ to $\left.-60^{\circ}\right)$. The temperature effect on the n.m.r. spectrum of parent amine 62 is shown in Figure $10(a, b)$. Specifically it is seen that cooling from $+6^{\circ}$ to $-48^{\circ}$ effects the following spectral changes: (i) all coupling constants remain essentially unchanged, (ii) all signals associated with protons bound to cis $\mathrm{C}-\mathrm{C}$ functions, i.e. $5 \mathrm{H}$ multiplet at $\tau 3.08$ and $1 \mathrm{H}$ triplet at $\tau 3.90$, show temperature-invariant chemical shifts, (iii) the two highest-field, 'inner'-proton, resonances and the two overlapping doublets, seen at $\tau 4.32\left(+6^{\circ}\right)$ and associated with the 'outer' protons of the same two trans bonds move significantly to higher and lower field respectively and (iv) the two coupled resonances at $\tau 4.88$ and $5.99\left(+6^{\circ}\right)$ known to be associated with the third trans link move toward one another, the upper one shifting to lower field and the lower one to higher field. The temperature invariance of coupling constants is clearly indicative of the absence of any significant conformational changes in the molecular frame, while the upfield shift of 'inner' protons and corresponding downfield shift of their 'outer' counterparts is fully consistent with the expected increase in ring current (possibly due to suppressed thermal motions) at the lower temperature. On the other hand the observation described in (iv) is somewhat puzzling, for here the shifts are seen to occur in the reverse direction! Possibly, these seemingly abnormal shifts are the outcome of thermally accessible rotational mobility of the trans bond leading to the gradual interchange between 'inner' and 'outer' hydrogens. An alternate interpretation of the observation described in (iv) and one to which Professor Schröder indicated preference in private discussion, is of course, that the 'inner'-'outer' proton assignment must be reversed, thus leading to normal temperature-induced shifts. It is not clear, of course, on the basis of this explanation as to why the 'inner' proton of this trans bond should resonate at substantially lower field than its 'outer' neighbour. Clearly, more work is needed if we are to understand the underlying factors of this intriguing temperature-dependent effect. It is also noteworthy in this connection that the temperature response of the n.m.r. spectrum of the $N$-methyl analogue, 63, is not subject to this complication, i.e. here all three high-field, 'inner'-proton, resonances shift to higher fields on cooling.

Before bringing our discussion of the n.m.r. criterion of aromaticity among aza[13] annulenes to a close we should like to draw the reader's attention to the chemical-shift data collected in Table 3 and pertaining, specifically, to the 'inner' $\alpha$ protons of the various 13 -membered $\pi$-excessives we synthesized in our laboratories. It is immediately seen that the chemical shift of this $\mathbf{C}-\mathbf{H}$ function changes quite dramatically $(\Delta \delta>8.3$ p.p.m.!) on passing from the 
atropic acetamide (57) and carbamate (61a) to the strongly diatropic anion (67). In fact, by following the change in chemical shift of this proton one readily discovers good qualitative correlation between the decrease in heteroatom electronegativity, as measured by the magnitude of the $\sigma_{p}^{-}$constant associated with the $N$-substituent, and the gradual development of diatropic character. Finally, we should like to stress that our association of the chemical shifts shown in Table 3 with the same type of proton in each case, i.e. one linked to a carbon directly adjacent to nitrogen, is drawn from the fact that the said signal invariably appears as a clean doublet (doublet of doublets in the case of 62) with a coupling constant of $14 \mathrm{~Hz}$.

Table 3. N.m.r. chemical shifts and coupling constants of the 'inner' $\alpha$ hydrogen of the ctctctaza[13]annulenes

\begin{tabular}{|c|c|c|c|c|c|}
\hline \multirow[b]{2}{*}{ No. } & \multirow{2}{*}{$\begin{array}{l}\text { Compound } \\
\text { N-substituent }\end{array}$} & \multirow{2}{*}{ solvent } & 'inner' & proton & \multirow{2}{*}{$\begin{array}{c}\sigma_{p}^{-} \text {constant } \\
\text { of N-sub- } \\
\text { stituent }\end{array}$} \\
\hline & & & $\begin{array}{l}\text { chemical } \\
\text { shift }(\tau)\end{array}$ & $\begin{array}{c}\text { coupling } \\
\text { constant }(\mathbf{H z})\end{array}$ & \\
\hline $\begin{array}{l}57 \\
61 \mathbf{a} \\
61 \mathbf{b} \\
\mathbf{6 2} \\
63 \\
67\end{array}$ & $\begin{array}{l}\mathrm{COCH}_{3} \\
\mathrm{COOCH}_{3} \\
\mathrm{CON}\left(\mathrm{CH}_{3}\right)_{2} \\
\mathrm{H} \\
\mathrm{CH}_{3} \\
-\end{array}$ & $\begin{array}{l}\mathrm{CDCl}_{3}^{a} \\
\mathrm{CDCl}_{3}^{\mathrm{a}} \\
\mathrm{CDCl}_{3}^{a} \\
\text { acetone-d } \\
\text { acetone-d } \\
\text { THF-d } \\
\text { TH }\end{array}$ & $\begin{aligned}< & 4.2 \\
< & 4.2 \\
& 4.50 \\
& 7.22 \\
& 7.37 \\
& 12.5\end{aligned}$ & $\begin{array}{l}- \\
\overline{14.0} \\
14.5 \\
14.0 \\
14\end{array}$ & $\begin{array}{r}+0.87 \\
+0.68 \\
+0.55 \\
0.00 \\
-0.17 \\
-\end{array}$ \\
\hline
\end{tabular}

- Spectrum was recorded at ca. $35^{\circ}$.

b Spectrum was recorded at ca. $0^{\circ}$.

c Spectrum was recorded at $c a$. $-60^{\circ}$.

We shall now briefly compare our various aza[13]annulenes in terms of u.v. spectral characteristics. As seen from the data collected in Table 4 each member is characterized by two major bands above $c a .250 \mathrm{~nm}$ of which the lower-energy one is invariably the weaker. Comparison of the relative energies of those bands as a function of effective heteroatom electronegativity, reveals an interesting if somewhat puzzling characteristic, namely that it is the higher energy band which appears to best reflect the change of the annulene periphery from strictly localized to extensively delocalized. In other words, the situation here is the exact reverse of that encountered with the 9-membered relatives, the heteronins (section A) where the lower-energy u.v. band best senses the geometric variations attending the change from localized to delocalized. It is of course difficult to offer a theoretical explanation for the high observed sensitivity of the second-lowest u.v. band of an aza[13] annulene to N-substitution, since the various compounds studied here are expected to differ in shape, i.e. some are believed to be more nearly planar than others. Nonetheless, HMO calculation reveals that the second lowest u.v. band should be due to a transition from $\psi_{6}[S$ (second)HFMO $]$ to $\psi_{8}(L V M O)$ and, further, that the gap associated with this transition ought to widen with increased heteroatom electronegativity. $\Delta E\left(\psi_{6} \rightarrow \psi_{8}\right)$ thus changes from $0.89 \beta$ to $0.94 \beta$ on varying $h$ in the coulomb term: $a_{\mathrm{x}}=\alpha_{\mathrm{c}}+h \beta$ from 0.5 to 2.0 . Possibly, it is meaningful that the direction of the calculated change parallels 


\section{A. G. ANASTASSIOU}

that observed. By contrast, HMO theory and experiment yield conflicting results in connection with the lowest-energy electronic transition, i.e. $\Delta E\left(\psi_{7} \rightarrow\right.$ $\psi_{8}$ ), the calculation predicting a decrease and experiment yielding an actual increase in the HFMO to LVMO energy gap. Interestingly, the present disagreement between HMO prediction and experiment reminds one of a similar discrepancy in the case of the heteronins which is believed to chiefly reflect shape differences between the two kinds of heteroannulene. Moreover, the smaller discrepancy between $\Delta E\left(\psi_{7} \rightarrow \psi_{8}\right)$ and experiment observed in the 13-membered ring as compared to the 9-membered counterpart, may well reflect the larger member's less drastic shape change on passing from polyenic to 'aromatic'.

Table 4. U.v. absorption spectra of ctctct-aza[13]annulenes

\begin{tabular}{|c|c|c|c|c|}
\hline \multicolumn{2}{|c|}{ Substance } & solvent & $\begin{array}{l}\text { weak band } \\
(\mathrm{nm})\end{array}$ & $\begin{array}{l}\text { strong band } \\
(\mathrm{nm})\end{array}$ \\
\hline $\begin{array}{l}\mathbf{5 7} \\
61 \mathrm{a} \\
61 \mathrm{~b} \\
\mathbf{6 2} \\
63\end{array}$ & $\begin{array}{l}\mathrm{COCH}_{3} \\
\mathrm{COOCH}_{3} \\
\mathrm{CON}\left(\mathrm{CH}_{3}\right)_{2} \\
\mathrm{H} \\
\mathrm{CH}_{3}\end{array}$ & $\begin{array}{l}\mathrm{C}_{6} \mathrm{H}_{14} \\
\mathrm{C}_{6} \mathrm{H}_{14} \\
\mathrm{C}_{6} \mathrm{H}_{14} \\
\mathrm{C}_{6} \mathrm{H}_{14} \\
\mathrm{C}_{6} \mathrm{H}_{14}\end{array}$ & $\begin{array}{l}350 \\
335 \\
350 \\
360 \\
360\end{array}$ & $\begin{array}{r}260 \\
263 \\
280 \\
297 \\
300\end{array}$ \\
\hline
\end{tabular}

In concluding our remarks about the general aza[13]annulene system we should like to briefly note that here too, as in the case of the heteronins, 'aromatic' and polyenic members of the series seem to differ in terms of thermal stability. We thus find diatropic $1 \mathrm{H}$-aza[13]annulene (62) to effectively resist thermolysis when heated at $56^{\circ}$ for $c a .4 .5 \mathrm{~h}$ and its atropic relative 57 to readily $\left(t_{\frac{1}{2}}<1 \mathrm{~h}\right)$ yield under analogous thermal exposure undergoing double electrocyclization to a tricycle believed to be 69 .

We shall now close this section by briefly touching upon any systems bearing possible direct relation to the aza[13]annulenes discussed here. A survey of the published literature along these lines reveals the hetero[13]annulene system to be quite scarce, neither oxa[13]annulene nor its second row counterpart thia[13] annulene having been prepared. In fact, the only such system known appears to be the multi-annellated thia[13]annulene shown in $70^{64}$. The molecule was found to be strictly atopic by n.m.r. but the heavy steric congestion and possibly, electronic perturbation introduced by its substituents clearly prevents one from seriously extrapolating to the unencumbered parent on this basis.

Hetero[17] annulenes are more abundant than their 13-membered relatives. Thus, Schröder and his associates have recently employed procedures similar to those practised in their synthesis of aza[13]annulene to successfully prepare the 17-membered analogue ${ }^{65}$ both in conjugate acid (71b) and conjugate base (71a) form ${ }^{62}$. Gratifyingly, both 71a and 71b were found to be strongly diatropic by n.m.r. By contrast, the oxygen analogue 72, also synthesized by the Karlsruhe group, was shown to be unexceptionally atropic ${ }^{66}$. The situation here is thus seen to strictly parallel that described earlier for the 9-membered ring and enables one to conjecture that the elusive oxa[13]annulene will be atropic as well. 
Besides the unrestricted hetero[17]annulenes shown in $\mathbf{7 1}$ and 72 there have, in recent years, been reports of bridged and annellated relatives. Possibly, the most interesting among these are the specimens shown under 73, recently synthesized and extensively studied by Sondheimer and his group $^{67-69}$. Of the aza analogues ${ }^{67-69}$, shown in $73(\mathrm{a}-\mathrm{e})$, the first three, $73(\mathbf{a}-\mathbf{c})$ were found to be strongly diatropic in the expected order, i.e. $\mathbf{a}>\mathbf{b}>\mathbf{c}$, while urethane 73d and acetamide 73e were shown to be much less so. Interestingly, the $o x a$ and thia analogues ${ }^{69} 73 \mathrm{f}$ and $73 \mathrm{~g}$ were also found to possess some diatropic character, the effect here being of intermediate magnitude, i.e. more pronounced than in the 73 (d, e) pair but considerably less so than in the $73(\mathrm{a}-\mathrm{c})$ triad. The presence of ring diamagnetism in $73 \mathrm{f}$ contrasts with its virtual absence in the unrestricted relative $\mathbf{7 2}^{\mathbf{6 6}}$ and appears to indicate that the effect develops in the former chiefly as a result of perturbation by the bridge, i.e. imposed planarity on the molecular frame leading to forcible participation of the lone pair into the $\pi$ system. Finally, it is worth noting that Sondheimer and his associates have recently succeeded in extending their work with the basic frame 73, to include a paratropic aza[19]annulene ${ }^{70}$ as well as a diatropic aza[21] annulene ${ }^{71}$, both in urethane form.

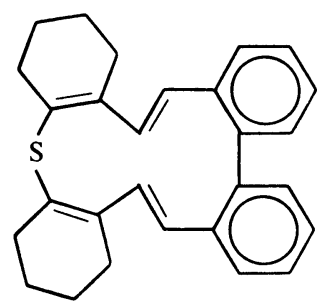

70

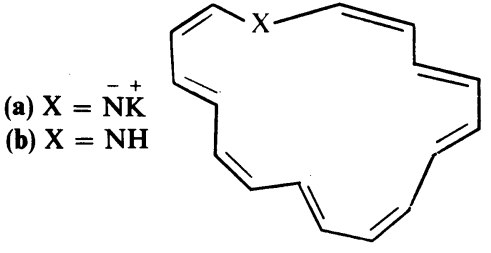

71

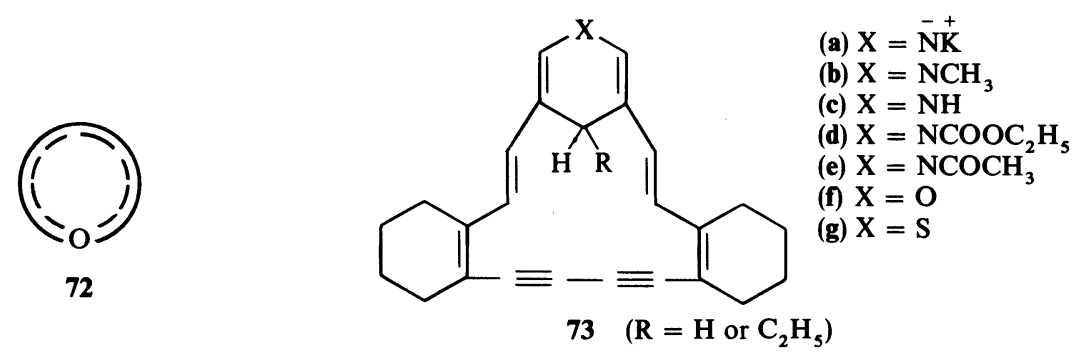

To briefly sum up then, we should like to stress that the work described in this section lends unmistakable validity to Hückel's $4 n+2$ rule as applied to matters relating to heteroaromaticity. One has already witnessed the extension of the rule's tested limits to $\pi$-excessive heterocycles of such impressive dimensions as the unrestricted 17-membered ring and the bridged 21membered ring and there is certainly more to come. In fact, to paraphrase a famous statement (offered in different context), one seriously wonders what degree of skeletal torture would molecules submit to in their obedience to Hückel's $(4 n+2)$ directive; one dares not predict! 
In the preceding three sections we examined the concept of heteroaromaticity in a purely conventional sense, i.e. as applied to molecules with structural potential for uninterrupted $\pi$ delocalization. In the remainder of this account we shall attempt to offer recently acquired insight into the affinity of a heteroatom's lone pair for interaction with $\pi$ segments which are not in direct conjugation.

Recent years have witnessed the coining of such operational terms as homoconjugation ${ }^{72}$ and bicycloconjugation ${ }^{73}$ for the purpose of denoting interaction between two or more formally isolated $\pi$ functions. Of course, the effects of $\pi$ delocalization here are significantly less pronounced and thus more difficult to discern than those arising from the direct, uninterrupted, process. Nonetheless, the chemical literature now abounds with experimental manifestations of such non-classical effects. Possibly, the most intriguing characteristic of non-bonded $\pi$ interaction is that the prediction of beneficial delocalization (aromaticity?) is not always associated with a $4 n+2 \pi$-electron count. It is noted, for instance, that while 'pericycle' $\nmid 74$ is known ${ }^{74}$ to display homoaromatic properties as a $4 n+2-\pi$ entity, i.e. in the form of carbanion 74a, the corresponding longicycle ${ }^{6} 75$ is expected to benefit from bicycloconjugation only when associated with a total count of $4 n \pi$-electrons, i.e. in the form of the $8 \pi$ anion $75 \mathbf{a}^{75}$.

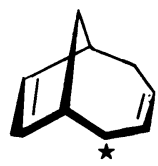

74 (a) $\star=-$

(b) $\star=+$

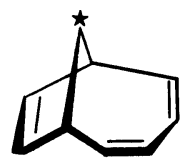

75

Despite extensive recent activity in this area of research, the bulk of the work has, until now, been limited to hydrocarbon specimens with practically no extension to heterocyclic analogues. In the light of this, we resolved to examine the question of non-bonded $\pi$ interaction in certain choice $\pi$ heterobicycles namely the direct hetero counterparts of 74 and 75 recently prepared in our laboratories.

\section{9-HETERO[4.2.1]NONABICYCI.O-2,4,7-TRIENES}

Work by: J. C. Wetzel and H. Yamamoto

The title substances (76) are heteronin valence tautomers, formally constructed by transposition of the heteroatom from ring to bridge. They consist of three isolated $p-\pi$ ribbons totalling eight electrons. In other words, they are iso- $\pi$-electronic with 75a and thus ideally designed for the purpose of assessing a heteroatom's affinity to share its lone pair in a potentially stabilized longicyclic environment. In practice, the effects of non-bonded $\pi$

$\dagger$ For a description of the various terms employed here to denote non-bonded interaction see ref. 75 . 


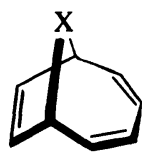

76

$$
\mathrm{X}=\text { heteroatom }
$$

interaction are, because of their small magnitude, best probed by the method of photoelectron spectroscopy (pes) with its proved potential for quantitatively locating MO levels on the energy manifold ${ }^{76}$. To this end, a joint pe study was initiated with Professor Armin Schweig and his group at Marburg and we now report on the results of this work.

From a synthetic viewpoint, the 9-azabicyclo[4.2.1]nona-2,4,7-triene skeleton (76; $\mathrm{X}=$ nitrogen) has long been available as the product of 1,4 addition of cyanonitrene to cyclooctatetraene, i.e. in the form of cyanamide $77^{4 c, 5}$. More recently, the parent amine (78) and a selection of variously saturated relatives $\mathbf{8 0 , 8 1}$ and $\mathbf{8 3}$, necessary for this study, were synthesized in straightforward fashion as shown in Scheme $14^{77,78}$.

Scheme 14
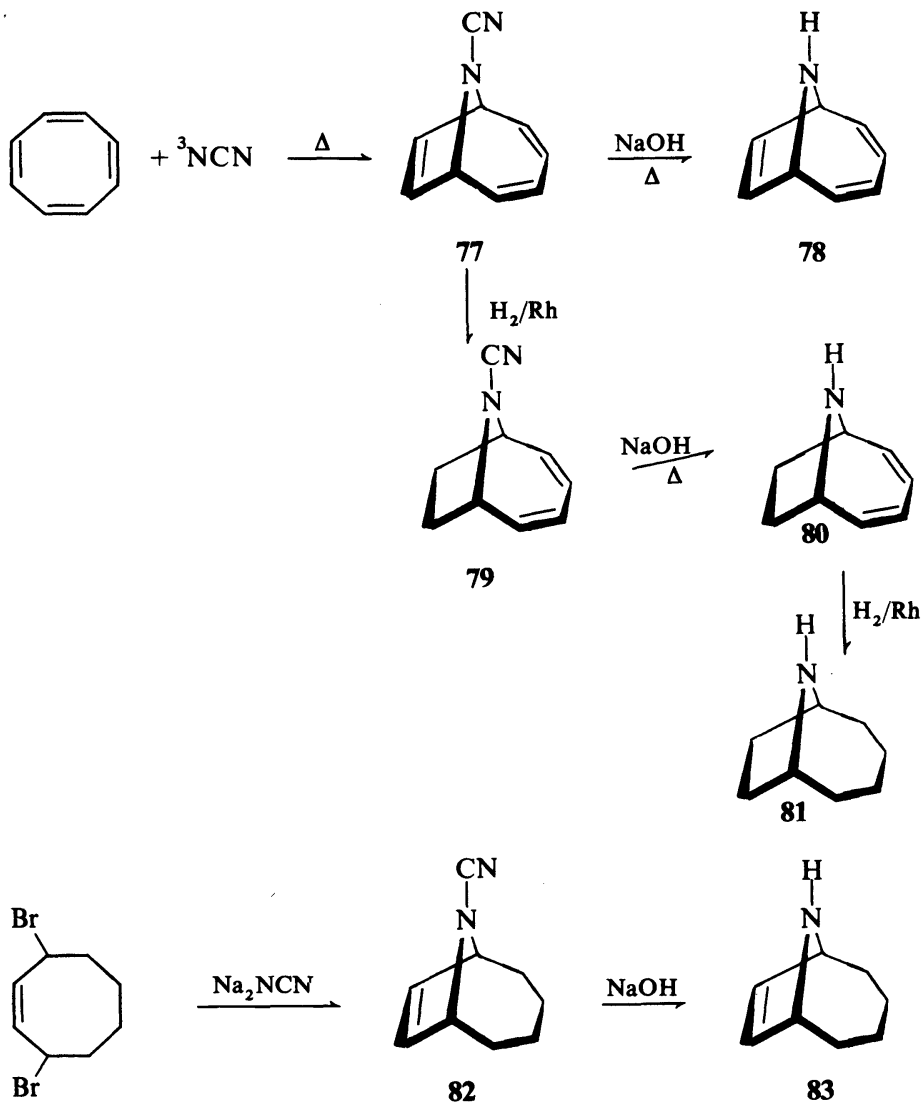

\section{$\mathrm{Na}_{2} \mathrm{NCN}$}

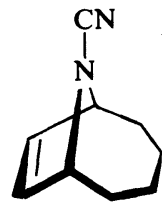

82

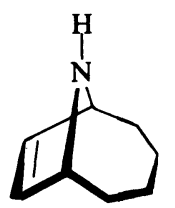

83 


\section{A. G. ANASTASSIOU}

Synthetic entry into the 9-thiabicyclo[4.2.1]nona-2,4,7-triene frame (76; $\mathrm{X}=$ sulphur) has recently been realized here by the thermal addition of SO to cyclooctatetraene to yield sulphoxide $\mathbf{8 4}^{\mathbf{2 3}}$ which was then transformed, directly or indirectly, to the majority of sulphoxides and sulphides described in Scheme $15^{79}$.

\section{Scheme 15}

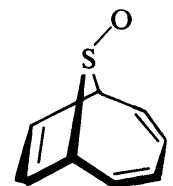

84

$\mathrm{H}_{\mathbf{2}} / \mathbf{R h}$

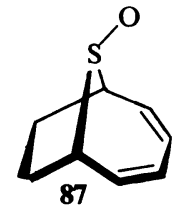

$\left(\mathrm{CH}_{3}\right)_{3} \stackrel{+}{\mathrm{O}} \mid \overline{\mathrm{BF}}_{4}$

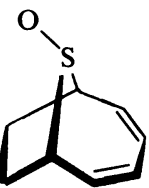

88
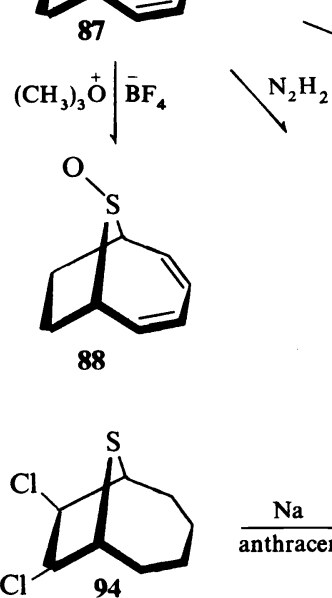

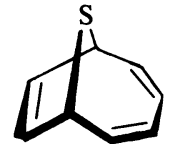

86
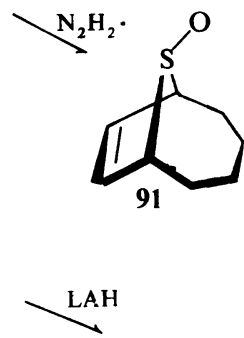

MCPBA

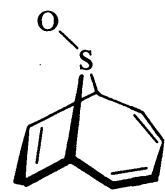

85

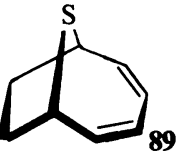

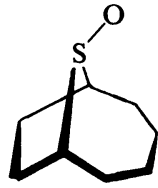

90

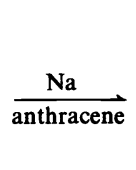

$\overrightarrow{\text { anthracene }}$

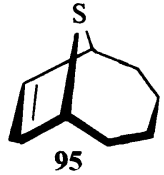

MCPBA
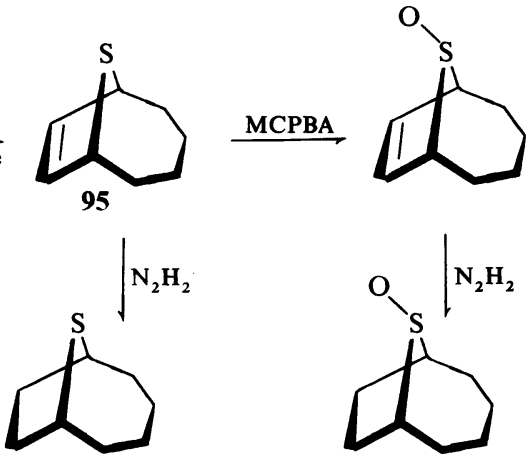

92

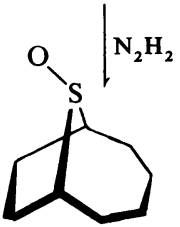

93

Finally, 9-oxabicyclo[4.2.1]nona-2,4,7-triene (98) was prepared from the deoxygenation of recently thermosynthesized epoxide $97^{80}$ (Scheme 16). The variously saturated derivatives 99,100 and 101 were already available 81,82 at the outset of this investigation. 
Scheme 16

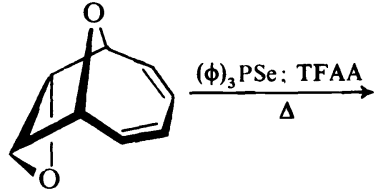

97

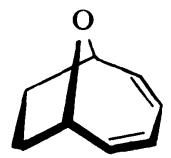

99

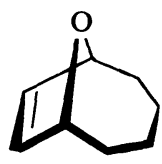

100

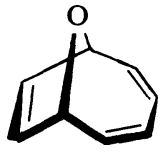

98

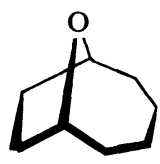

101

Before describing the photoelectron spectroscopic characteristics of the various heterobicycles described here and attempting their interpretation, it would perhaps be instructive to briefly review the types of non-bonded $\pi$ interactions available to 76. First, there is mutual inductive polarization of the interacting groups and second there is conjugative interaction. The two operate in fundamentally different ways, with the former being independent of molecular symmetry and invariably leading to stabilization of all interacting $\pi$ levels and the latter adhering to the strict condition that only levels of like symmetry be allowed to interact, leading either to stabilization or destabilization of a level, depending on its location on the manifold of interacting orbitals.

The pe spectra of amines 78, 80, 81 and 83 consist of the expected number of sharp low-energy maxima due to ionization from all possible non- $\sigma$ levels, i.e. one band for each lone pair $\left(n_{s}\right)$ and ethylene unit $\left(\pi_{1 s}\right.$ level) and two bands for each butadiene segment $\left[\pi_{1 a}\right.$ (HFMO) and $\pi_{2 s}$ levels]. Table 5 contains the collected pe spectroscopic information on the four bicyclic amines examined here ${ }^{83}$; parenthesized values denote the degree of stabilization $(+)$ or destabilization (-) of a level relative to its counterpart in the model compound; e.g. $\pi_{1 s}$ of $\mathbf{7 8}$ is stabilized relative to its counterpart in bicyclo-

Table 5. MO levels of select 9-aza[4.2.1]nonabicycles as located by photoelectron spectroscopy

\begin{tabular}{|c|c|c|c|c|c|}
\hline \multirow{2}{*}{ No. } & Substance & \multicolumn{4}{|c|}{ MO levels $\mathrm{eV}^{\mathrm{a}}$} \\
\hline & double bonds & $\mathrm{n}_{\mathrm{s}}$ & $\pi_{1 \mathrm{~s}}$ & $\pi_{2 \mathrm{~s}}$ & $\pi_{1 \mathrm{a}}$ \\
\hline 81 & - & 8.50 & - & - & - \\
\hline 83 & 1 & $\begin{array}{l}8.76 \\
(+0.26)\end{array}$ & $\begin{array}{l}9.17 \\
(+0.20)\end{array}$ & - & - \\
\hline 80 & 2 & $\begin{array}{l}8.64 \\
(+0.14)\end{array}$ & - & $\begin{array}{l}10.73 \\
(+0.27)\end{array}$ & $\begin{array}{l}8.36 \\
(+0.13)\end{array}$ \\
\hline 78 & 3 & $\begin{array}{l}8.45 \\
(-0.45)\end{array}$ & $\begin{array}{l}9.39 \\
(+0.37)\end{array}$ & $\begin{array}{l}11.17 \\
(+0.62)\end{array}$ & $\begin{array}{l}8.45 \\
(+0.09)\end{array}$ \\
\hline
\end{tabular}

a Parenthesized values denote the stabilization $(+)$ or destabilization $(-)$ of a level relative to its counterpart in the chosen model. 


\section{A. G. ANASTASSIOU}

[4.2.1]nona-2,4,7-triene ${ }^{76}$ by $0.37 \mathrm{eV}$, etc. In Figure 12 we offer graphic comparison of 78 with its constituent models 81 and the hydrocarbon triene in terms of an MO level diagram, where open arrows denote the stabilizing effect of mutual inductive interaction between lone pair and each $\pi$ segment (estimated from the tabulated data), and filled arrows depict the level readjustment due to conjugative interaction between all three segments in $\mathbf{7 8}$.

Clearly, there is strong bicycloconjugative or 'closed-loop' interaction in $\mathbf{7 8}$ leading to substantial stabilization of symmetric $\pi$ levels, $\pi_{1 \mathrm{~s}}$ (by $0.17 \mathrm{eV}$ ) and $\pi_{2 s}\left(\mathrm{by} 0.35 \mathrm{eV}\right.$ ) and impressive destabilization of $n_{s}$ (by $0.45 \mathrm{eV}$ ). 9-Azabicyclo[4.2.1]nona-2,4,7-triene is thus best regarded as a strongly bicycloconjugated molecule.

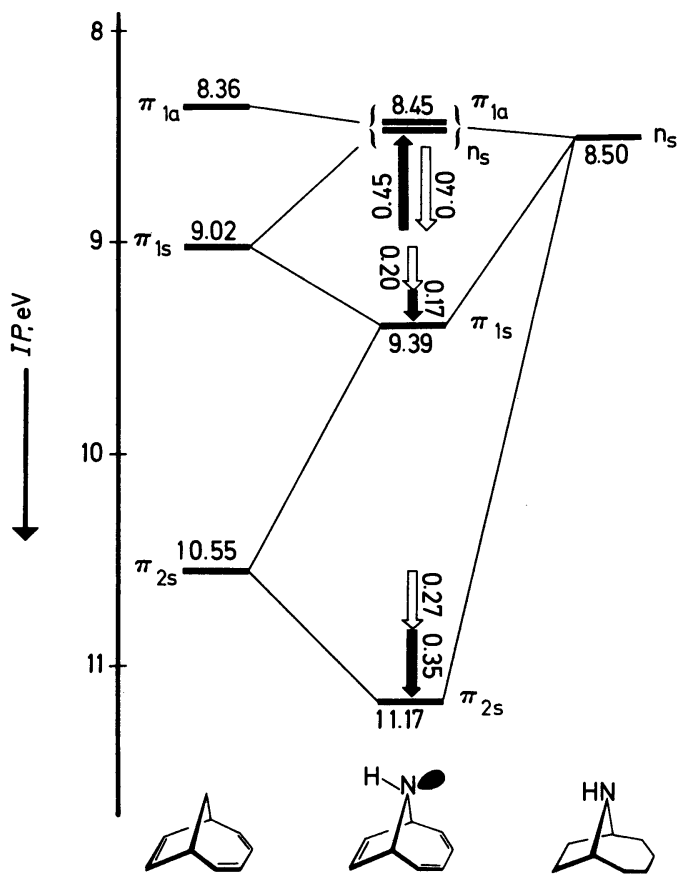

Figure 12. MO level diagram of select occupied orbitals of bicyclo[4.2.1]nona-2,4,7-triene, 76 $\left(\mathrm{X}=\mathrm{CH}_{2}\right), 9 \mathrm{H}$-azabicyclo[4.2.1] nona-2,4,7-triene, 78 and $9 \mathrm{H}$-azabicyclononane, 81. The open and filled arrows represent the inductive and conjugative effects (in $\mathrm{eV}$ ), respectively. The numbers shown above or below the levels are vertical ionization potentials (in $\mathrm{eV}$ ).

In thiabicyclotriene 86 the situation is fundamentally different. It is seen for instance from the pe data collected in Table 6 and the resulting level diagram of Figure $13^{84}$ that the splitting pattern observed in the triene (86) is, in magnitude, simply the sum total of those displayed by its partially saturated counterparts 89 and 95 . In other words, 86 appears not to sustain bicycloconjugation. In fact, judging from the tabulated information on 89 and 95 it is obvious that the only conjugative interaction present in 86 is one between lone pair and 
ethylene, leading to strong stabilization of the latter while leaving $n_{s}$ invariant undoubtedly because of a fortuitous cancellation between stabilizing induction (interaction with $\pi_{1 a}$ ) and destabilizing conjugation (interaction with $\pi_{1 s}$ ). Triene 86 is thus best regarded simply as a heterohomoconjugated molecule, with $\pi$ interaction residing chiefly between lone pair and ethylene. Operationally then, the molecule appears unable to derive energetic advantage from the presence of the butadiene function and thus to realize its bicycloconjugative potential.

Table 6. MO levels of select 9-thia[4.2.1] nonabicycles as located by photoelectron spectroscopy

\begin{tabular}{|c|c|c|c|c|c|}
\hline \multirow{2}{*}{ No. } & \multirow{2}{*}{$\begin{array}{l}\text { Substance } \\
\text { number of double } \\
\text { bonds }\end{array}$} & \multirow[b]{2}{*}{$\mathrm{n}_{\mathrm{s}}$} & \multicolumn{3}{|c|}{ MO levels ${ }^{\mathrm{b}}(\mathrm{eV})$} \\
\hline & & & $\pi_{1 \mathrm{~s}}$ & $\pi_{2 \mathrm{~s}}$ & $\pi_{1 \mathrm{a}}$ \\
\hline 92 & - & 8.16 & - & - & - \\
\hline 95 & 1 & $\begin{array}{l}8.20 \\
(+0.04)\end{array}$ & $\begin{array}{l}9.28 \\
(+0.31)\end{array}$ & - & - \\
\hline 89 & 2 & $\begin{array}{l}8.26 \\
(+0.10)\end{array}$ & - & $\begin{array}{l}10.51 \\
(+0.05)\end{array}$ & $\begin{array}{l}8.59 \\
(+0.36)\end{array}$ \\
\hline 86 & 3 & $\begin{array}{l}8.39 \\
(+0.09)\end{array}$ & $\begin{array}{l}9.33 \\
(+0.31)\end{array}$ & $\begin{array}{l}10.66 \\
(+0.11)\end{array}$ & $\begin{array}{l}8.65 \\
(+0.29)\end{array}$ \\
\hline
\end{tabular}

b Parenthesized values denote the stabilization of a level relative to its counterpart in the chosen model.
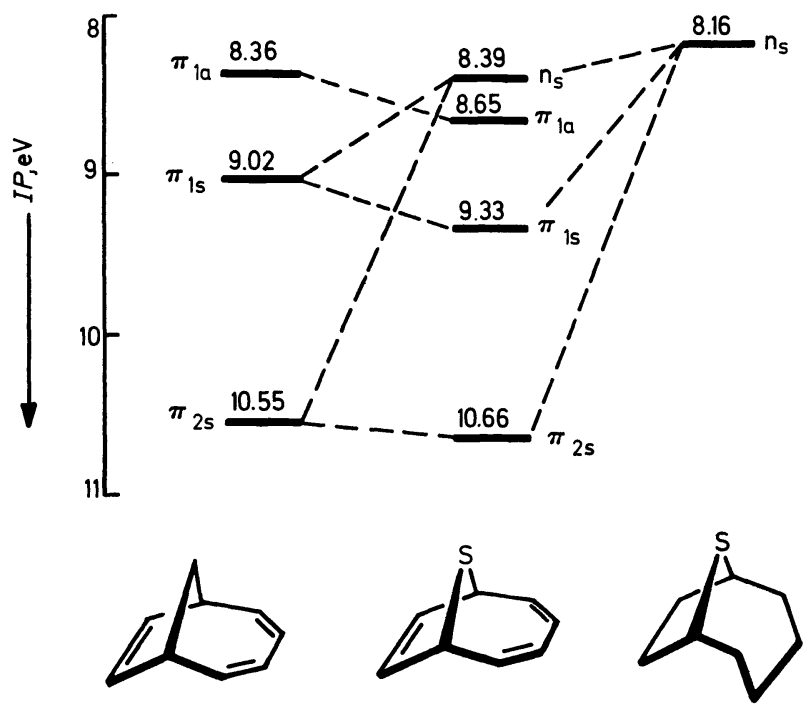

Figure 13. MO level diagram of select occupied orbitals of bicyclo[4.2.1]nona-2,4,7-triene, 76 $\left(\mathrm{X}=\mathrm{CH}_{2}\right)$, 9-thiabicyclo[4.2.1]nona-2,4,7-triene, 86 and 9-thiabicyclo[4.2.1]nonane, 92. The numbers shown above the levels are vertical ionization potentials (in $\mathrm{eV}$ ).

The question of course now arises as to why are the two heterobicyclotriene relatives 78 and 86 so radically different in their ability to realize bicycloconjugation? First, we might note that the preferential conjugative coupling 


\section{A. G. ANASTASSI()L}

between sulphur and ethylene in $\mathbf{8 6}$ may not be reasonably attributed to a proximity effect since the hetero bridge is, if anything, located closer to the butadiene function; a 'Dreiding' molecular model of $\mathbf{8 6}$ clearly reveals a preferential 'tilt' of the sulphur bridge away from the ethylene appendage, generating a $\mathrm{C}-\mathrm{C}-\mathrm{S}$ angle of $c a .110^{\circ}$ on the side of the butadiene as compared to $c a .140^{\circ}$ on the side of the ethylene. Nor is the behavioural dissimilarity between 78 and 86 explainable in terms of differences in conventional lone pair availability, since the two heteroatoms are normally associated with comparable electronegativities. In fact, judging from the energies of the isolated lone pairs as they relate to the fully saturated environments of 81 and $92,8.50 \mathrm{eV}$ for nitrogen and $8.16 \mathrm{eV}$ for sulphur, one is made to realize that it is the more stable and hence more electronegative of the two, i.e. that associated with nitrogen, which satisfies the requirement for the development of a bicycloconjugated frame! In other words, the electronic demands imposed on a heteroatom for activating heterobicycloconjugation are exactly the reverse of those controlling the development of conventional heteroconjugation, as described in sections $\mathrm{A}-\mathrm{C}$, where the process is unmistakably facilitated by decreased heteroatom electronegativity. Interestingly, brief comparison of heterobicyclotrienes $\mathbf{7 8}$ and 86 in terms of MO energetics (Figures 12 and 13) immediately reveals that the seemingly reverse electronegativity requirements imposed on heteroatom participation may well be indicative of the importance of energy matching as the major pre-requisite for the activation of nonbonded interaction ${ }^{76}$. Within this line of reasoning then, the bicycloconjugative potential of 86 fails to materialize chiefly because of the relatively large energy gap $(2.25 \mathrm{eV})$ separating its two extreme isosymmetric levels, $\mathrm{n}_{\mathrm{s}}$ (located at $8.30 \mathrm{eV}$ after separate stabilizing interaction with ethylene and butadiene) and $\pi_{2 s}$ of $76\left(\mathrm{X}=\mathrm{CH}_{2}\right)$, located at $10.55 \mathrm{eV}^{76}$. In 78 , on the other hand, where the greater electronegativity of nitrogen reduces the difference between the same two levels to $1.66 \mathrm{eV}$ and where the inductively stabilized $\mathrm{n}_{\mathrm{s}}$ levels $(8.90 \mathrm{eV})$ is now nearly isoenergetic with $\pi_{1 \mathrm{~s}}$ of $76\left(\mathrm{X}=\mathrm{CH}_{2}\right)$, located at $9.02 \mathrm{eV}^{76}$, three-centre $\pi$ interaction (bicycloconjugation)becomes possible. An amusing paradox of the importance of energy matching in the development of bicycloconjugation and one which offers striking illustration of the differing $\pi$ dynamics between 9-heterobicyclo[4.2.1]nona-2,4,7-triene and heteronin, is of course, that 9-oxabicyclo[4.2.1] nona-2,4,7-triene (98) with its strongly electronegative hetero bridge is expected to provide grounds for better energy matching between $n_{s}$ and the $\pi_{1 s}$ and $\pi_{2 s}$ pairt and thus to be more extensively bicycloconjugated than its nitrogen counterpart 78. We hope soon to secure sufficient quantities of pure 98 and thus be in a position to test this crucial point.

In closing, we might also make brief mention of the carbocyclic ion of the series 75a, and venture to predict that the high availability of its lone pair (high-energy $n_{\mathrm{s}}$ ) will have an adverse effect on the develonment of a bicycloconjugated frame. In other words the prediction here is that carbanion 75a should be less extensively bicycloconjugated than its heterocyclic analogues 78 and 98 ! For obvious reasons then hydrocarbon ions may not be the best models for the study of bicycloconjugation.

† The inductively stabilized lone pair here may well emerge at a lower energy than $\pi_{1 \mathrm{~s}}$. 


\section{E. THE 2-AZABICYCLO[3.2.1]OCTA-3,6-DIENE SYSTEM}

Work by: Prof. H. Kasmai ${ }^{85}$

The concept of homoaromaticity, first formalized by Winstein some 15 years ago $^{86}$, has gained ample experimental support ${ }^{87}$ over the years, so that one is now faced with a rather impressive collection of molecules showing clear signs of 'homoaromatic' character. Of these, none perhaps offers more vivid illustration of the property than the bicyclic carbanion shown in 74a. The molecule has long been known to materialize with over 10000 -fold kinetic favour over its partially saturated counterpart ${ }^{74 a}$ (the one missing the isolated ethylene group) and to exhibit n.m.r. characteristics which are strongly implicative of non-bonded charge delocalization ${ }^{74 b}$.

Bearing this in mind and having had, for some years now, ready access to a hetero analogue of 74a, namely cyanamide $102^{88}$, we resolved to examine this general [3.2.1] $\pi$-excessive skeleton in our quest for homoconjugative and

Scheme 17

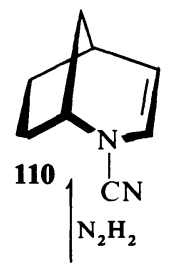

11

$\mid \begin{gathered}\mathrm{N}_{3} \mathrm{COOCH}_{3} \\ \Delta\end{gathered}$

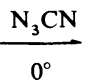

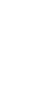
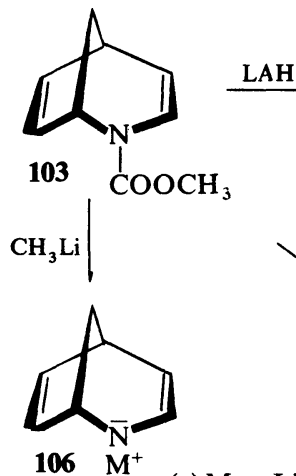

$\mathrm{H}_{2} \mathrm{O} \|_{K H^{(b)} M=K}$

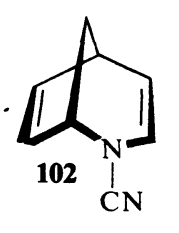

(2) $\mathrm{CH}_{3} \overline{\mathrm{O}}^{+} \mathrm{Na}$
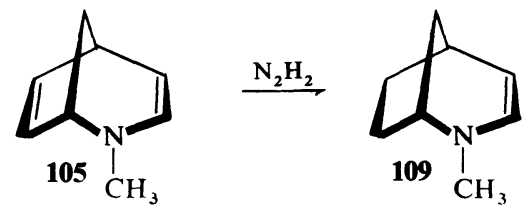

$\mathrm{H}_{2} / \mathrm{Pd}$

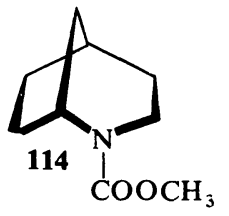

LAH

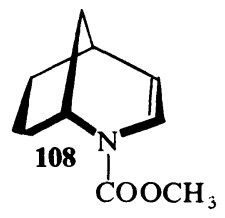




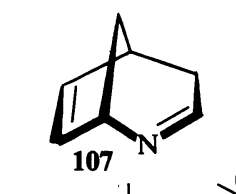

(1) $\mathrm{LAH}$

(2) $\mathrm{CNBr}$

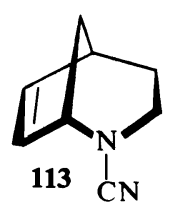

(1) LAH

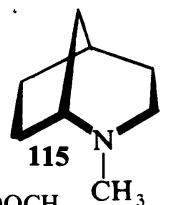

$\underset{\Delta}{\stackrel{\mathrm{CNBr}}{\longrightarrow}}$

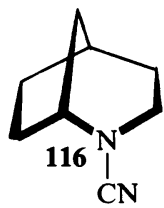

(2) $\mathrm{ClCOOCH}_{3} \mathrm{CH}_{3}$

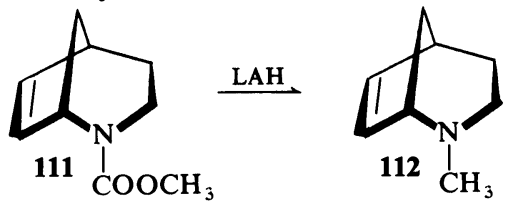

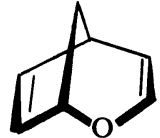

117

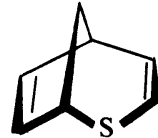

118

possibly homoaromatic behaviour among heterocycles. The present section summarizes our effort and discoveries along these lines.

The synthetic design successfully employed in the preparation of certain select members of the [3.2.1] azabicyclic family needed for this study is summarized in Scheme 17. In brief, it is seen that following construction of the basic skeleton in cyanamide (102) or carbamate (103) form by ring expansive addition of the appropriate organic azide to norbornadiene, the system was first subjected to exchange or removal of the $\mathrm{N}$-substituent and then to selective diimide saturation of its remote double bond. Finally, 107 was conveniently employed as the source of reverse selective saturation leading to a dihydro skeleton incorporating the remote double bond but lacking its nitrogen-bonded counterpart.

Our search for possible heterohomoconjugative ${ }^{89}$ interaction in 2-azabicyclo[3.2.1.] octa-3,6-dienes was conducted with the use of n.m.r., u.v. and pe spectroscopy. In each case an attempt was made to correlate the spectroscopic information with the results of simple HMO theory which is known to offer a good account of the n.m.r. characteristics of carbanion $\mathbf{7 4 a}^{\mathbf{7 4 b}, 87}$. Moreover, since lone pair availability normally has direct bearing on a heteroatom's affinity to participate in delocalization, we carried out the calculation by the method of variable heteroatom electronegativity, namely by associating the heteroatom $(\mathrm{X})$ with the Coulomb term, $\alpha_{\mathbf{X}}=\alpha_{\mathrm{C}}+h \beta$ and running $h$ from 0.5 (for a mildly electronegative heteroatom) to 2.0 (for a strongly electronegative specimen $)^{90}$. Pertinent MO constants calculated for the two extreme values of $h(0.5$ and 2.0) are given in Table 7. In Table 8 are collected the corresponding constants calculated for limited delocalization of the lone pair into the adjacent double bond, i.e. without taking into account non-bonded $\pi$ interaction.

To the extent that $\pi$ stability is normally associated with a closed-shell configuration consisting of fully occupied bonding MOs (BMOs) and 
SYNTHESIS AND STUDY OF SELECT HETEROCYCLES

Table 7. Select HMO constants for a homoconjugated 2-heterobicyclo[3.2.1]octa-3,6-diene ${ }^{\mathrm{a}}$

\begin{tabular}{cccccc}
\hline atom & $\begin{array}{c}\text { electron } \\
\text { density }\left(q_{r}\right) \\
\text { for } h=0.5\end{array}$ & $\begin{array}{c}\text { electron } \\
\text { density }\left(q_{r}\right) \\
\text { for } h=2.0\end{array}$ & $\begin{array}{c}\text { MO } \\
\text { level }\end{array}$ & $\begin{array}{c}\text { MO } \\
\text { energy }\left(\varepsilon_{i}\right)^{\mathrm{b}} \\
\text { for } h=0.5\end{array}$ & $\begin{array}{c}\text { MO } \\
\text { energy }\left(\varepsilon_{i}\right)^{\mathrm{b}} \\
\text { for } h=2.0\end{array}$ \\
\hline $\mathrm{a}$ & 1.689 & 1.900 & 1 & 1.539 & 2.384 \\
$\mathrm{~b}$ & 0.974 & 0.942 & 2 & 0.900 & 1.055 \\
$\mathrm{c}$ & 1.245 & 1.125 & 3 & 0.377 & 0.745 \\
$\mathrm{~d}$ & 1.046 & 1.022 & 4 & -1.037 & -0.942 \\
$\mathrm{e}$ & 1.044 & 1.009 & 5 & -1.278 & -1.242 \\
\hline
\end{tabular}

- Calculation was carried out under the following assumptions: $\beta_{\mathrm{vit}}=0.8 \beta ; \beta_{\mathrm{cd}}=0.4 \beta ; \beta_{\mathrm{ac}}=0.3 \beta$.

${ }^{b}$ Levels given in units of $\beta$.

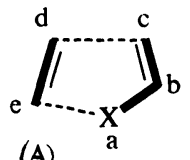

(A)

Table 8. Select HMO constants for a 2-heterobicyclo[3.2.1]octa-3-enea

\begin{tabular}{cccccc}
\hline atom & $\begin{array}{c}\text { electron } \\
\text { density }\left(q_{r}\right) \\
\text { for } h=0.5\end{array}$ & $\begin{array}{c}\text { electron } \\
\text { density }\left(q_{r}\right) \\
\text { for } h=2.0\end{array}$ & $\begin{array}{c}\text { MO } \\
\text { level }\end{array}$ & $\begin{array}{c}\text { MO } \\
\text { energy }\left(\varepsilon_{i}\right)^{\mathbf{b}} \\
\text { for } h=0.5\end{array}$ & $\begin{array}{c}\text { MO } \\
\text { energy }\left(\varepsilon_{i}\right)^{\mathbf{b}} \\
\text { for } h=2.0\end{array}$ \\
\hline a & 1.769 & 1.930 & 1 & 1.411 & 2.336 \\
b & 0.951 & 0.935 & 2 & 0.294 & 0.773 \\
c & 1.279 & 1.139 & 3 & -1.205 & -1.108 \\
\hline
\end{tabular}

- Calculation was carried out with $\beta_{\mathrm{ab}}=0.8 \beta$.

bevels given in units of $\beta$.

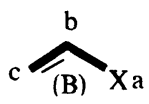

entirely vacant antibonding MOs (ABMOs) the pseudo $6 \pi$-electron system described in Table 7 may be termed stable. It is seen to consist of three fully occupied BMOs and two vacant ABMOs and this irrespective of heteroatom electronegativity. On the other hand, comparison of the homoconjugated frame with its localized counterpart, described in Table 8, in terms of frontier MO energetics clearly reveals a distinct resistance on the part of highly electronegative heteroatoms to developing a heterohomoconjugated frame. In specific terms, it is seen that while the FMO (frontier molecular orbital) of model $A\left(\varepsilon_{3}=0.377 \beta\right)$ is significantly stabilized relative to that of model $\mathbf{B}$ $\left(\varepsilon_{2}=0.294 \beta\right)$ for $h=0.5$, use of $h=2.0$ in the calculation reverses the situation, with $\varepsilon_{3}$ of $A$ now emerging at a higher energy $(0.745 \beta)$ than $\varepsilon_{2}$ of $B$ $(0.773 \beta)$. HMO theory thus appears to indicate that the 2-heterobicyclo[3.2.1] octa-3,6-diene frame chosen for this study is potentially capable of benefiting from interaction between its two formally isolated $\pi$ units and, further, that its affinity to sustain heterohomoconjugation ought to increase with decreasing heteroatom electronegativity.

We shall now deal with the question of non-bonded $\pi$ interaction in terms of spectroscopic observables. concentrating first on the n.m.r. data. In order to 
offer meaningful comparison on this basis we shall concentrate chiefly on the methyl and cyano derivatives 105 and 102 and their respective partially saturated analogues, 109, 112 and 110, 113. The rationale here being, of course, that the two substituents chosen for this comparison are (i) associated with strongly opposing electronic demands, methyl being an electrondonating group $\left(\sigma_{p}^{-}=-0.17\right)$ and cyano a strongly electron-withdrawing function $\left(\sigma_{p}^{-}=+1.00\right)$ and (ii) conveniently symmetric, thus eliminating any complication which might originate from the development of substituentinduced molecular asymmetry. Pertinent p.m.r. chemical shifts of $N$-methyl derivatives 105,109 and 112 and cyanamides 102,110 and 113 are shown below, alongside the corresponding formulas $\dagger$. Brief examination of this information immediately reveals that the $\alpha$ and $\beta$ protons associated with the $\pi$ unit directly linked to nitrogen retain essentially the same chemical shift on passing from the dihydro derivatives to the basic frame, i.e. 109 to 105 and 110 to 102 . In fact, the chemical shifts displayed by the $\beta$ protons of each of the four systems as well as those of carbamates 108 and 103 (not given here) may be shown to yield good linear correlation when plotted against the corresponding $\sigma_{p}^{-}$substituent constants. In other words, as probed by p.m.r. and irrespective of heteroatom-electronegativity, the ethylene function bound to nitrogen appears not to 'sense' the presence of the remote double bond. Interestingly, a fundamentally different picture emerges when one focuses attention on the protons of the remote double bond. Specifically, it is noted that while one of the protons associated with this function $\left(H_{6}\right)$ retains essentially the same chemical shift on passing from the dihydro form to the basic skeleton, namely 112 to 105,111 to 103 and 113 to 102 , its neighbour $\left(H_{7}\right)$ displays unmistakable sensitivity to the presence of the 'other' double bond. The net effect is seen to be one of upfield shift of the $H_{7}$ resonance by 0.7 p.p.m. for $105,0.3$ p.p.m. for 103 and 0.3 p.p.m. for 102. Moreover, the observed shift appears to be a function of heteroatom electronegativity its magnitude significantly increasing on going from carbamate 103 and cyanamide 102 to $N$-methyl derivative 105. It is perhaps significant that this is precisely the prediction one would formulate on the basis of the calculated $\pi$ electron density on $\mathrm{C}_{7}$, i.e. $q_{e}$ in Table 7 , which is seen to experience detectable reduction from 1.044 for a mildly electronegative heteroatom $(h=0.5)$ such as $>\mathrm{NCH}_{3}$ to 1.009 for a strongly demanding one $(h=2.0)$ such as $>\mathrm{NCN}$.

Possibly, comparison between the methyl resonances of the various $N$-methyl derivatives supplies one with the most convincing argument in support of homoconjugative interaction in 105. In brief, it is seen that the methyl singlet shifts from $\tau 7.48$ in 109 to $\tau 7.28$ in 105, the direction and magnitude ( 0.2 p.p.m.) of this change being consistent with a substantial reduction of electron density on nitrogen as a result of heterhomoconjugative delocalization of its lone pair. This notion receives full support from HMO theory which predicts a decrease in $q_{\mathrm{X}}\left(q_{a}\right.$ in Tables 7 and 8$)$ from 1.77 in B to 1.69 in $\mathrm{A}$, both values calculated for $h=0.5$.

$\dagger$ All spectra were recorded in carbon tetrachloride and the chemical shifts are given in $\tau$ units. 


\section{SYNTHESIS AND STUDY OF SELECT HETEROCYCLES}

Finally we might note that our efforts to generate and directly observe the potentially ideal heterohomoaromatic member of the series, i.e. the 2-azabicyclo[3.2.1] octa-3,6-dienyl anion 106, have thus far met with only partial success, for while the species has been generated from two distinct sources and securely characterized by chemical trapping (Scheme 18), it has yet to be fully characterized by direct observation. Nonetheless, examination of 106 by n.m.r. readily reveals the presence of a doublet $(J \sim 6.5 \mathrm{~Hz})$ appearing at $\tau 3.88$ in the spectrum of 106a (DME) and $\tau 4.25$ in the spectrum of $106 \mathrm{~b}$ (THF), which is, in each case, clearly due to the $\alpha$ proton and whose low-field position, despite the molecule's greatly reduced heteroatom electronegativity compared to 105, is strongly implicative of a diatropic environment.

Before closing the discussion on the n.m.r. criterion of heterohomoconjugation in 2-heterobicyclo[3.2.1] octa-3,6-dienes we might briefly point out that the system is also available in both ether $(117)^{91}$ and thioether (118) ${ }^{92}$ form. It is interesting that the difference in p.m.r. chemical shift between the two sites of the remote double bond $\left(\Delta \delta_{7,6}\right)$ is substantially greater in the oxa derivative; 1.07 p.p.m. for 117 as compared to a mere 0.07 p.p.m. for 118, suggesting that this molecule, 117, is more extensively heterohomoconjugated than its second-row relative, 118. On the other hand. 117 is known to rapidly rearrange to a bicyclo[3.1.0] aldehyde on warming to ambient temperature ${ }^{91}$ while there is no indication that $\mathbf{1 1 8}$ is similarly unstable ${ }^{92}$.

N.m.r. spectral characteristics of certain choice 2-heterobicyclo[3.2.1]octa-3,6-dienes, -3-enes and -6-enes

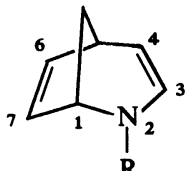

$\mathbf{R}$

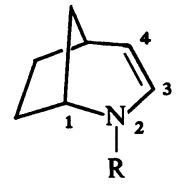

$\mathrm{H}_{3} ; \tau 4.60$

$\mathbf{H}_{4} ; \tau 5.40$

$\mathrm{H}_{1} ; \tau 6.78$

$\mathrm{CH}_{3} ; \tau 7.48$

$\mathrm{H}_{4} ; \tau 5.37$

$\mathrm{H}_{1} ; \tau 6.25$

$\mathrm{CH}_{3} ; \tau 7.28$

$\underline{\mathbf{R}}=\mathbf{C N}$

$\mathbf{H}_{6} ; \tau 3.71$
$\mathbf{H}_{3} ; \tau 4.30$
$\mathbf{H}_{7} ; \tau 4.36$
$\mathbf{H}_{4} ; \tau 4.80$
$\mathbf{H}_{1} ; \tau 5.61$

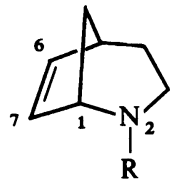

$\mathrm{H}_{6} ; \tau 3.98$

$\mathbf{H}_{7} ; \tau \mathbf{4 . 2 5}$

$\mathrm{H}_{1} ; \tau 6.68$

$\mathrm{CH}_{3} ; \tau 7.95$

$\mathbf{H}_{6} ; \tau 3.73$

$\mathrm{H}_{7} ; \tau 4.06$

$\mathrm{H}_{1} ; \tau 5.95$

U.v. spectroscopy fully confirms one's conclusions derived from n.m.r. chemical shifts, namely that the system does, to a large extent, realize its homoconjugative potential. Specifically, we note from the spectral information collected in Table 9 that whereas the isolated $-\mathrm{C}=\mathrm{C}-\mathrm{NR}$ chromophore of the 3,4-dihydro variant gives rise to a single u.v. maximum, introduction of the remote double bond into the system leads to the formal splitting of this 


\section{A. G. ANASTASSIOU}

band, with consequent emergence of two such maxima in the spectrum of the diene. The two formally isolated $\pi$ units of the title system are thus unmistakably coupled under the u.v. criterion. It is also interesting to note that the observed splitting remains essentially invariant in magnitude on passing from cyanamide $(27 \mathrm{~nm})$ to carbamate $(27 \mathrm{~nm})$ to $N$-methyl derivative $(30 \mathrm{~nm})$, suggesting that interaction between the two isolated $\pi$ units is largely insensitive to the availability of the lone pair. This is indeed a surprising result and may well be due to the fortuitous cancellation of opposing factors (vide infra).

Not unexpectedly, HMO calculation gives good qualitative account of the u.v.-spectral observations, affording logical explanation both for the observed decrease in the lowest energy band (HFMO to LVMO) on passing from isolated chromophore, e.g. $109(\mathrm{~B} ; \Delta E=1.499 \beta$ for $h=0.5)$ to homoconjugated counterpart, e.g. $105(\mathrm{~A} ; \Delta E=1.414 \beta$ for $h=0.5)$ and for the fact that both these bands decrease in energy upon reducing the effective electronegativity of the heteroatom; compare, for example, the immediately preceding parenthesized values to $\Delta E(\mathrm{~B})=1.881 \beta$ and $\Delta E(\mathrm{~A})=1.687 \beta$ calculated for $h=2.0$.

Table 9. U.v. absorption spectra and HMO-calculated LVMO-HFMO energy differences relating to $\mathrm{N}$-substituted 2-azabicyclo[3.2.1]octa-3,6-dienes and 2-azabicyclo[3.2.1]-3-enes

\begin{tabular}{cllc}
\hline Compound & $N$-substituent & \multicolumn{1}{c}{ maxima $^{\mathrm{a}} \mathrm{nm}(\varepsilon)$} & $\Delta E$ (LVMO-HFMO) \\
\hline 105 & $\mathrm{CH}_{3}$ & $242(2470) ; 272(1350)$ & $1.414 \beta(h=0.5)$ \\
109 & $\mathrm{CH}_{3}$ & $248(1950)$ & $1.499 \beta(h=0.5)$ \\
103 & $\mathrm{COOCH}_{3}$ & $222(5670) ; 249(5700)$ & $1.660 \beta(h=1.5)$ \\
108 & $\mathrm{COOCH}{ }_{3}$ & $230(14100)$ & $1.811 \beta(h=1.5)$ \\
102 & $\mathrm{CN}$ & $233(600) ; 250(3600)$ & $1.687 \beta(h=2.0)$ \\
110 & $\mathrm{CN}$ & $225(2250)$ & $1.881 \beta(h=2.0)$ \\
\hline
\end{tabular}

a All determinations were made in $n$-hexane.

In brief summary then of the available spectral information described in this section we should like to make note of the fact that both n.m.r. and u.v. spectroscopy provide clear evidence for the existence of non-bonded $\pi$ interaction in the 2-azabicyclo[3.2.1] octa-3,6-diene system. Further, it is seen that while the p.m.r. information must be interpreted to mean that lone-pair homodelocalization is, as expected, more pronounced when the system carries a strongly electron-donating $\mathrm{N}$-substituent, note for example that $\Delta \delta\left(H_{7}\right)$ between diene and appropriate ene more than doubles $(0.3$ p.p.m. $\rightarrow$ 0.7 p.p.m.) on passing from $>\mathrm{NCN}$ and splitting remains largely insensitive $(\Delta \lambda \sim 3 \mathrm{~nm}$ !) to this rather drastic progression in heteroatom electronegativity. Brief scrutiny of the situation reveals a possible reason for this otherwise puzzling discrepancy. In brief, we believe the u.v. data are reflective of the importance of two opposing operational factors contributing to the system's development of a heterohomoconjugated frame (i) lone-pair availability and (ii) energy matching between non-bonded units. For obvious reasons the first condition, i.e. lone-pair availability, is better satisfied in 2-azabicyclo[3.2.1] octa-3,6-dienes carrying weakly electronegative heteroatoms such as $>\mathrm{NCH}_{3}$, while the second requirement, i.e. 
energy matching, is best fulfilled by the presence of a $C=C-N R \pi$ unit incorporating a strongly electron-withdrawing $\mathrm{N}$-substituent such as $\mathrm{CN}$ or $\mathrm{COOCH}_{3}$; note, for example, that the HFMO level of ethylene, $\varepsilon=\alpha+\beta$ is significantly closer to its counterpart in B (see Table 8) calculated for $h=2.0$ $\left(\varepsilon_{2}=\alpha+0.773 \beta\right)$ than for $h=0.5\left(\varepsilon_{2}=\alpha+0.294 \beta\right)$. Hence, the misleading manifestation of virtually superimpossible u.v. shifts in the spectra of cyanamide 102 and $N$-methyl derivative 105.

\section{F. RECENT RESULTS AND DEVELOPMENTS}

\section{(1) Addendum to Section B}

Work by: (Miss) E. Reichmanis

As might be expected, carbamates 49a and 53 differ in their response to cycloadditive trapping, only the latter yielding an adduct on exposure to dienone 27 at $100^{\circ}$. Nonetheless, judging from the structure of the resulting cycloadduct, 119, one might be justifiably surprised with the realization that it is the isolated cis ethylene unit and not the normally more responsive trans bond, which participates in the cycloaddition of 53. On the other hand, it is clearly the presence of the trans bond which renders the cycloaddition process possible insofar as $49 \mathrm{a}$, the inert isomer, also contains an isolated cis bond which is formally analogous to that of 53. When translated into operational detail this obviously means that the trans bond in $\mathbf{5 3}$ serves merely to increase the molecule's skeletal strain and thus to heighten its response towards cycloaddition, particularly in the region surrounding the isolated cis bond, while itself remaining inaccessible to such attack possibly because of steric constraints imposed on the motion of its 'inner' proton.

Synthetically, the formation of $\mathbf{1 1 9}$ further accentuates the potential of cycloaddition as a means of enlarging a molecule's $\pi$ system. Obviously, 119, or better still, its hypothetical relative expected to form from 53 ana $\alpha$-pyrone, is ideally structured for ready conversion to the hitherto unknown dibenzo aza[9] annulene and benzo aza[13] annulene frames.

Scheme 18

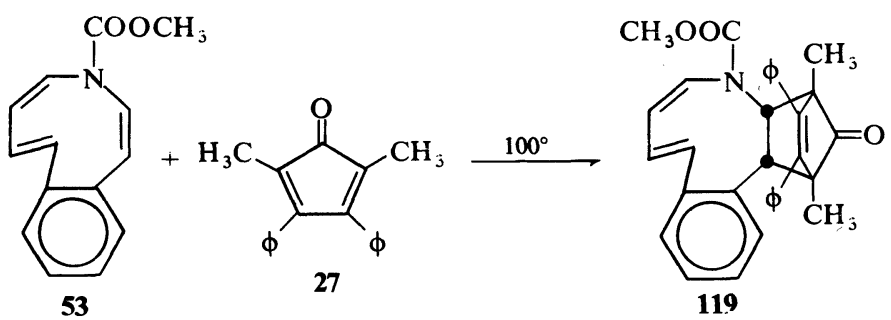

\section{(2) Addendum to Section C}

Work by: (Miss) E. Reichmanis and R. L. Elliott

In our previous discussion of the ctctct-aza[13]annulene skeleton we limited ourselves, for the sake of convenience, to a single rotameric arrange- 


\section{A. G. ANASTASSIOU}

ment, A. We shall now attempt an evaluation of the relative merits of other acceptable ctctct possibilities as well. Owing to the restriction imposed by the n.m.r. information collected on $61 \mathrm{~b}, 62,63$ and 67 , namely that the molecule incorporates an 'inner' $\alpha$ proton, there obviously exists a total of four acceptable rotamers out of eight possible. These are shown in Scheme 19, together with a designation of the specific bond rotation needed for unirotational interconversion. Moreover, it may easily be seen from examination of 'Dreiding' molecular models that all but one of these, $\mathbf{D} \dagger$, are predicted to have ready skeletal access to a flat frame.

Scheme 19
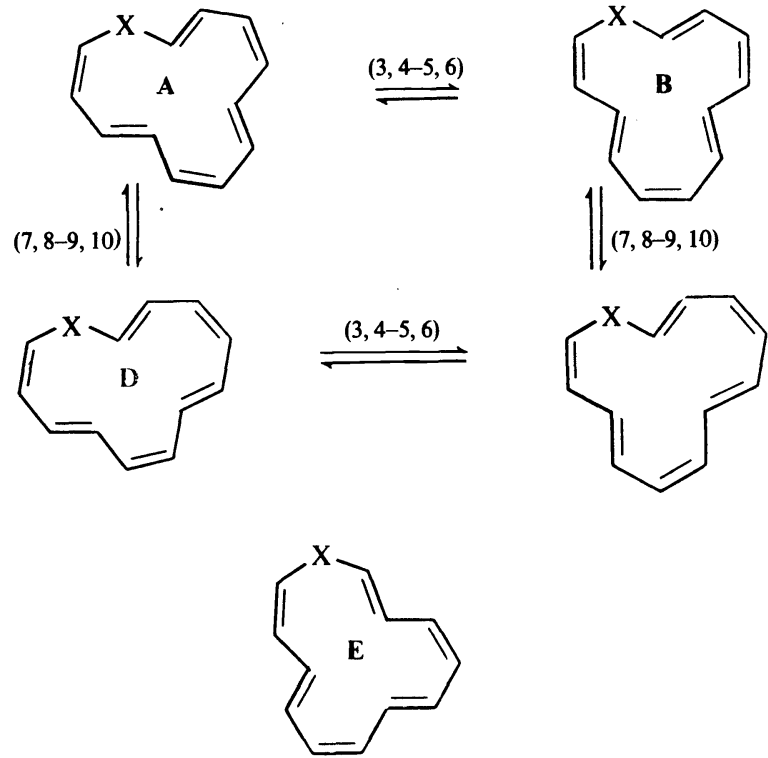

Now, judging from the n.m.r. spectrum of parent ctctct-aza[13]annulene (Figure 11) which shows clear signs of vicinal coupling between the lowestfield 'inner' proton, i.e. that giving rise to the dd pattern at $\tau 5.99$ and what is believed to be the $\beta$ hydrogen $\left(\mathrm{H}_{3}\right.$; triplet at $\tau$ 3.86) associated with the cis double bond directly linked to nitrogen, one may justifiably express preference for a rotameric form incorporating an 'inner' proton at $\mathrm{C}_{4}$, i.e. one such as $B$ or $C$, as best representing the molecule in acetone at $-6^{\circ}$. Moreover, since the key 'inner' proton $\left(\mathrm{H}_{4}\right)$ considered here is the very same one which experiences the abnormal temperature-induced shift (see Figure 10) believed to reflect its rotational transformation into the type of 'outer' hydrogen associated with forms $\mathbf{A}$ and $\mathbf{D}$, it may be reasoned that a decrease in temperature would favour A over B and D over C. And since, for reasons expressed

$\dagger$ It is perhaps significant to note in this connection that this is the only form under consideration incorporating two pseudo-seven rather than pseudo-six membered units, as is the case with $\mathbf{A}, \mathbf{B}$ and $\mathbf{C}$. 


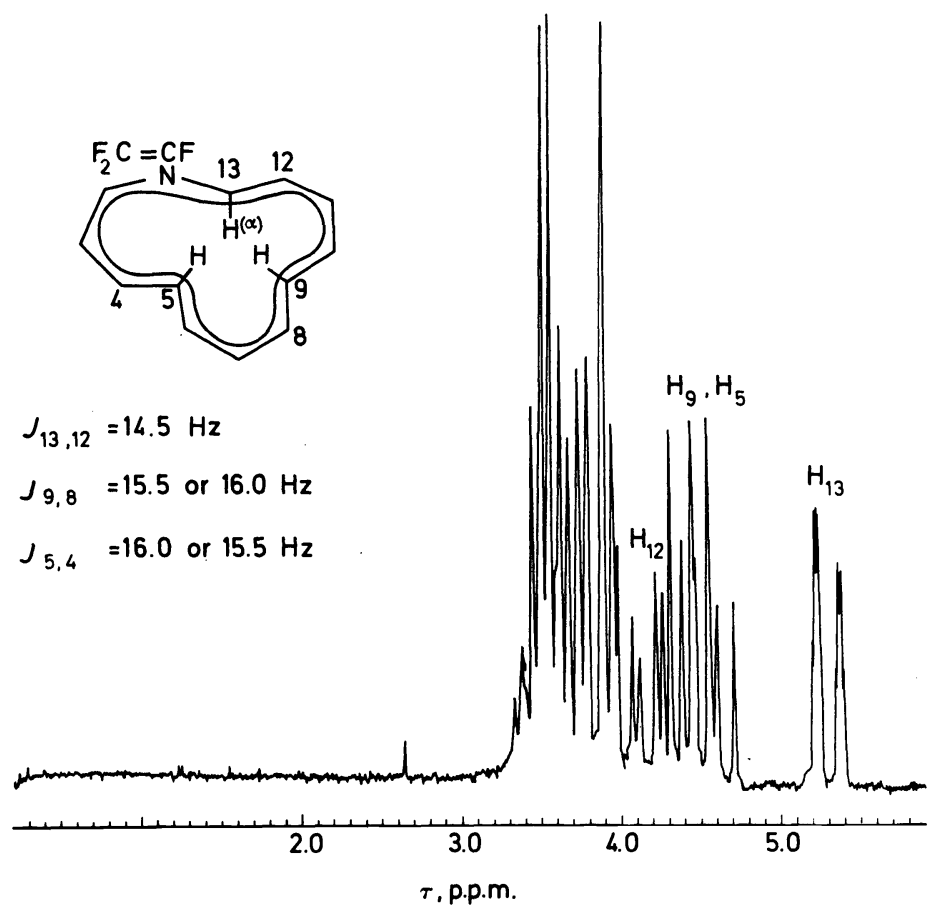

Figure 14. The n.m.r. spectrum (100 MHz) of $N$-(1,2,2-trifluoroethylene) cis, trans, cis, trans, cis, trans-aza[13]annulene.

earlier, it is unlikely that $\mathbf{D}$ would be favoured over $\mathbf{C}$ we must conclude that the A, B rotameric pair best describes the various ctctct-aza[13]annulenes incorporating 'inner' $\alpha$ protons. Turning now to $\mathrm{N}$-substituted derivatives with $\pi$-electronic affinity for molecular flattening, such as the $N$-methyl variant, we note that here the steric congestion between $\mathrm{N}$-substituent and peri hydrogen, i.e. the $\beta$ proton $\left(\mathrm{H}_{12}\right)$ located on the trans bond, may well have a decisive influence on the molecule's choice of rotameric modification inasmuch as the two forms $\mathbf{A}$ and $\mathbf{B}$ are expected to substantially differ in their ability to meet the spatial demands imposed by the substituent. Specifically, it may readily be estimated from examination of 'Dreiding' models that the minimum distance between methyl and $\mathrm{H}_{12}$ is ca. $1.5 \AA$ (worth $25.5 \mathrm{kcal} / \mathrm{mol}$ of $\mathrm{H}-\mathrm{H}$ repulsion) ${ }^{17}$ for rotamer $\mathrm{A}$ and $\mathrm{ca}$. $1.9 \AA$ (worth $9.5 \mathrm{kcal} / \mathrm{mol}$ of $\mathrm{H}-\mathrm{H}$ repulsion ${ }^{17}$ for modification $B$. Clearly then, the balance of rotameric preference shifts overwhelmingly toward $\mathbf{B}$ and it is, in fact, doubtful whether the molecule would have access to A under any conditions. It is certainly gratifying to note that the 'normal' temperature-induced n.m.r. shifts observed for all 'inner' hydrogens of $N$-methyl ctctct-aza[13]annulene (vide supra) are entirely in keeping with this notion, namely that the molecule experiences rotational rigidity.

Experimentally, our most recent synthetic effort in the area dealt with attempts to introduce the relatively small but intensely electron-withdrawing 
Scheme 20
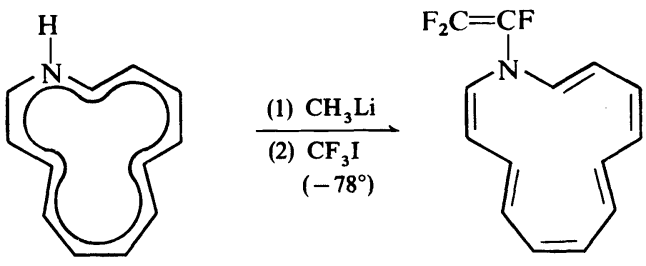

120

$\mathrm{CF}_{3}$ group. In practice, consecutive exposure of the parent amine to methyllithium and trifluoromethyl iodide led, cleanly, to the introduction of the no less intriguing, strongly demanding, $-\mathrm{CF}=\mathrm{CF}_{2}$ group! Judging from the n.m.r. spectrum of this fluorinated aza[13]annulene, 119, given in Figure 14, which shows unmistakable but unimpressive separation of the 'inner' proton triad we must conclude that the molecule is, at best, to be considered a borderline case, i.e. one not unlike the urea $61 \mathrm{~b}$ discussed earlier. It is also notable that the u.v. spectrum of 119 , with a strong band at $278 \mathrm{~nm}$ and a weak one at $334 \mathrm{~nm}$, bears close resemblance to that of $61 \mathrm{~b}$, especially in terms of the energy associated with the intense band (see Table 4).

\section{ACKNOWIEDGEMENT}

I sincerely thank my co-workers whose names are associated with this effort. In particular, I should like to to single out 'heteronin' chemists Robert P. Cellura and Hisa-aki Yamamoto for their contributions in the early stages of the work and the research team of Elsa Reichmanis, Robert L. Elliott, Professor Hamid Kasmai and John C. Wetzel for more recent accomplishments; in truth, it is the unending perseverance and utter dedication practised by these talented individuals that made this review at all possible. I also wish to express my appreciation to Dr Howard E. Simmons who supplied us with the SCF-CI results and to Professor Armin Schweig and his group for their enthusiastic collaboration. Last but certainly not least I should like to thank the National Science Foundation and the Petroleum Research Fund, administered by the American Chemical Society, whose financial backing made it all possible.

\section{REFERENCES}

1 J. Thiele, Ber. Dtsch. Chem. Ges. 34, 68 (1901).

2 (a) E. Hückel, Z. Phys. 70, 204 (1931);

(b) E. Hückel, Z. Phys. 76, 628 (1932).

3 (a) A. G. Anastassiou, Accounts. Chem. Res., 5, 281 (1972);

(b) A. G. Anastassiou in Topics in Nonbenzenoid Aromatic Chemistry, Vol. I, pp 1-27. Eds: T. Nozoe, R. Breslow, K. Hafner, S. Ito and I. Murata; Hirokawa Publishing Co.: Tokyo (1973).

4 (a) A. C. Cope and B. D. Tiffany, J. Amer. Chem. Soc. 73, 4158 (1951);

(b) S. Masamune and N. T. Castellucci, Angew. Chem. 76, 569 (1964);

(c) A. G. Anastassiou. J. Amer. Chem. Soc. 87, 5512 (1965). 


\section{SYNTHESIS AND STUDY OF SELECT HETEROCYCLES}

5 A. G. Anastassiou. J. Amer. Chem. Soc. 90,1527 (1968).

6 R. B. Woodward and R. Hoffmann, The Conservation of Orbital Symmetry. Academic Press: New York (1970).

7 We first publicized our intention to do so in the 12th Annual Report on Research, p. 81. Petroleum Research Fund, Washington, DC (1967).

8 A. G. Anastassiou and J. H. Gebrian, J. Amer. Chem. Soc. 91, 4011 (1969).

Several months later S. Masamune, K. Hojo and S. Takada, Chem. Commun. 1204 (1969), reported that 11b may also be prepared on direct low-temperature irradiation of either 12b or its valence tautomer shown in $\mathbf{i}$

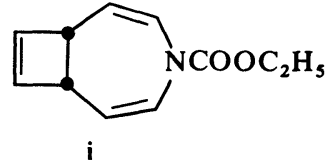

9 A. G. Anastassiou and R. P. Cellura, Chem. Commun. 903 (1969); see also ref. 27. Several months later the conversion of $12 \mathrm{a}$ to oxonin was also reported to occur on direct low-temperature irradiation ${ }^{10}$.

10 S. Masamune, S. Takada and R. T. Seidner, J. Amer. Chem. Soc. 91, 7769 (1969).

11 (a) A. G. Anastassiou and J. H. Gebrian, Tetrahedron Letters, 825 (1970);

(b) A. G. Anastassiou, S. W. Eachus, R. P. Cellura and J. H. Gebrian, Chem. Commun. 1133 (1970).

12 A. G. Anastassiou and S. W. Eachus, J. Amer. Chem. Soc. 94, 2537 (1972).

13 A. G. Anastassiou, V. Organos and J. H. Gebrian, Tetrahedron Letters, 4491 (1969).

14 G. Boche, H. Bohme and D. Martens, Angew. Chem. 81, 565 (1969).

15 P. Radlick and G. Alford, J. Amer. Chem. Soc. 91, 6529 (1969).

16 S. Masamune, P. M. Baker and K. Hojo, Chem. Commun. 1203 (1969).

17 The destabilizing interaction between vicinal protons of a planar nine-membered ring is expected to be significant: H. E. Simmons and J. K. Williams, J. Amer. Chem. Soc. 86, 3222 (1964).

18 This useful procedure whereby solvent anisotropy is measured in terms of an $S$ value defined by the ratio $\tau(X)-\tau\left(\mathrm{C}_{6} \mathrm{H}_{12}\right) / 60$ where $\tau(\mathrm{X})$ is the difference in chemical shift between cyclohexane and acetonitrile in solvent $X$ and $\tau\left(\mathrm{C}_{6} \mathrm{H}_{12}\right)$ is the analogous difference in cyclohexane solvent was developed by F. A. L. Anet and G. E. Schenck, J. Amer. Chem. Soc. 93,556 (1971).

19 A. G. Anastassiou and H. Yamamoto, Chem. Commun. 286 (1972).

20 Unpublished observations by H. Yamamoto; work described in Ph.D. Dissertation, Syracuse University (1973).

21 H. E. Simmons, private communication (1970).

22 C. C. Chiang, I. C. Paul, A. G. Anastassiou and S. W. Eachus, J. Amer. Chem. Soc. 96, 1636 (1974).

23 A. G. Anastassiou and B. Chao, Chem. Commun. 979 (1971).

24 A. G. Anastassiou and B. Chao, Chem. Commun. 277 (1972).

${ }^{25}$ For the sake of completeness, we should like to indicate that the preparation of 17 was also briefly claimed by Masamune, in two reviews [(a) S. Masamune and N. Darby, Accounts. Chem. Res. 5, 272 (1972); (b) A. V. Kemp-Jones and S. Masamune in Topics in Nonbenzenoid Aromatic Chemistry, Vol. I, pp 121-157 Eds: T. Nozoe, R. Breslow, K. Hafner, S. Ito and I. Murata; Hirokawa Publishing Co.: Tokyo (1973),), through photoinduced addition of COS to COT. We are mystified by this claim insofar as our initial attempts to prepare 17 several years ago, by this seemingly straightforward procedure, i.e. COS + COT + light, are vividly recalled as being unrewarding. As a result we feel highly sceptical of Masamune's undocumented claim to the contrary and remain unconvinced that the reaction has synthetic potential.

26 A. G. Anastassiou and J. H. Gebrian, Tetrahedron Letters, 5239 (1969).

27 A. G. Anastassiou and R. P. Cellura, Chem. Commun. 1521 (1969).

28 A. G. Anastassiou and R. P. Cellura. Tetrahedron Letters, 911 (1970).

29 A. G. Anastassiou and R. P. Cellura, Chem. Commun. 484 (1970).

30 A. G. Anastassiou, R. P. Cellura, J. M. Spence and S. W. Eachus, Chem. Commun. 325 (1972).

31 Unpublished observations by Mrs E. Yakali; work described in Ph.D. Dissertation, Syracuse University (1973). 


\section{A. G. ANASTASSIOU}

32 G. Boche, D. Martens and W. Danzer, Angew. Chem. 81, 1003 (1969).

33 J. M. Holovka, P. D. Gardner, C. B. Strow, M. L. Hill and T. V. van Auken, J. Amer. Chem. Soc. 90,5041 (1968).

34 J. M. Holovka, P. D. Gardner, C. B. Strow, M. L. Hill and T. V. van Auken, Chem. Commun. 1522 (1969).

35 E. Vogel, Angew. Chem. 73, 548 (1961); 74, 829 (1962).

36 A. G. Anastassiou and R. C. Griffith, J. Amer. Chem. Soc. 93, 3083 (1971).

37 T. Katz and P. J. Garrratt, J. Amer. Chem. Soc. 86, 5194 (1964).

38 W. H. Okamura and T. W. Osborn, J. Amer. Chem. Soc. 92, 1061 (1970).

39 C. S. Baxter and P. J. Garrattt, J. Amer. Chem. Soc. 92,1062 (1970).

40 L. A. Paquette, M. J. Broadhurst, L. K. Read and J. Clardy, J. Amer. Chem. 95, 4639 (1973).

41 L. A. Paquette, M. J. Broadhurst, C. Lee and J. Clardy, J. Amer. Chem. Soc. 95, 4647 (1973).

42 J. E. Baldwin and D. B. Bryan, J. Amer. Chem. Soc. 96, 319 (1974).

43 G. Boche, H. Weber and J. Benz, Angew. Chem. 86, 238 (1974).

44 A. G. Anastassiou, R. L. Elliott and A. Lichtenfeld, Tetrahedron Letters, 4569 (1972).

45 A. G. Anastassiou, R. L. Elliott, H. Wright and J. Clardy, J. Org. Chem. 38, 1959 (1973).

46 In a recent undocumented statement (note added in proof in reference 25b) Masamune objected to our correction of his work. Without offering any new information he simply expressed faith in his earlier observations! We now submit that until Masamune is ready to argue his case in open rebuttal with fresh evidence, and we doubt that he will. we shall have to simply ignore his ill-conceived explanation that our experiments were conducted under thermal conditions different from his (they were not!) and that originally formed cis isomer 14b may well have isomerized to the trans counterpart 35 on alumina chromatography at $-15^{\circ}$ (it most certainly does not!).

Inescapably then, Masamune's reports on the thermolysis of $\mathbf{1 2 b}$ and $\mathbf{3 4}$ are in serious error.

47 A. G. Anastassiou, S. W. Eachus. R. L. Elliott and E. Yakali, Chem. Commun. 531 (1972).

48 A. P. Bindra, J. A. Elix, P. J. Garratt and R. H. Mitchell, J. Amer. Chem. Soc. 90, 7372 (1968).

49 M. Rabinovitz, A. Gazit and E. D. Bergmann, Chem. Commun. 1430 (1970).

50 M. Rabinovitz, E. D. Bergmann and A. Gazit, Tetrahedron Letters, 2671 (1971).

51 A. G. Anastassiou, S. S. Libsch and R. C. Griffith, Tetrahedron Letters, 3103 (1973).

52 A. G. Anastassiou, E. Reichmanis and R. L. Elliott, Tetrahedron Letters. 3805 (1973).

53 A. G. Anastassiou and R. C. Griffith, J. Amer. Chem. Soc. 96, 611 (1974).

54 A. G. Anastassiou and R. Reichmanis, to be published.

55 P. J. Garratt and K. A. Knapp. Chem. Commun. 1215 (1970).

56 A. G. Anastassiou and E. Reichmanis, Angew. Chem. 86, 410 (1974).

57 A. G. Anastassiou and R. L. Elliott, Chem. Commun. 601 (1973).

58 A. G. Anastassiou and E. Reichmanis, to be published.

59 G. Schröder, G. Frank and J. F. M. Oth, Angew. Chem. 85, 353 (1973).

60 A. G. Anastassiou and R. L. Elliott, J. Amer. Chem. Soc. 96, 5257 (1974).

61 A. G. Anastassiou, R. L. Elliottt and E. Reichmanis, to be published.

62 G. Schröder, G. Frank, H. Röttele and J. F. M. Oth, Angew. Chem. 86, 237 (1974).

63 Private communication from Prof. G. Schröder.

64 A. B. Holmes and F. Sondheimer, J. Amer. Chem. Soc. 92, 5284 (1970).

65 G. Schröder, G. Heil, H. Röttele and J. F. M. Oth, Angew. Chem. 84, 474 (1972).

66 G. Schröder, G. Plinke and J. F. M. Oth, Angew. Chem. 84, 472 (1972).

67 P. J. Beeby and F. Sondheimer, J. Amer. Chem. Soc. 94, 2128 (1972).

68 P. J. Beeby, J. M. Brown, P. J. Garratt and F. Sondheimer, Tetrahedron Letters, 599 (1974).

69 J. M. Brown and F. Sondheimer, Angew. Chem. 86, 346 (1974).

70 P. J. Beeby and F. Sondheimer, Angew. Chem. 85, 406 (1973).

71 P. J. Beeby and F. Sondheimer, Angew. Chem. 85, 404 (1973).

72 S. Winstein, H. M. Walborsky and K. Schreiber, J. Amer. Chem. Soc. 72, 5795 (1950).

${ }^{73}$ M. J. Goldstein, J. Amer. Chem. Soc. 89, 6357 (1967).

74 (a) J. M. Brown and J. L. Occolowitz, Chem. Commun. 376 (1965);

(b) S. Winstein, M. Ogliaruso, M. Sakai and J. M. Nicholson, J. Amer. Chem. Soc. 89, 3656 (1967).

75 M. J. Goldstein and R. Hoffmann, J. Amer. Chem. Soc. 93, 6193 (1971).

${ }^{76}$ For an authoritative description of the method as applied to the study of non-bonded interaction see: E. Heilbronner, 23rd International Congress of Pure and Applied Chemistry (Boston, USA, 1971), Special Lectures, Vol. 7, pp 9-31. Butterworths: London (1971). 


\section{SYNTHESIS AND STUDY OF SELECT HETEROCYCLES}

77 A. G. Anastassiou and R. P. Cellura, J. Org. Chem. 37, 3126 (1972).

78 A. G. Anastassiou and H. Yamamoto, Chem. Commun. 840 (1973).

79 Unpublished work by J. C. Wetzel. A different synthetic entry into sulphoxide 93 is given by: P. Chao and D. M. Lemal, J. Amer. Chem. Soc. 95, 922 (1973). Dichloride 94 was prepared according to: E. D. Weil, K. S. Smith and R. J. Gruber, J. Org. Chem. 31, 1669 (1966).

80 A. G. Anastassiou and R. Reichmanis, J. Org. Chem. 38, 2421 (1973).

81 N. Heap, G. E. Green and G. H. Whitham, J. Chem. Soc. (C), 160 (1069).

82 F. G. Bordwell and M. L. Douglass, J. Amer. Chem. Soc. 88, 993 (1966).

83 H. Schmidt, A. Schweig, A. G. Anastassiou and H. Yamamoto, Chem. Commun. 218 (1974).

84 C. Müller, A. Schweig, A. G. Anastassiou and J. C. Wetzel, Tetrahedron, in press.

85 On sabbatical leave (1973-74) from the Department of Chemistry, Pahlavi University, Shiraz, Iran.

86 S. Winstein, J. Amer. Chem. Soc. 81, 6524 (1959).

87 For an authoritative enumeration of existing cases see: S. Winstein, Chemical Society International Symposium on Aromaticity, Sheffield, England, July 6-8, 1966; Spec. Publ. No. 21. The Chemical Society: London (1967).

88 A. G. Anastassiou, J. Org. Chem. 31, 1131 (1966).

89 The term heterohomoconjugation is employed here to denote a special type of homoconjugation just as heteroconjugation characterizes a special category of conjugation.

90 For a lucid description of the method see: A. Streitwieser in Molecular Orbital Theory for Organic Chemists, pp 97-116. Wiley: New York (1961).

91 M. Rey and A. S. Dreiding, Helv. Chim. Acta, 48, 1985 (1965).

92 T. Fugisawa and T. Kobori, Chem. Commun. 1298 (1972). 